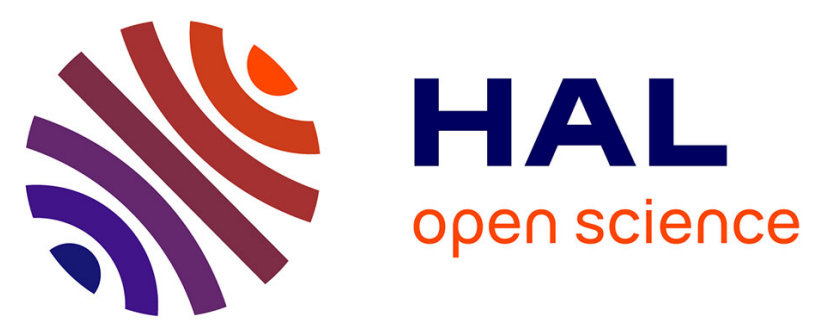

\title{
Synthesis and pharmacological evaluation of benzamide derivatives as potent and selective sigma-1 protein ligands
}

\author{
Marion Donnier-Marechal, Pascal Carato, Paul-Emmanuel Larchanché, \\ Séverine Ravez, Rajâa Boulahjar, Amelie Barczyk, Bénédicte Oxombre, \\ Patrick Vermersch, Patricia Melnyk
}

\section{To cite this version:}

Marion Donnier-Marechal, Pascal Carato, Paul-Emmanuel Larchanché, Séverine Ravez, Rajâa Boulahjar, et al.. Synthesis and pharmacological evaluation of benzamide derivatives as potent and selective sigma-1 protein ligands. European Journal of Medicinal Chemistry, 2017, 138, pp.964-978. 10.1016/j.ejmech.2017.07.014 . hal-02011792

\section{HAL Id: hal-02011792 https://hal.science/hal-02011792}

Submitted on 7 Mar 2019

HAL is a multi-disciplinary open access archive for the deposit and dissemination of scientific research documents, whether they are published or not. The documents may come from teaching and research institutions in France or abroad, or from public or private research centers.
L'archive ouverte pluridisciplinaire HAL, est destinée au dépôt et à la diffusion de documents scientifiques de niveau recherche, publiés ou non, émanant des établissements d'enseignement et de recherche français ou étrangers, des laboratoires publics ou privés. 


\section{SYNTHESIS AND PHARMACOLOGICAL EVALUATION OF BENZAMIDE DERIVATIVES AS POTENT AND SELECTIVE SIGMA-1 PROTEIN LIGANDS}

Marion Donnier-Marechal ${ }^{\mathrm{a}}$, Pascal Carato ${ }^{\mathrm{a},{ }^{*}, \#}$, Paul-Emmanuel Larchanchéa ${ }^{\mathrm{a}}$, Séverine Ravez ${ }^{\mathrm{a}}$, Rajaa Boulahjar $^{\mathrm{a}}$, Amélie Barczyk ${ }^{\mathrm{b}}$, Bénédicte Oxombre ${ }^{\mathrm{b}}$, Patrick Vermersch $^{\mathrm{b}}$ and Patricia Melnyk ${ }^{\mathrm{a}, *}$

${ }^{a}$ Univ. Lille, Inserm, CHU Lille, UMR-S 1172 - JPArc - Centre de Recherche Jean-Pierre AUBERT Neurosciences et Cancer, F-59000 Lille, France

${ }^{b}$ Univ. Lille, Inserm, CHU Lille, U995 - LIRIC - Lille Inflammation Research International Center, F59000 Lille, France

Mail adress : Faculté de Pharmacie, 3 rue du Pr Laguesse, BP83, 59006 Lille, France

\section{List of e-mail adresses :}

marion.donnier-marechal@univ-lyon1.fr, pascal.carato@univ-poitiers.fr, paul-

emmanuel.larchanche@univ-lille2.fr, amelie.barczyk@univ-lille2.fr, benedicte.vanteghem@univlille2.fr, patrick.vermersch@univ-lille2.fr, patricia.melnyk@univ-lille2.fr

* Corresponding authors

\# Present address : Univ Poitiers, CIC INSERM 1402, F-86073 Poitiers, France. 


\section{Graphical Abstract}

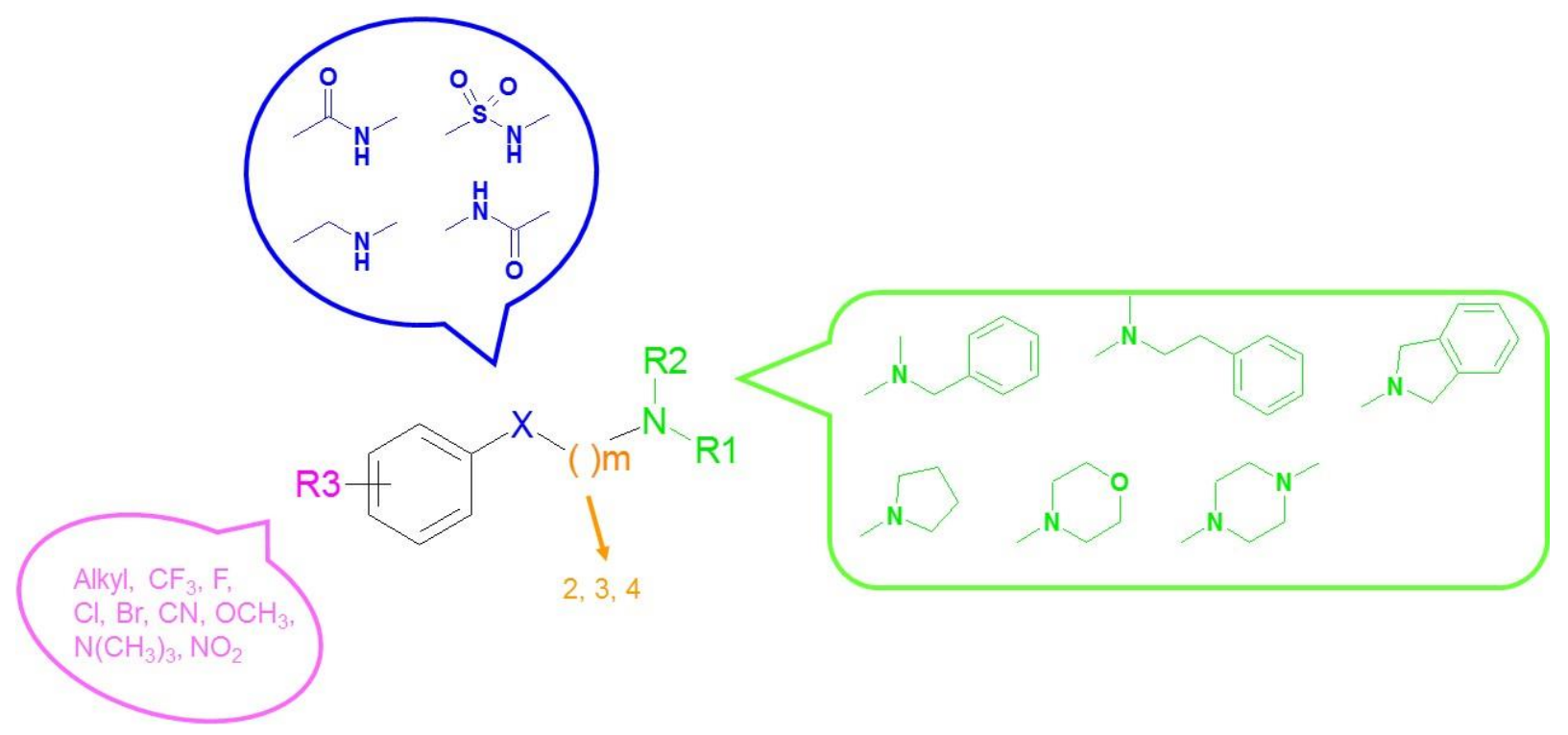

A series of benzamide-derived compounds was synthesized, evaluated in vitro toward their S1R, S2R affinities and cytotoxic effects on SY5Y cells and selectivities on a panel of 40 receptors. 


\begin{abstract}
A series of novel benzamide-derived compounds was designed, synthesized and pharmacologically evaluated. Among all 37 synthesized compounds, two series were developed with the modulation of the nature, the position of atoms or groups on the benzamide scaffold, but also the nature of the amine group separated from the benzamide with 2, 3 or 4 methylene groups. In vitro competition binding assays against sigma proteins (sigma-1 S1R and sigma-2 S2R) revealed that most of them conferred S2R/S1R selectivity toward without cytotoxic effects on SY5Y cells, especially with the first series with compounds 7a-z. Some selected compounds were also evaluated for their agonist and antagonist activities on a panel of 40 receptors. Results showed the importance of the nature and the position with halogeno atom on the benzamide scaffold, the length chain but also the contribution of the hydrophobic part on the amine group. Among them, compounds 7i, w, $\mathbf{y}$ with $\mathrm{Cl}, \mathrm{CN}$ or $\mathrm{NO}_{2}$ groups at the 4-position of the benzamide scaffold showed excellent affinity for S1R $(K i=1.2$ to $3.6 \mathrm{nM}$ ), selectivity for S2R ( $K i$ up to $1400 \mathrm{nM})$ and high selectivity index ( $\mathrm{IC}_{50\left(\mathrm{SY}_{5} \mathrm{Y}\right)} / K i_{(\mathrm{S} 1 \mathrm{R})}$ ratio from 28000 to 83000$)$. Futhermore, these compounds presented an excellent safety profile over 40 other receptors. These derivatives will be selected for further biological investigations.
\end{abstract}

Key words: benzamide, sigma protein, CNS 


\section{Introduction}

More than 40 years after their discovery and due to their involvement in various CNS pathologies, the sigma proteins continue to be widely studied [1-3]. These proteins have been first described as opioid receptors [4] and then classified in the literature as distinct sigma-1 and sigma-2 receptors (S1R and S2R) differing from their pharmacologically and ligand binding profile, anatomical distribution, function and molecular size [5-8]. The protein S2R has not been cloned from any species, while the S1R protein was cloned from various mouse [9], rat [10] and human [11] tissues.

The S1R have been identified as a small-ligand regulated chaperone protein. They are located at the interface between endoplasmic reticulum (ER) and mitochondria called mitochondria associated membrane (MAM) [12,13]. They modulate the $\mathrm{Ca}^{2+}$ homeostasis under conditions of cellular stress $[13,14]$, but also the $\mathrm{K}^{+}$and $\mathrm{Cl}^{-}$channels $[15,16]$. Additionally, S1R have been shown to regulate the cholinergic [17,18], adrenergic [19,20], dopaminergic [21,22], glutamatergic [21] and serotoninergic [23] neurotransmissions.

$\mathrm{S} 1 \mathrm{R}$ are involved in the regulation of numerous neurotransmitter systems, the signal transduction pathway is not completely understood but S1R pharmacological modulators have been shown to modulate several CNS diseases such as pain [24,25], depression [26] or schizophrenia [27,28], but also neurodegenerative disorders like Alzheimer's and Parkinson's diseases [29-31]. Thus, the synthesis of such S1R ligands represents a promising strategy to develop novel treaments for various CNS diseases or even cancers [3233]. Many drugs described in the literature show affinity for S1R, and some of them have undergone clinical trials, but no selective S1R ligands have so far been marketed [34]. A phase 2 study is ongoing to evaluate Anavex 2-73 - a mixed muscarinic and S1R agonist - in patients with Alzheimer's disease $[35,36]$.

Numerous studies described the synthesis, as well as the biological and pharmacological activities of S1R ligands that exhibit $\mathrm{Ki}$ values in the nanomolar range, Among them, previous work of our laboratory underlines a first series of tetrahydroisoquinoline-hydantoin (tic-hydantoin) compounds (Figure 1) as efficient S1R ligands ( $\mathrm{Ki}=4.5$ to $7.1 \mathrm{nM})$, with low affinity for $\mathrm{S} 2 \mathrm{R}(\mathrm{Ki}=500$ to $1000 \mathrm{nM})$ and therefore high S2R/S1R selectivity (100 to 140). These S1R ligands were evaluated in different pharmacological models. One derivative increased cocaine-induced locomotor stimulation and sensitisation in anti-cocaine evaluation [37], an other one brought about a 57\% decrease of infarct volume in an ischaemia model [38]. These compounds were described as neuroprotective agents by their strong anti-inflammatory and neuroprotective effects in an experimental model of multiple sclerosis [39]. Despite chemical stability of tic-hydantoin derivatives in neutral and acidic media, they demonstrated a low metabolic stability, preventing from the perspective of drug development. 


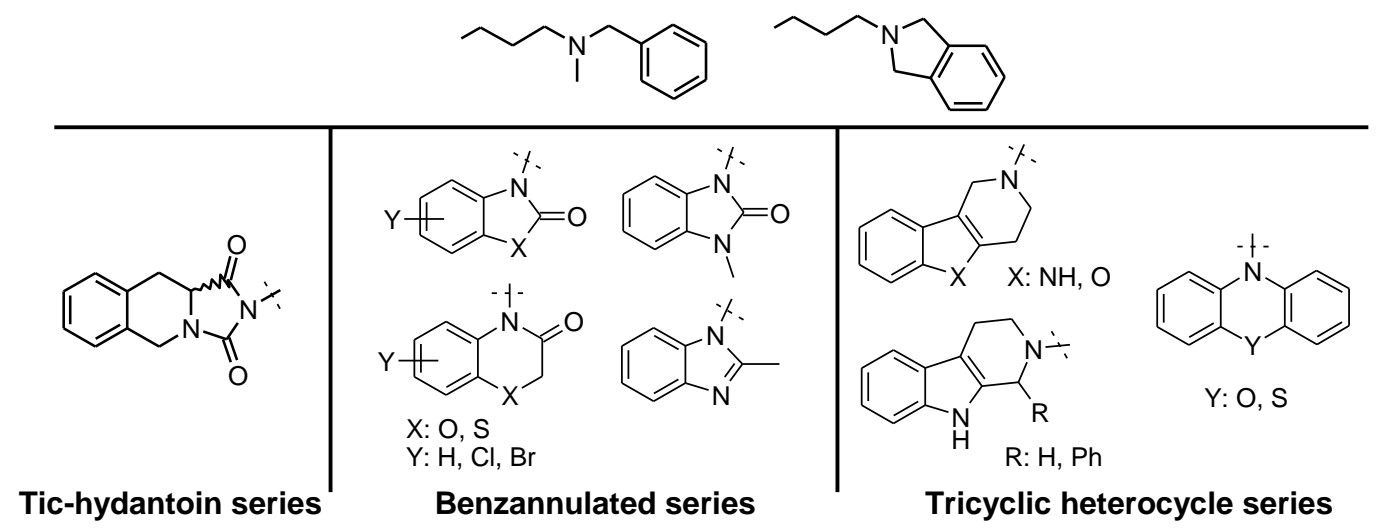

Figure 1: Tic-hydantoin, benzannulated and tricyclic series with propyl-N-methyl-N-benzylamine or isoindoline chains

Continuing our efforts in the synthesis of S1R ligands to solve this problem of metabolic stability, other works (Figure 1) were dedicated to replacement of the tic-hydantoin moieties with different tricyclic heterocycles [40] or benzannulated scaffold [41]. Though the S1R affinity was maintained for most of the compounds ( $\mathrm{Ki}=0.6$ to $30 \mathrm{nM})$, but the $\mathrm{S} 2 \mathrm{R} / \mathrm{S} 1 \mathrm{R}$ selectivity remained low $(<30)$.

Thus we report here our efforts to simplify the structure and replace the different heterocycle moieties by benzamide scaffold with a length chain of 2,3 or 4 methylene functions separated from the amine part with benzylmethylamine to afford compounds 7a-z (Figure 2) [42]. The design of these compounds could be compared to 4-IBP [43], which was recently cocrystallized with S1R [44]. In a first series, numerous substitutions on the benzamide scaffold were adopted by varying the nature and the position of halogeno atoms $\left(\mathrm{Cl}, \mathrm{Br}\right.$ ) and groups (alkyl, $\mathrm{CF}_{3}, \mathrm{OCH}_{3}, \mathrm{NO}_{2}, \mathrm{~N}\left(\mathrm{CH}_{3}\right)_{2}, \mathrm{CN}$ ). Considering the good results with compounds 7a-z, we developed a second series of derivatives 8a-h where we kept the 4-chlorobenzamide moieties and modulated the nature of the amine part with $\mathrm{N}$-phenylethyl-N-methylamine, isoindoline, pyrrolidine, morpholine and methylpiperazine (Figure 2). In this second series, compounds 8a-h were synthesized with length chain of 2 or 3 methylene groups between the benzamide and the functionalized amine. In this series, we also evaluated the importance of the hydrophobic part with the phenyl ring and the hydrophilic part with morpholine and piperazine moieties. In a third series, analogues of the promising compound $\mathbf{7 i}$ were prepared while modifying the linker. On the benzamide scaffold (7i), the amide function was changed by sulfamide function to give compound $\mathbf{9}$, the benzamide was reduced in benzylamine to furnish derivative $\mathbf{1 0}$ and the retroamide was also synthesized with compound $\mathbf{1 3}$ (Figure 2).

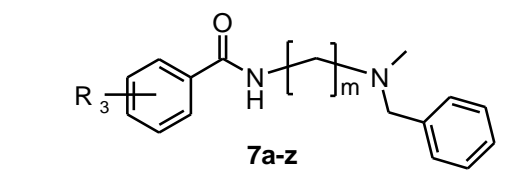

$\mathrm{R}_{3}$ : alkyl, halogen, $\mathrm{CF}_{3}, \mathrm{OCH}_{3}, \mathrm{NO}_{2}, \mathrm{~N}\left(\mathrm{CH}_{3}\right)_{2}, \mathrm{CN}$

$m=2,3,4$
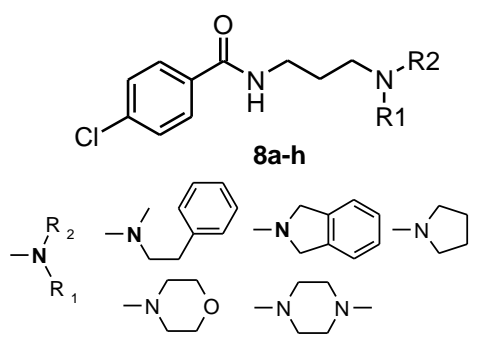

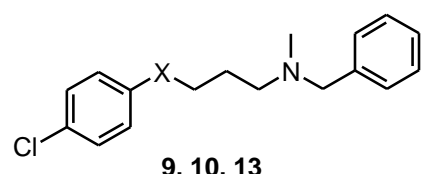

$9,10,13$

$X: \mathrm{SO}_{2} \mathrm{NH}, \mathrm{CH}_{2} \mathrm{NH}, \mathrm{NHCO}$ 


\section{Chemistry}

To synthesize final compounds 7a-z, a first attempt was realized in two steps starting from commercially avalaible 4-chlorophenylacyl chloride (Scheme 1). Reaction with 3-bromopropylamine in dichloromethane with 4-chlorophenylacyl chloride gave the intermediate 1. Nucleophilic substitution in DMF with potassium carbonate and isoindoline as reagent, as the second step, did not afford the corresponding isoindoline compound but derivative $\mathbf{2}$ obtained by cyclization of bromo compound $\mathbf{1}$.

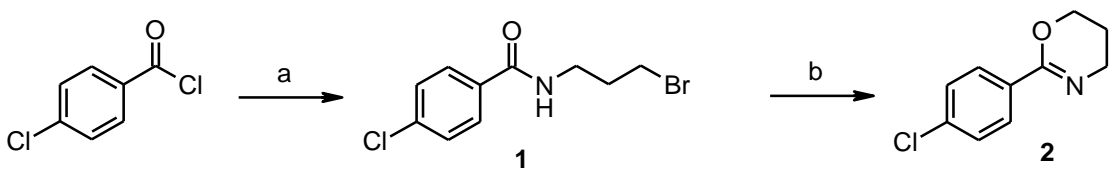

Scheme 1: attempt to synthesized final compounds

Reagents and conditions: (a): 3-bromopropylamine, $\mathrm{CH}_{2} \mathrm{Cl}_{2}, 12 \mathrm{~h}, 0^{\circ} \mathrm{C}$ to rt, $65 \%$; (b): isoindoline, potassium carbonate, DMF, $12 \mathrm{~h}, 70^{\circ} \mathrm{C}, 70 \%$.

In a first time, diamino compounds 5a-f were prepared in two or three steps and final compounds 7a-z were synthesized (Scheme 2). From the first route, diamines 5a-c were synthesized in three steps. 3Bromopropylamine was protected with Boc group in $\mathrm{CH}_{2} \mathrm{Cl}_{2}$ with triethylamine and di-tertbutylcarbonate to afford derivative $\mathbf{3}$, which reacted with the corresponding substituted amine $\left(\mathrm{HNR}_{1} \mathrm{R}_{2}\right)$ in $\mathrm{CH}_{3} \mathrm{CN}$ or DMF with potassium carbonate to give compounds $\mathbf{4 a - c}$. These derivatives $\mathbf{4 a - c}$ were deprotected in $3 \mathrm{M} \mathrm{HCl}$ in dry dioxane to give compounds 5a-c. From the second route, the ethyl and butyl analogues of benzylmethylpropane-1,3-diamine (5a) were synthesized in two steps (Scheme 2). Starting from bromoalkylphtalimides, substitution reaction in DMF with potassium carbonate and benzylmethylamine afforded compounds $\mathbf{6 a - b}$, which were deprotected in ethanol with hydrazine to give intermediates $\mathbf{5 d - e . ~ I n ~ t h e ~ s e r i e s ~ w i t h ~} \mathrm{m}=2$ we also synthetize the superior analogue of compound $\mathbf{5 d}$ with derivative $\mathbf{5 f}$ which contained methylethylbenzylamine group as $\mathrm{NR}_{1} \mathrm{R}_{2}$.

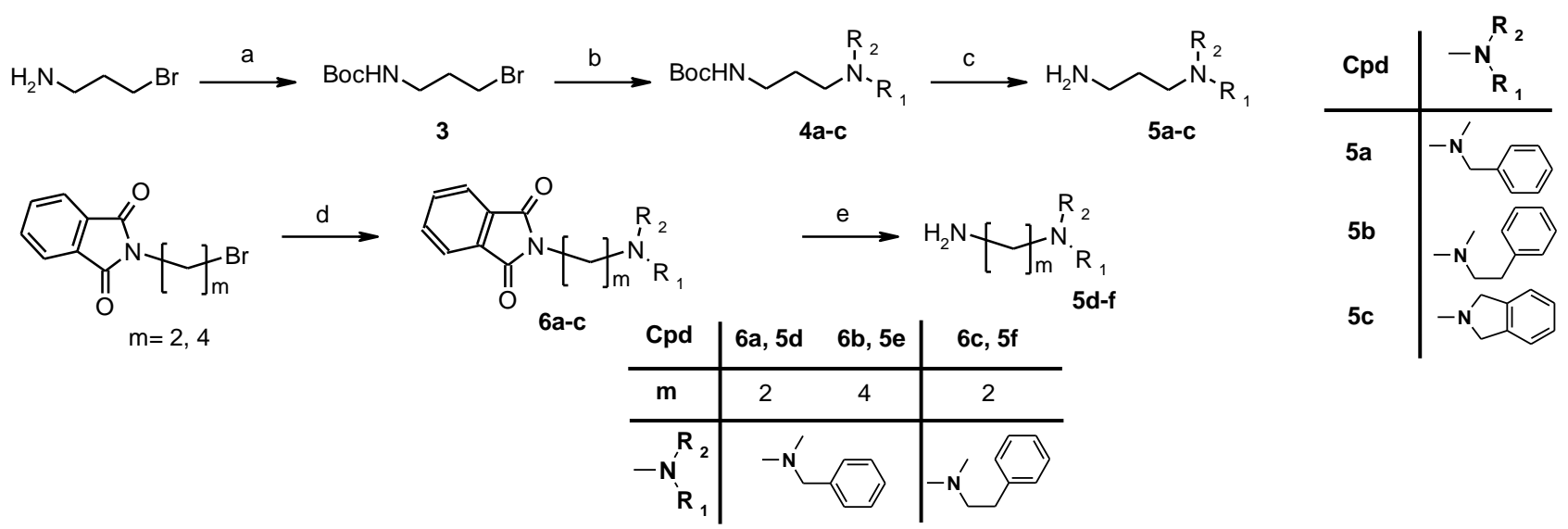

Scheme 2: Preparation of diamine compounds 5a-f

Reagents and conditions: (a): di-tert-butylcarbonate, triethylamine, $\mathrm{CH}_{2} \mathrm{Cl}_{2}, 18 \mathrm{~h}, \mathrm{rt}, 97 \%$; (b): $\mathrm{HNR}_{1} \mathrm{R}_{2}$, potassium carbonate, DMF or $\mathrm{CH}_{3} \mathrm{CN}, 24 \mathrm{~h}, 70^{\circ} \mathrm{C}, 65-81 \%$; (c): $3 \mathrm{M} \mathrm{HCl}$ in dry dioxane, $18 \mathrm{~h}$, rt, 83-98\%; (d): benzylmethylamine, potassium carbonate, DMF, $16 \mathrm{~h}, 90^{\circ} \mathrm{C}, 52-64 \%$; (e): $\mathrm{H}_{2} \mathrm{NNH}_{2}$, EtOH $96^{\circ}$, $16 \mathrm{~h}$, reflux, $55-73 \%$. 
These diamine intermediates 5a,d,e afforded final compounds 7a-z (Scheme 3). Compounds 7a-z were synthesized according two routes, starting from commercially substituted benzoyl acids, in dichloromethane with hydroxybenzotriazole and O-benzotriazole-N,N,N',N'-tetramethyluronium hexafluorophosphate at room temperature or with commercially substituted benzoyl chlorides, in dichloromethane with triethylamine The SAR study of compounds 7a-z showed that the substitution of compounds $\mathbf{7 h}$-j with a chlorine atom in para position induced good affinities for S1R, high S2R/S1R selectivities and low cytotoxicities (Table 1). We thus decided to synthesize a second series with 4chlorobenzamide compounds 8a-h using the same experimental conditions. We synthesized compounds 9 and 10 respectively as the sulfonyl and reduced analogues of the amide compound 7i (Scheme 3). Derivative 9 was synthesized starting from the 4-chlorophenyl sulfonyl chloride in dichloromethane with trimethylamine and the diamine intermediate 5a. Derivative $\mathbf{1 0}$ was obtained by a reductive amination of diamine intermediate $\mathbf{5 a}$ in $\mathrm{MeOH}$ with 4-chlorobenzaldehyde, followed by the addition of sodium borohydride. We also decided to synthesize the retroamide analogue 13 of compound 7i. Starting from 4chloroaniline, reaction in dichloromethane with 4-chlorobutyryl chloride gave compound 11. This derivative 11 never afforded derivative 13 in DMF with potassium carbonate or in $\mathrm{CH}_{3} \mathrm{CN}$ with triethylamine and benzylmethylamine, but gave compound $\mathbf{1 2}$ after cyclization. The desired derivative $\mathbf{1 3}$ was obtained from compound $\mathbf{1 1}$ in benzylmethylamine which reacted both as base and solvent.
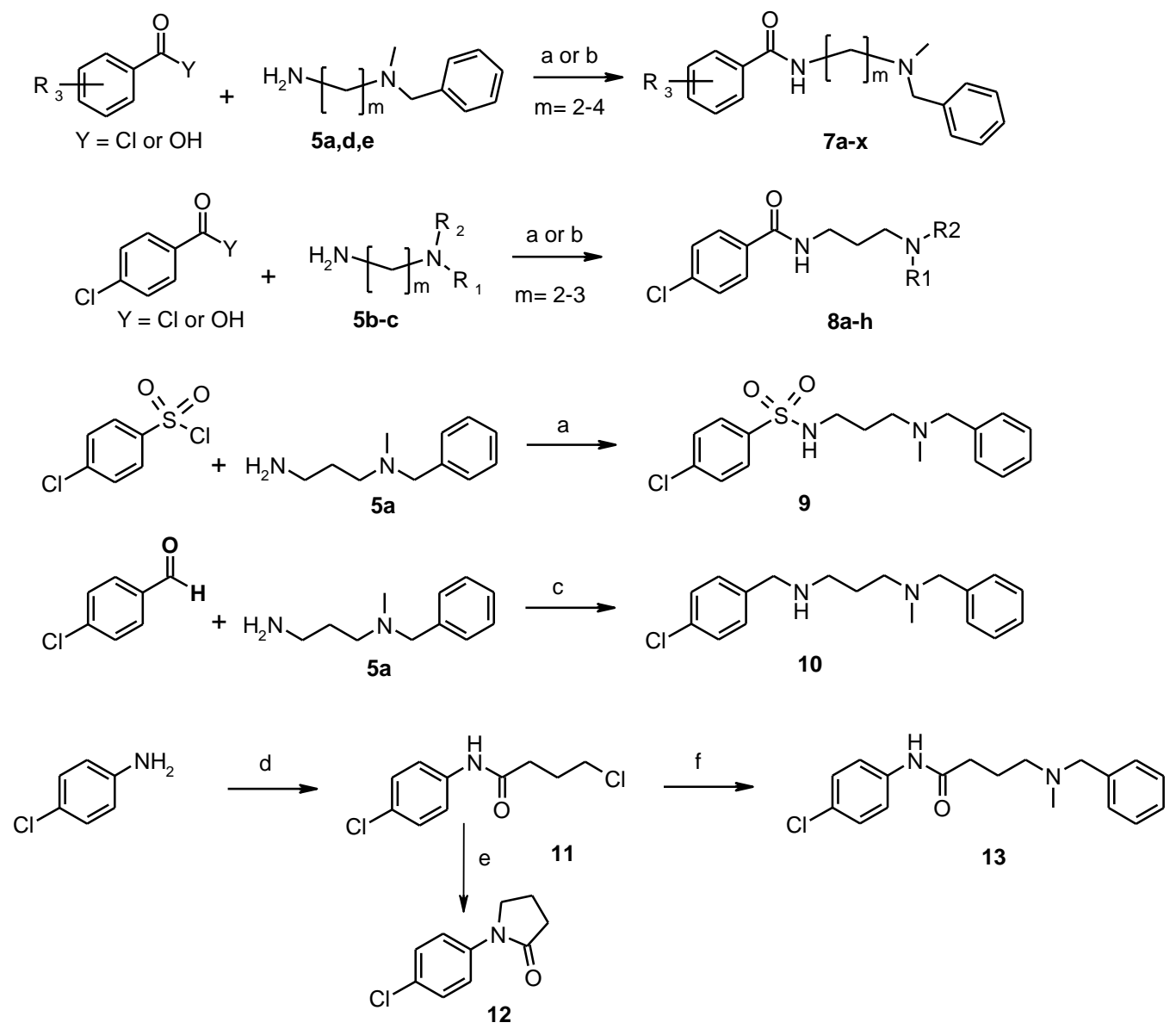

Scheme 3: Synthesis of final compounds 7a-x, 8a-h, 9, 10 and 13

Reagents and conditions: (a): triethylamine, $\mathrm{CH}_{2} \mathrm{Cl}_{2}, 12 \mathrm{~h}, 0^{\circ} \mathrm{C}$ to $\mathrm{rt}, 7-69 \%$; (b): $\mathrm{HOBt}, \mathrm{HBtu}, \mathrm{DIEA} \mathrm{CH}_{2} \mathrm{Cl}_{2}, 12 \mathrm{~h}, \mathrm{rt}, 31-$ 75\%; (c): i: $\mathrm{MeOH}, 18 \mathrm{~h}$, rt; ii: $\mathrm{NaBH}_{4}, 2 \mathrm{~h}, \mathrm{rt}, 35 \%$; (d): 4-chlorobutyryl chloride, $\mathrm{CH}_{2} \mathrm{Cl}_{2}, 12 \mathrm{~h}, 0^{\circ} \mathrm{C}$ to rt, $87 \%$; (e): 
benzylmethylamine, potassium carbonate, DMF, $12 \mathrm{~h}, 70^{\circ} \mathrm{C}$ or $\mathrm{Et}_{3} \mathrm{~N}, \mathrm{CH}_{3} \mathrm{CN}, 12 \mathrm{~h}, 50^{\circ} \mathrm{C} ; 67 \%$ (f): benzylmethylamine, $18 \mathrm{~h}$, rt, $37-80 \%$.

\section{Results and Discussion}

\subsection{Biological evaluations and SAR}

S1R and S2R affinities were investigated in competition experiments with radioligands according to the methods described by Ganapathy [45]. In the S1R assay, the selective ligand $\left[{ }^{3} \mathrm{H}\right](+)$-pentazocine was employed as the radioligand. Since a selective $S 2 R$ radioligand was not commercially available, the nonselective ligand $\left[{ }^{3} \mathrm{H}\right]-\mathrm{DTG}$ was employed in the S2R assay, in the presence of an excess of non-tritiated (+)-pentazocine, which selectively occupies S1R. In both assays, Jurkat cell membranes were used as a source of receptors.

The $K_{i}$ values for S1R and S2R were determined from the corresponding $\mathrm{IC}_{50}$ values for each compounds 7a-z, 8a-h, 9, 10, and 13. The S2R/S1R selectivity ratios were also calculated (Table 1).

In the first series, as all compounds $\mathbf{7 b}$-x exhibited good affinities for $\mathrm{S} 1 \mathrm{R}$ ( $K i=1.1$ to $47 \mathrm{nM})$ except for derivative 7a $(K i>100 \mathrm{nM})$, we could conclude that substitution on the benzamide scaffold was necessary. The substitution with alkyl group, as propyl, butyl and tert-butyl for compounds $\mathbf{7 b - d}$ induced excellent affinities for S1R with $K i=1.6$ to $7.3 \mathrm{nM}$ and good selectivity toward S2R with a S2R/S1R ratio of 126 expecially for derivative $\mathbf{7 d}$. The modulation of the tert-butyl group of compound $\mathbf{7 d}$ by trifluoromethyl group with 7e, allowed to keep excellent S1R affinity but led to selectivity decrease with a S2R/S1R ratio of 70 .

The substitution with one halogen atom, such as $\mathrm{Cl}$ or $\mathrm{Br}$, gave high affinities for $\mathrm{S} 1 \mathrm{R}(K i=1.7$ to 47 $\mathrm{nM}$ ). On the contrary, the substitution with a fluorine decreased S1R affinity dramatically (compound 7n). In this series, the best affinities were obtained when benzamide moiety was substituted at the 4 position with a chlorine or bromine atom $(\mathbf{7 h}, \mathbf{7 m}$ ). Substitution in meta position (for $7 \mathbf{g} K i=10 \mathrm{nM}, 7 \mathbf{l}$ $K i=3.9 \mathrm{nM}$ ) or ortho position (for $7 \mathbf{f} K i=47 \mathrm{nM}, 7 \mathbf{k} K i=42 \mathrm{nM}$ ) induced a decrease in S1R affinity, but also a meaningful decrease for S2R affinity. Therefore, S2R/S1R selectivities remained modest in the case of substitutions in meta or ortho position compared to the para-substituted compound $\mathbf{7 h}$ with excellent affinity for S1R $(K i=3.6 \mathrm{nM})$ and selectivity S2R/S1R of 236 . According to these results, we decided to introduce two halogens, with two chlorines (compounds 7o-r) or one fluorine and one bromine (compound 7s). In this set of compounds 7n-s, S1R and S2R affinities, and thus selectivities were in the same range. For the last compounds described in table 1 (compounds $\mathbf{7 t - x}$ ), the nature and the position of the substitutents were modulated with methoxy, dimethylamine, cyano and nitro groups. Substitution with methoxy group (compounds 7t-u) gave moderate affinities for S1R $(K i=37-40 \mathrm{nM})$ with a S2R/S1R ratio higher than 27 . Compounds $\mathbf{7 v - z}$ with dimethylamine, cyano and nitro groups allowed good affinities for S1R $(K i=1.2-24 \mathrm{nM})$ and especially derivative $7 \mathbf{y}$ with the best S2R/S1R selectivity ratio of 389. Finally, we also noticed the influence of the length chain between the benzamide scaffold and the 
benzylmethylamine. Indeed the decrease in the chain length (from butyl to ethyl) induced a higher selectivity (compare compounds $7 \mathbf{h}-\mathbf{j}, \mathrm{S} 2 \mathrm{R} / \mathrm{S} 1 \mathrm{R}=12$ to 236 ). Moreover, as a comparison, in the case of cyano substitution, a slight modification in the length's chain drastically modified the affinities and selectivity (see compounds $\mathbf{7 w}$ and $\mathbf{7 x}$ ).

Table 1 : Evaluation of S1R, S2R affinities and cytotoxicity of target compounds 7a-z

\begin{tabular}{|c|c|c|c|c|c|c|c|}
\hline \multirow[t]{3}{*}{ Compounds } & \multirow[t]{3}{*}{$\mathbf{R}_{3}$} & \multirow[t]{3}{*}{$\mathbf{m}$} & \multicolumn{2}{|c|}{$K i(\mathrm{nM})^{\mathrm{a}}$} & \multirow{3}{*}{$\begin{array}{c}K i\left(\sigma_{2}\right) / \\
K i\left(\sigma_{1}\right)\end{array}$} & \multirow{3}{*}{$\begin{array}{c}\text { IC }_{50} \\
(\mu \mathrm{M}) \\
\text { SY5Y b }^{b}\end{array}$} & \multirow{3}{*}{$\begin{array}{c}\mathrm{IC}_{50} / K i \\
\left(\sigma_{1}\right)\end{array}$} \\
\hline & & & $\sigma_{1}$ & $\sigma_{2}$ & & & \\
\hline & & & & & & & \\
\hline $7 a$ & $\mathrm{H}$ & 3 & $>100$ & $>400^{a}$ & - & $>100$ & - \\
\hline $7 b$ & 4-Pr & 3 & 3.7 & 160 & 43 & $>100$ & $>27027$ \\
\hline $7 c$ & $4-\mathrm{Bu}$ & 3 & 7.3 & 49 & 7 & 90.2 & 12356 \\
\hline $7 d$ & 4-tBu & 3 & 1.6 & 200 & 126 & $>100$ & $>62500$ \\
\hline $7 e$ & $4-\mathrm{CF}_{3}$ & 3 & 1.4 & 98 & 70 & $>100$ & $>71429$ \\
\hline $7 f$ & $2-\mathrm{Cl}$ & 3 & 47 & $>1200$ & $>26$ & $>100$ & $>2128$ \\
\hline $7 g$ & $3-\mathrm{Cl}$ & 3 & 10 & 340 & 34 & $>100$ & $>10000$ \\
\hline $7 \mathrm{~h}$ & 4-Cl & 2 & 3.6 & 850 & 236 & $>100$ & $>27778$ \\
\hline $7 \mathbf{i}$ & 4-Cl & 3 & 3.2 & 190 & 60 & $>100$ & $>31250$ \\
\hline $7 \mathbf{j}$ & $4-\mathrm{Cl}$ & 4 & 1.7 & 20 & 12 & $>100$ & $>58824$ \\
\hline $7 k$ & $2-\mathrm{Br}$ & 3 & 42 & $>1200$ & $>29$ & $>100$ & $>2381$ \\
\hline 71 & $3-\mathrm{Br}$ & 3 & 3.9 & 350 & 90 & $>100$ & $>25641$ \\
\hline $7 \mathrm{~m}$ & $4-\mathrm{Br}$ & 3 & 2.1 & 160 & 76 & 60.2 & 28667 \\
\hline $7 n$ & $4-\mathrm{F}$ & 3 & 20 & 470 & 24 & $>100$ & $>5000$ \\
\hline 70 & $2,3-\mathrm{Cl}$ & 3 & 10 & 310 & 31 & $>100$ & $>10000$ \\
\hline $7 p$ & $2,3-\mathrm{Cl}$ & 2 & 6.5 & 110 & 17 & $>100$ & $>15385$ \\
\hline $7 q$ & $3,4-\mathrm{Cl}$ & 3 & 1.1 & 59 & 54 & 56.6 & 51455 \\
\hline $7 r$ & $3,5-\mathrm{Cl}$ & 3 & 23 & 48 & 2 & 60.0 & 2609 \\
\hline $7 s$ & 2-F-4-Br & 3 & 2.9 & 200 & 69 & $>100$ & $>34483$ \\
\hline $7 t$ & $3-\mathrm{OCH}_{3}$ & 3 & 40 & $>1200$ & $>30$ & $>100$ & $>2500$ \\
\hline $7 u$ & $4-\mathrm{OCH}_{3}$ & 3 & 37 & $>1200$ & $>27$ & 100.0 & 2702 \\
\hline $7 v$ & $3-\mathrm{N}\left(\mathrm{CH}_{3}\right)_{2}$ & 3 & 1.9 & 321 & 159 & $>100$ & $>52632$ \\
\hline $7 w$ & $4-\mathrm{CN}$ & 2 & 1.2 & 170 & 142 & $>100$ & $>83334$ \\
\hline $7 x$ & $4-\mathrm{CN}$ & 3 & 24 & $>1200$ & $>50$ & $>100$ & $>4167$ \\
\hline $7 y$ & $4-\mathrm{NO}_{2}$ & 2 & 3.6 & 1400 & 389 & $>100$ & $>27778$ \\
\hline $7 z$ & $4-\mathrm{NO}_{2}$ & 3 & 4.3 & 360 & 84 & $>100$ & $>23256$ \\
\hline
\end{tabular}

${ }^{\text {a }}$ Mean $K_{i}$ values for 2-3 independent experiments are shown with less than $10 \%$ deviation.

${ }^{\mathrm{b}}$ Compound concentration causing $50 \%$ of cell death after $24 \mathrm{~h}$ treatment.

We then modulated the nature of the amine $\left(\mathrm{HNR}_{1} \mathrm{R}_{2}\right)$ and the length's chain with $\mathrm{m}=2,3$ between this amine group and the 4-chlorobenzamide. We preserved the chlorine atom at the 4 position, considering the good and maintained affinities and selectivities obtained with compounds $\mathbf{7 h}$-i. Physicochemical properties of compound 7i were evaluated and shown the potency of this compound with high LLe, solubility and metabolic stability (Figure 3).<smiles>CN(CCCNC(=O)c1ccc(Cl)cc1)Cc1ccccc1</smiles>

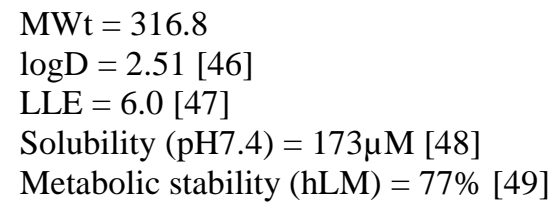

Figure 3: Physicochemical properties of compound 7i 
The modulation of the nature of the amine group, benzylmethylamine (7i) to 2-(phenylethyl)methylamine (8a), led to good affinity S1R $(K i=4.3 \mathrm{nM})$, but low selectivity toward S2R $(K i=200 \mathrm{nM})$ with a $\mathrm{S} 2 \mathrm{R} / \mathrm{S} 1 \mathrm{R}$ ratio of 47 . The restricted conformation of the benzylmethylamine group with isoindoline moiety for compound $\mathbf{8 b}$ afforded acceptable affinity for $\operatorname{S1R}(K i=19 \mathrm{nM})$ but low selectivity toward $\mathrm{S} 2 \mathrm{R}(K i=350 \mathrm{nM})$ with a S2R/S1R ratio of 16 . For compounds $\mathbf{8 c}-\mathbf{h}$, various substituted amine, such as pyrrolidine, morpholine and piperazine, were introduced and we modulated the length's chain with two or three methylene. As expected, the elimination of the phenyl ring with these derivatives 8c-d, identified as an essential hydrophobic part, and the replacement by morpholine or piperazine for derivatives $\mathbf{8 e - h}$, as hydrophilic moieties, induced a dramatic lost of affinity for S1R $(K i \geq 100 \mathrm{nM})$.

Table 2 : Evaluation of S1R, S2R affinities and cytotoxicity of target compounds $\mathbf{8 a - h}$

\begin{tabular}{|c|c|c|c|c|c|c|c|}
\hline \multirow[t]{3}{*}{ Compounds } & \multirow[t]{3}{*}{$\mathbf{m}$} & \multirow[t]{3}{*}{$-\mathbf{N R}_{\mathbf{1}} \mathbf{R}_{\mathbf{2}}$} & \multicolumn{2}{|c|}{$K i(\mathrm{nM})^{\mathrm{a}}$} & \multirow{3}{*}{$\begin{array}{l}K i\left(\sigma_{2}\right) / \\
K i\left(\sigma_{1}\right)\end{array}$} & \multirow{3}{*}{$\begin{array}{c}\mathrm{IC}_{50} \\
(\mu \mathrm{M}) \\
\text { SY5Y }^{\mathrm{b}}\end{array}$} & \multirow[t]{3}{*}{$\mathrm{IC}_{50} / K i\left(\sigma_{1}\right)$} \\
\hline & & & $\sigma_{1}$ & $\sigma_{2}$ & & & \\
\hline & & & & & & & \\
\hline $8 a$ & 3 & & 4.3 & 200 & 47 & $>100$ & $>23256$ \\
\hline $8 b$ & 3 & & 19 & 350 & 16 & $>100$ & $>5264$ \\
\hline $8 c$ & 2 & & $>100$ & $>200$ & - & $>100$ & - \\
\hline $8 d$ & 3 & & $>100$ & $>200$ & - & $>100$ & - \\
\hline $8 e$ & 2 & & $>100$ & $>200$ & - & $>100$ & - \\
\hline $8 f$ & 3 & & $>100$ & $>200$ & - & $>100$ & - \\
\hline $8 g$ & 2 & & $>100$ & $>200$ & - & $>100$ & - \\
\hline $8 h$ & 3 & & $>100$ & $>200$ & - & $>100$ & - \\
\hline
\end{tabular}

Starting from 7i, we decided to replace the amide linker with a sulfonylamide function (9), to reduce the amide to amine function (10) and to synthesize the retroamide derivative (13) (Table 3). These three compounds 9, 10 and 13 displayed good affinities for S1R $(K i=2.9-6.5 \mathrm{nM})$ but low selectivities toward S2R with a S2R/S1R ratio of 26-35.

Table 3 : Evaluation of S1R, S2R affinities and cytotoxicity of target compounds $\mathbf{9 , 1 0 , 1 3}$

\begin{tabular}{|c|c|c|c|c|c|c|}
\hline \multirow[t]{2}{*}{ Compounds } & \multirow[t]{2}{*}{$\mathbf{X}$} & \multicolumn{2}{|c|}{$K i(\mathbf{n M})^{\mathbf{a}}$} & \multirow{2}{*}{$\begin{array}{c}K i\left(\sigma_{2}\right) / \\
K i\left(\sigma_{1}\right)\end{array}$} & \multirow{2}{*}{$\begin{array}{c}\mathrm{IC}_{50}(\boldsymbol{\mu M}) \\
\text { SY5Y }\end{array}$} & \multirow[t]{2}{*}{$\mathrm{IC}_{50} / K i\left(\sigma_{1}\right)$} \\
\hline & & $\sigma_{1}$ & $\sigma_{2}$ & & & \\
\hline 9 & $\mathrm{SO}_{2} \mathrm{NH}$ & 5.8 & 200 & 35 & $>100$ & $>17242$ \\
\hline 10 & $\mathrm{CH}_{2} \mathrm{NH}$ & 2.9 & 95 & 33 & $>100$ & $>34483$ \\
\hline 13 & NHCO & 6.5 & 170 & 26 & $>100$ & $>15385$ \\
\hline
\end{tabular}

${ }^{\mathrm{a}-\mathrm{d}}$ see footnotes of Table 1 


\subsection{Docking study of benzamide $7 \boldsymbol{i}$}

To investigate the potential binding mode of benzamide derivatives, compound $7 \mathbf{i}$ was docked into the binding site of S1R [44]. As illustrated in Figure 3, the representative docking solutions highlighted common interactions of S1R ligands. The benzyl moiety interact with hydrophobic regions of the receptor and the $p$-chlorobenzamide scaffold is stabilized by an aromatic stacking interaction with the Tyr103. In addition, the basic amine of $\mathbf{7} \mathbf{i}$ is engaged in a persistent salt bridge with the carboxylate group of the highly conserved Glu172.

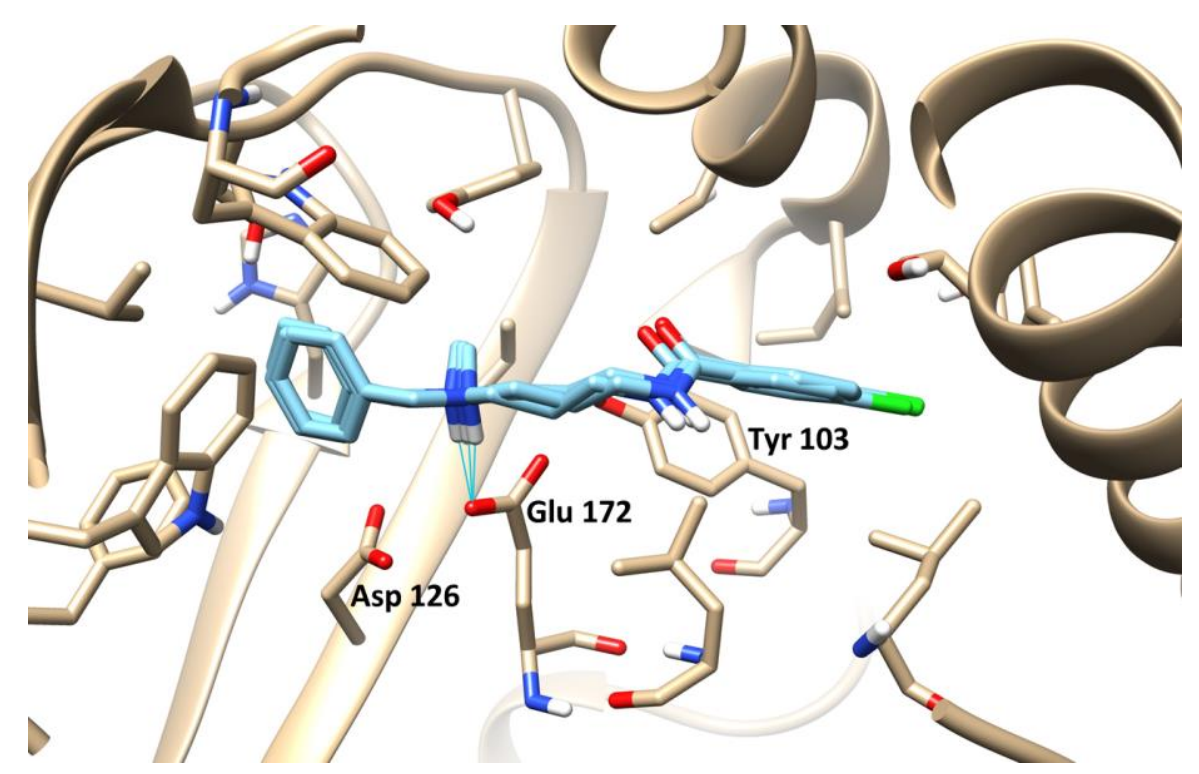

Figure 3: Docking of compound 7i in the binding site of S1R (PDB Entry: 5HK2)

\subsection{Evaluation of cytotoxic effects}

To determine the potential cytotoxic effects of our compounds on CNS tissues, a human neuroblastoma cell line was treated with the whole compounds at different concentrations up to $100 \mu \mathrm{M}$. Cell viability was calculated using a colorimetric MTT assay.

All target compounds exhibited very low cytotoxicity (Table 1, 2, 3) with selectivity index between 2128 and 76923 ( $\mathrm{IC}_{50(\mathrm{SY} 5 \mathrm{Y})} / K i_{(\mathrm{S} 1 \mathrm{R})}$ ratio). In particular, derivatives $7 \mathbf{i}$ and $7 \mathbf{p}$ with high affinities for $\mathrm{S} 1 \mathrm{R}(K i=$ 1.3-3.6 nM) and S2R/S1R selectivities (236-238) showed excellent selectivity index of 31250 and 15385 respectively. Compound $7 \mathbf{y}$ with the best selectivity for S2R $(\mathrm{S} 2 \mathrm{R} / \mathrm{S} 1 \mathrm{R}=389)$ also showed excellent selectivity index of 27778 .

\subsection{Selectivity profile over a panel of 40 recombinant human receptors}

Among these compounds, eleven were selected regarding their affinity, selectivity, ligand efficiency and chemical diversity. Compounds (7b, 7e, 7h, 7i, 7l, 7m, 7t, 7u, 7w, 7y, 7z, 8a) were tested on their agonist and antagonist activities on 40 receptors relevant for CNS diseases like serotonine, adenosine, adrenergic, cannabinoide, dopamine, histamine, muscarinic and others receptors. They were tested at $10 \mu \mathrm{M}$, in 
duplicate, on the Aequorin [50], $\mathrm{CAMP}^{\mathrm{HTRF}}{ }^{\mathrm{TM}}$ [51] and GTP $\gamma^{35} \mathrm{~S}$ [52] binding assays as described in Table 4.

None of the studied compounds provided significant agonist activity at $10 \mu \mathrm{M}$, except compound 8a which showed an agonist activity on serotonine receptors $\left(5-\mathrm{HT}_{2 \mathrm{~B}}, \quad 5-\mathrm{HT}_{2 \mathrm{C}}\right.$ and $\left.5-\mathrm{HT}_{7}\right)$. Significant antagonist activity was observed at $10 \mu \mathrm{M}$ for serotonine $\left(5-\mathrm{HT}_{2 \mathrm{~B}}, 5-\mathrm{HT}_{2} \mathrm{C}\right.$ and $\left.5-\mathrm{HT}_{3}\right)$, adrenergic (all subtypes), histamine H1, dopamine D4 and muscarinic M1 receptors for compounds 7b, 7e, 7i, 7l, 7m, 8a with propyl, trifluoromethyl groups or chlorine, bromine atoms. In these cases, the position of the substitution (meta or para) or the length's chain played a significant part in the antagonist activities of the compounds. For exemple, 4-bromo benzamide $\mathbf{7 m}$ was more selective than the 3-bromo derivative $\mathbf{7 1}$, which showed significant antagonist activity on 5- $\mathrm{HT}_{2 \mathrm{~B}}, 5-\mathrm{HT}_{2} \mathrm{C}, \alpha_{2 \mathrm{~A}}$ and $\mathrm{H} 1$ receptors. For 4chlorobenzamide derivatives, propyl chain and benzylmethylamine seemed optimal (compound 7i) as the decrease from propyl to ethyl (compound $7 \mathbf{h}$ ) induced activity on 5- $\mathrm{HT}_{2 \mathrm{~A}}, 5-\mathrm{HT}_{2 \mathrm{C}}$ and $\mathrm{D} 2$ receptors. In a similar manner, the stretching from benzylamine (compound 7i) to phenethylamine (compound 8a) led to an increased activity on 5- $\mathrm{HT}_{1 \mathrm{~B}}, 5-\mathrm{HT}_{2 \mathrm{~B}}, 5-\mathrm{HT}_{2 \mathrm{C}}, 5-\mathrm{HT}_{3}, \alpha_{2 \mathrm{~A}}, \alpha_{2 \mathrm{~B}}, \mathrm{H} 1$ and $\mathrm{M} 2$ receptors. 


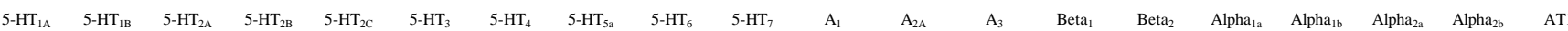

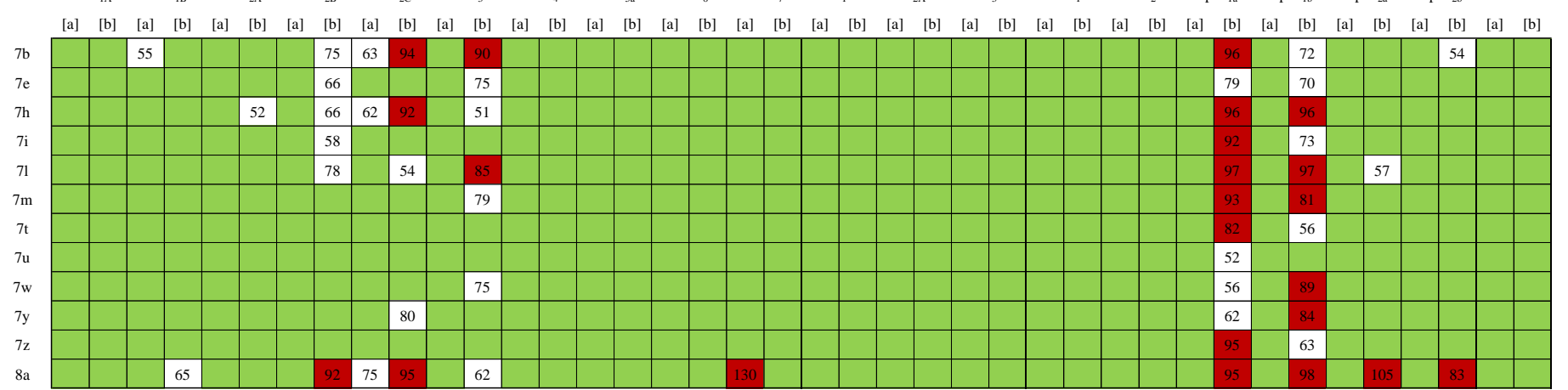

$\begin{array}{lllllllllllllllllllll}\text { CB1 } & \text { CCK1 } & \text { D1 } & \text { D2 } & \text { Eta } & \text { H1 } & \text { H2 } & \text { M1 } & \text { M2 } & \text { M3 } & \text { M4 } & \text { NK1 } & \text { NK2 } & \text { NMDA } & \text { NPY1 } & \text { Delta } & \text { Kappa } & \text { Mu } & \text { SST4 } & \text { V1 } 1_{a} & \text { VPAC1 }\end{array}$

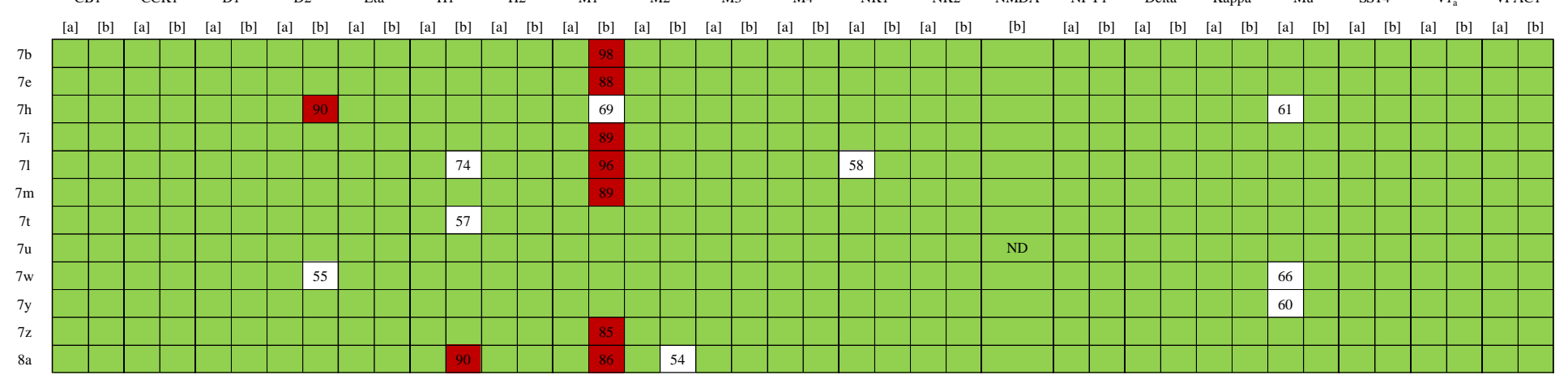

Table 4 : [a]: Agonist activity at $10 \mu \mathrm{M}$ in duplicate; [b] : Antagonist activity at $10 \mu \mathrm{M}$ in duplicate. For the agonist activity, data are expressed as the percentage of the activity of the reference agonist. For the antagonist activity, data are expressed as the percentage of inhibition of the reference agonist activity In green, $0-50 \%$, in white $51-80 \%$, in red $81-100 \%$. Numerical value are indicated over $51 \%$. ND, not determined. 
Compounds $7 \mathbf{t}, \mathbf{7} \mathbf{u}, \mathbf{7 w}, \mathbf{7 y}$ could be considered as selective compounds-because they show excellent profil toward all receptors and hight selectivities for S1R. In particular, methoxy derivatives $\mathbf{7 t}$ and $\mathbf{7 u}$ showed no activity upon near all tested receptors at a concentration of $10 \mu \mathrm{M}$. Compounds $\mathbf{7 w}, \mathbf{7 y}$ with cyano and nitro group showed low affinities for $\mathrm{H}_{1}, 5-\mathrm{HT}_{3}$ and $\mu$ opioid receptors. Once again, the length's chain between the benzylmethylamine and the benzamide scaffold was important. When we compared the nitro compounds $\mathbf{7 y}$ and $\mathbf{7 z}$ the elongation of the ethyl (7y) to propyl chain $(\mathbf{7 z})$ induced higher affinities for antagonist activities for $\alpha_{1 a}$ and $\mathrm{M}_{1}$. It is important to emphasize that compound $7 \mathbf{y}$ showed an excellent profil S1R toward S2R (S1R : $K i=3.6 \mathrm{nM}, \mathrm{S} 2 \mathrm{R}: K i>1400 \mathrm{nM}, \mathrm{S} 2 \mathrm{R} / \mathrm{S} 1 \mathrm{R}=389)$ and an excellent profil for agonist and antagonist activities against all the tested receptors.

\section{Conclusion}

Starting from previous work in our lab and in the literature, we used benzamide moiety as tic-hydantoin surrogate and various modulations were realized. In the first series, we modulated the nature and the position of atoms or groups on the benzamide moiety and kept the benzylmethylamine separated with alkyl chain with 2 to 4 methylene group from the heterocycle, to give compounds 7a-z. In a second series, 4-chlorobenzamide moiety was kept and the nature of the amine group was modulated $\left(\mathrm{HNR}_{1} \mathrm{R}_{2}\right)$ to afford derivatives 8a-h. Then, three compounds were prepared as the sulfonyl (9), reduced (10) and retroamide (13) analogues of derivative 7i. The $K_{i}$ values for S1R and S2R were determined from the corresponding $\mathrm{IC}_{50}$ values for each compound. The modulation with chlorine or bromine atoms gave good affinities for S1R and selectivities toward S2R. The length's chain also played an important part from these 2 parameters. As expected, the introduction of hydrophilic moieties in compounds 8c-h induced a dramatic lost of affinities for S1R, underlining the major importance of both hydrophobic moieties highlighted in the Glennon's pharmacophore. All together this study underlined the interest of compounds 7i, w, $\mathbf{y}$ with $\mathrm{Cl}, \mathrm{CN}$ or $\mathrm{NO}_{2}$ groups at the 4-position of the benzamide scaffold showed excellent affinity for $\mathrm{S} 1 \mathrm{R}(K i=1.2$ to $3.6 \mathrm{nM}$ ), selectivity for $\mathrm{S} 2 \mathrm{R}$ ( $K i$ up to $1400 \mathrm{nM}$ ) and high selectivity index (from 28000 to 83000 ). Physicochemical properties of compound $7 \mathbf{i}$ are very compatible with drug development. Futhermore, these compounds showed a highly selective profile over 40 other receptors. These derivatives will be considered for further biological investigations.

\section{Experimental}

\subsection{Chemistry}

Chemicals and solvents were obtained from commercial sources, and used without further purification unless otherwise noted. Reactions were monitored by TLC performed on Macherey-Nagel Alugram® Sil 
$60 / \mathrm{UV}_{254}$ sheets (thickness $0.2 \mathrm{~mm}$ ). Purification of products was carried out by either column chromatography or thick layer chromatography. Column chromatography was carried out on using Macherey-Nagel silica gel (230-400 mesh). Thick layer chromatography was performed on glass plates coated with Macherey-Nagel Sil/UV 254 (thickness $2 \mathrm{~mm}$ ), from which the pure compounds were extracted with the following solvent system: $\mathrm{DCM} / \mathrm{MeOH}\left(\mathrm{NH}_{3}\right), 90: 10$. IR spectra were performed on a Bruker Alpha FT-IR Spectrometer. NMR spectra were recorded on a Bruker DRX 300 spectrometer (operating at $300 \mathrm{MHz}$ for ${ }^{1} \mathrm{H}$ and $75 \mathrm{MHz}$ for ${ }^{13} \mathrm{C}$ ). Chemical shifts are expressed in ppm relative to either tetramethylsilane (TMS) or to residual proton signal in deuterated solvents. Chemical shifts are reported as position $(\delta$ in $\mathrm{ppm})$, multiplicity $(\mathrm{s}=$ singlet, $\mathrm{d}=$ doublet, $\mathrm{t}=$ triplet, $\mathrm{q}=$ quartet, $\mathrm{p}=$ pentet, $\mathrm{dd}=$ double doublet, br $=$ broad and $\mathrm{m}=$ multiplet $)$, coupling constant $(J$ in Hz), relative integral and assignment. The attributions of protons and carbons were achieved by analysis of $2 \mathrm{D}$ experiments (COSY, HSQC and HMBC). Mass spectra were recorded on a Varian triple quadrupole 1200W mass spectrometer equipped with a non-polar C18 TSK-gel Super ODS (4.6 x $50 \mathrm{~mm}$ ) column, using electrospray ionisation and a UV detector (diode array). HRMS experiments were performed on Q Exactive Benchtop LC-MS/MS (Thermo Scientific). The purity of final compounds was verified by two types of high pressure liquid chromatography (HPLC) columns: C18 Interchrom UPTISPHERE and C4 Interchrom UPTISPHERE. Analytical HPLC was performed on a Shimadzu LC-2010AHT system equipped with a UV detector set at $254 \mathrm{~nm}$ and $215 \mathrm{~nm}$. Compounds were dissolved in $50 \mu \mathrm{L}$ methanol and $950 \mu \mathrm{L}$ buffer $\mathrm{A}$, and injected into the system. The following eluent systems were used: buffer A $\left(\mathrm{H}_{2} \mathrm{O} / \mathrm{TFA}, 100: 0.1\right)$ and buffer $\mathrm{B}\left(\mathrm{CH}_{3} \mathrm{CN} / \mathrm{H}_{2} \mathrm{O} / \mathrm{TFA}, 80: 20: 0.1\right)$. HPLC retention times (HPLC $\left.\mathrm{t}_{\mathrm{R}}\right)$ were obtained at a flow rate of $0.2 \mathrm{~mL} / \mathrm{min}$ for $35 \mathrm{~min}$ using the following conditions: a gradient run from $100 \%$ of buffer A over1 min, then to $100 \%$ of buffer B over the next $30 \mathrm{~min}$.

\section{Preparation of $N$-(3-bromopropyl)-4-chlorobenzamide (1)}

To a solution of 3-bromopropylamine hydrobromide $(2.86 \mathrm{mmol}, 625 \mathrm{mg})$ in $10 \mathrm{~mL}$ of DCM at $0^{\circ} \mathrm{C}$ was added slowly a solution of 4-chlorobenzoyl chloride $(2.86 \mathrm{mmol}, 363 \mu \mathrm{L})$ in $5 \mathrm{~mL}$ of DCM. The resulting mixture was stirred at room temperature for 12 hours. Then the solution was diluted with DCM and washed successively with $\mathrm{HCl}(2 \mathrm{M})$ solution, $\mathrm{NaHCO}_{3}$ saturated solution and $\mathrm{NaCl}$ solution. The organic layer was dried over magnesium sulfate and evaporated. The crude product 2.1 was purified by column chromatography (DCM: cyclohexane, 5:5 (v/v)). Yield: 65\%. Mp: 84 ${ }^{\circ} \mathrm{C} .{ }^{1} \mathrm{H}$ NMR $\left(300 \mathrm{MHz}, \mathrm{CDCl}_{3}\right), \delta$ : $7.72\left(\mathrm{~d}, J=9.1 \mathrm{~Hz}, 2 \mathrm{H}, \mathrm{H}_{2}, \mathrm{H}_{6}\right) ; 7.38\left(\mathrm{~d}, J=9.2 \mathrm{~Hz}, 2 \mathrm{H}, \mathrm{H}_{3}, \mathrm{H}_{5}\right) ; 6.69$ (br s, $\left.1 \mathrm{H}, \mathrm{NH}\right) ; 3.60(\mathrm{q}, J=7.1 \mathrm{~Hz}$, $\left.2 \mathrm{H}, \mathrm{H}_{\mathrm{a}}\right) ; 3.48\left(\mathrm{t}, J=7.3 \mathrm{~Hz}, 2 \mathrm{H}, \mathrm{H}_{\mathrm{c}}\right) ; 2.19\left(\mathrm{p}, J=7.1 \mathrm{~Hz}, 2 \mathrm{H}, \mathrm{H}_{\mathrm{b}}\right) .{ }^{13} \mathrm{C} \mathrm{NMR}\left(75 \mathrm{MHz}, \mathrm{CDCl}_{3}\right) \delta: 166.8$ (CO); 137.8 ( $\left.\mathrm{C}_{\text {aro }}\right) ; 132.7$ ( $\left.\mathrm{C}_{\text {aro }}\right) ; 128.8\left(2 \mathrm{C}_{\text {aro }}\right) ; 128.4\left(2 \mathrm{C}_{\text {aro }}\right) ; 38.8\left(\mathrm{CH}_{2}\right) ; 32.0\left(\mathrm{CH}_{2}\right) ; 31.0\left(\mathrm{CH}_{2}\right)$. LCMS $\mathrm{m} / \mathrm{z}$ calc for $\left[\mathrm{M}+\mathrm{H}^{+}\right]: 275.9,277.9$; found: $276.0 ; 278.0$.

\section{2-(4-Chlorophenyl)-5,6-dihydro-4H-1,3-oxazine (2)}


To a solution of isoindoline $(20.4 \mu \mathrm{L}, 0.18 \mathrm{mmol})$ in $1 \mathrm{~mL}$ of DMF was added a $24 \mathrm{mg}(0.18 \mathrm{mmol})$ amount of potassium carbonate. The resulting mixture was stirred at $70^{\circ} \mathrm{C}$. After 30 minutes, the 4chloro- $N$-(3-bromopropyl)-4-chlorobenzamide $(50 \mathrm{mg}, 0.18 \mathrm{mmol}$ ) was added and the reacting mixture was stirred at $70^{\circ} \mathrm{C}$ overnight. The solvent was removed under reduced pressure and $15 \mathrm{~mL}$ of water added to the residue. The crude product was extracted with $3 \times 15 \mathrm{~mL}$ of DCM. The combined organic fractions were washed with water and dried over magnesium sulphate. The compound was purified by column chromatography (DCM:MeOH( $\left.\mathrm{NH}_{3}\right), 99: 1(\mathrm{v} / \mathrm{v})$ ) and obtained as a colourless oil. Yield: $70 \%$. $\mathrm{Mp}=84^{\circ} \mathrm{C} .{ }^{1} \mathrm{H}$ NMR $\left(300 \mathrm{MHz}, \mathrm{CDCl}_{3}\right) \delta: 7.83\left(\mathrm{~d}, J=9.2 \mathrm{~Hz}, 2 \mathrm{H}, \mathrm{H}_{2}, \mathrm{H}_{6}\right) ; 7.34\left(\mathrm{~d}, J=9.1 \mathrm{~Hz}, 2 \mathrm{H}, \mathrm{H}_{3}\right.$, $\left.\mathrm{H}_{5}\right) ; 4.36\left(\mathrm{t}, J=6.3 \mathrm{~Hz}, 2 \mathrm{H}, \mathrm{CH}_{2}\right) ; 3.61\left(\mathrm{t}, J=6.1 \mathrm{~Hz}, 2 \mathrm{H}, \mathrm{CH}_{2}\right) ; 1.99\left(\mathrm{p}, J=6.3 \mathrm{~Hz}, 2 \mathrm{H}, \mathrm{CH}_{2}\right) .{ }^{13} \mathrm{C} \mathrm{NMR}$

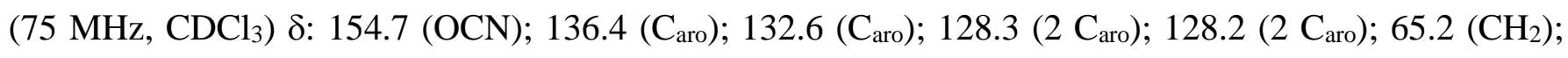
$42.6\left(\mathrm{CH}_{2}\right) ; 21.9\left(\mathrm{CH}_{2}\right)$. LCMS (ESI $\left.{ }^{+}\right)$: LCMS m/z calc for $\left[\mathrm{M}+\mathrm{H}^{+}\right]$: 196.0, 198.0; found: 196.0; 198.0.

\section{Preparation of diamine intermediates (5a-e)}

\section{tert-Butyl-3-bromopropylcarbamate (3)}

3-Bromopropylamine (13.70 mmol, $3.0 \mathrm{~g}$ ) was dissolved in $80 \mathrm{~mL}$ of DCM. After addition of triethylamine $(16.4 \mathrm{mmol}, 2.32 \mathrm{~mL})$ and di-tert-butylcarbonate $(13.70 \mathrm{mmol}, 3.0 \mathrm{~g})$, the resulting mixture was stirred at room temperature overnight. Then, it was washed with $2 \times 60 \mathrm{~mL}$ of a citric acid solution $(5 \%)$ and $50 \mathrm{~mL}$ of saturated brine solution. The organic fraction was dried over magnesium sulphate and concentrated to give the desired product as yellow oil of sufficient purity for use without purification in the next step. Yield: 97\%. ${ }^{1} \mathrm{H}$ NMR (300 MHz, $\left.\mathrm{CDCl}_{3}\right), \delta: 4.67$ (br s, $\left.1 \mathrm{H}, \mathrm{NH}\right) ; 3.45$ (t, J = 7.4 Hz, 2H,

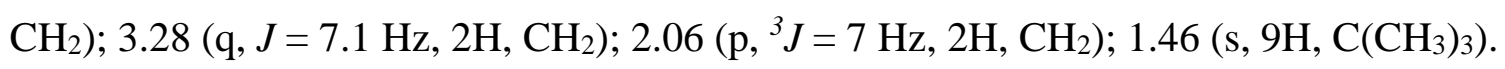

\section{General procedure for the synthesis of substituted compounds 4a-c}

To a mixture of tert-butyl-3-bromopropylcarbamate 1.2 (5.6 mmol, $1.3 \mathrm{eq}, 1.3 \mathrm{~g}$ ) and $N, N$-disubstituted amine (4.3 mmol, $1 \mathrm{eq})$ in $30 \mathrm{~mL}$ of DMF was added potassium carbonate (13.0 mmol, $3 \mathrm{eq}, 1.8 \mathrm{~g})$. The resulting mixture was heated at $70^{\circ} \mathrm{C}$ for 24 hours. Then, the solvent was removed under reduced pressure and water $(80 \mathrm{~mL})$ added to the residue. The crude product was extracted with $3 \times 60 \mathrm{~mL}$ of DCM. The combined organic fractions were washed with $60 \mathrm{~mL}$ of water and dried over magnesium sulphate. The solvent was evaporated and the crude product collected as yellow oil. Purification by column chromatography (DCM: $\mathrm{MeOH}\left(\mathrm{NH}_{3}\right)$, 9.7:0.3 (v/v)) was performed.

\section{tert-Butyl-3-[benzyl(methyl)amino]propyl carbamate (4a)}

Yield: 74\%. ${ }^{1} \mathrm{H}$ NMR (300 MHz, $\left.\mathrm{CDCl}_{3}\right), \delta: 7.36-7.19\left(\mathrm{~m}, 5 \mathrm{H}, \mathrm{H}_{\mathrm{aro}}\right) ; 5.61$ (br s, $\left.1 \mathrm{H}, \mathrm{NH}\right) ; 3.48$ (s, 2H, $\left.\mathrm{H}_{\mathrm{e}}\right) ; 3.20\left(\mathrm{q}, J=6.4 \mathrm{~Hz}, 2 \mathrm{H}, \mathrm{CH}_{2}\right) ; 2.45\left(\mathrm{t}, J=6.3 \mathrm{~Hz}, 2 \mathrm{H}, \mathrm{CH}_{2}\right) ; 2.17\left(\mathrm{~s}, 3 \mathrm{H}, \mathrm{CH}_{3}\right) ; 1.68(\mathrm{p}, J=6.2 \mathrm{~Hz}$, $\left.2 \mathrm{H}, \mathrm{CH}_{2}\right) ; 1.46\left(\mathrm{~s}, 9 \mathrm{H}, \mathrm{C}\left(\mathrm{CH}_{3}\right)_{3}\right) .{ }^{13} \mathrm{C} \mathrm{NMR}\left(75 \mathrm{MHz}, \mathrm{CDCl}_{3}\right) \delta: 156.1(\mathrm{CO}) ; 139.0\left(\mathrm{C}_{\text {aro }}\right) ; 129.0\left(2 \mathrm{C}_{\text {aro }}\right)$; 
$128.3\left(2 \mathrm{C}_{\text {aro }}\right) ; 127.0\left(\mathrm{C}_{\text {aro }}\right) ; 78.7\left(\underline{\mathrm{C}}\left(\mathrm{CH}_{3}\right)_{3}\right) ; 62.7\left(\mathrm{CH}_{2}\right) ; 56.5\left(\mathrm{CH}_{2}\right) ; 42.1\left(\mathrm{CH}_{3}\right) ; 40.1\left(\mathrm{CH}_{2}\right) ; 28.5$ $\left(\mathrm{C}\left(\underline{\mathrm{CH}}_{3}\right)_{3}\right) ; 26.6\left(\mathrm{CH}_{2}\right)$. LCMS $\mathrm{m} / z$ calc for $\left[\mathrm{M}+\mathrm{H}^{+}\right]: 279.2$; found: 279.1 .

\section{tert-Butyl-3-[ $N$-methyl- $N$-(2-phenylethyl)amino] propyl carbamate (4b)}

Yield: 81\%. ${ }^{1} \mathrm{H}$ NMR (300 MHz, $\mathrm{CDCl}_{3}$ ), $\delta: 7.30$ (m, 2H, $\mathrm{H}_{\text {aro }}$ ); 7.20 (m, 2H, $\mathrm{H}_{\text {aro }}$ ); 5.66 (br s, 1H, NH); $3.16\left(\mathrm{~m}, 2 \mathrm{H}, \mathrm{CH}_{2}\right) ; 2.79\left(\mathrm{~m}, 2 \mathrm{H}, \mathrm{CH}_{2}\right) ;$ ); $2.61\left(\mathrm{~m}, 2 \mathrm{H}, \mathrm{CH}_{2}\right) ; 2.45\left(\mathrm{t}, J=6.8 \mathrm{~Hz}, 2 \mathrm{H}, \mathrm{CH}_{2}\right) ; 2.28(\mathrm{~s}, 3 \mathrm{H}$, $\left.\mathrm{CH}_{3}\right) ; 1.65$ (q, $\left.J=6.6 \mathrm{~Hz}, 2 \mathrm{H}, \mathrm{CH}_{2}\right) ; 1.47\left(\mathrm{~s}, 9 \mathrm{H}, \mathrm{C}\left(\mathrm{CH}_{3}\right)_{3}\right) .{ }^{13} \mathrm{C} \mathrm{NMR}\left(75 \mathrm{MHz}, \mathrm{CDCl}_{3}\right) \delta: 156.1(\mathrm{CO})$; $140.4\left(\mathrm{C}_{\text {aro }}\right) ; 128.7\left(2 \mathrm{C}_{\text {aro }}\right) ; 128.4\left(2 \mathrm{C}_{\text {aro }}\right) ; 126.0\left(\mathrm{C}_{\text {aro }}\right) ; 78.8\left(\underline{\mathrm{C}}\left(\mathrm{CH}_{3}\right)_{3}\right) ; 59.6\left(\mathrm{CH}_{2}\right) ; 55.9\left(\mathrm{CH}_{2}\right) ; 42.1$ $\left(\mathrm{CH}_{3}\right) ; 39.7\left(\mathrm{CH}_{2}\right) ; 33.9\left(\mathrm{CH}_{2}\right) ; 28.5\left(\mathrm{C}\left(\underline{\mathrm{CH}}_{3}\right)_{3}\right) ; 27.0\left(\mathrm{CH}_{2}\right)$. LCMS m/z calc for [M+H- tertBut] ${ }^{+}: 237.1$; found: 237.0 .

\section{tert-Butyl-3-(isoindolin-2-yl)propylcarbamate (4c)}

Yield: 65\%. ${ }^{1} \mathrm{H}$ NMR (300 MHz, $\mathrm{CDCl}_{3}$ ), $\delta: 7.20$ (m, 4H, $\mathrm{H}_{\text {aro }}$ ); 5.12 (br s, 1H, NH); 3.96 (s, 4H, $2 \mathrm{CH}_{2}$ ); $3.24\left(\mathrm{~m}, 2 \mathrm{H}, \mathrm{CH}_{2}\right) ; 2.79\left(\mathrm{t}, J=6.0 \mathrm{~Hz}, 2 \mathrm{H}, \mathrm{CH}_{2}\right) ; 1.75\left(\mathrm{q}, J=6.7 \mathrm{~Hz}, 2 \mathrm{H}, \mathrm{CH}_{2}\right) ; 1.44\left(\mathrm{~s}, 9 \mathrm{H}, \mathrm{C}\left(\mathrm{CH}_{3}\right)_{3}\right)$. ${ }^{13} \mathrm{C} \mathrm{NMR}\left(75 \mathrm{MHz}, \mathrm{CDCl}_{3}\right) \delta: 156.1(\mathrm{CO}) ; 139.7\left(2 \mathrm{C}_{\mathrm{aro}}\right) ; 126.8\left(2 \mathrm{C}_{\mathrm{aro}}\right) ; 122.3\left(2 \mathrm{C}_{\text {aro }}\right) ; 79.1\left(\underline{\mathrm{C}}\left(\mathrm{CH}_{3}\right)_{3}\right)$; $59.1\left(2 \mathrm{CH}_{2}\right) ; 54.0\left(\mathrm{CH}_{2}\right) ; 39.5\left(\mathrm{CH}_{2}\right) ; 28.7\left(\mathrm{CH}_{2}\right) ; 28.5\left(\mathrm{C}_{\left.\left(\mathrm{CH}_{3}\right)_{3}\right) \text {. LCMS m/z calc for }[\mathrm{M}+\mathrm{H}-\text { tertBut] }}^{+}\right.$: 221.2; found: 221.0 .

\section{General procedure for the synthesis of substituted compounds 6a-c}

To a mixture of $\mathrm{N}$-(bromoethyl or bromobutyl)phtalimide $(5.9 \mathrm{mmol})$ and benzylmethylamine $(7.1 \mathrm{mmol}$, $0.8 \mathrm{~mL})$ or 2-phenylethylamine $(7.1 \mathrm{mmol}, 0.9 \mathrm{~mL})$ in $30 \mathrm{~mL}$ of DMF was added potassium carbonate $(11.80 \mathrm{mmol}, 1.6 \mathrm{~g})$. The resulting mixture was heated at $90^{\circ} \mathrm{C}$ for 16 hours. Then, inorganics were eliminated by filtration and the solvent was removed under reduced pressure. Purification by column chromatography (DCM: $\mathrm{MeOH}\left(\mathrm{NH}_{3}\right)$, 9.9:0.1 (v/v)) was performed.

\section{2-[2-(Benzylmethylamino)ethyl]-2,3-dihydro-1H-isoindole-1,3-dione (6a)}

Yield 52\%. ${ }^{1} \mathrm{H}$ NMR (300 MHz, $\left.\mathrm{CDCl}_{3}\right), \delta: 7.88$ (m, 2H, $\mathrm{H}_{\text {aro }}$ ); 7.72 (m, 2H, $\mathrm{H}_{\text {aro }}$ ); 7.09-7.11 (m, 5H, $\mathrm{H}_{\text {aro }}$ ); $3.82\left(\mathrm{t}, J=6.3 \mathrm{~Hz}, 2 \mathrm{H}, \mathrm{CH}_{2}\right) ; 3.55\left(\mathrm{~s}, 2 \mathrm{H}, \mathrm{CH}_{2}\right) ; 2.70\left(\mathrm{t}, J=6.3 \mathrm{~Hz}, 2 \mathrm{H}, \mathrm{CH}_{2}\right) ; 2.31\left(\mathrm{~s}, 3 \mathrm{H}, \mathrm{CH}_{3}\right)$. ${ }^{13} \mathrm{C}$ NMR (75 MHz, $\left.\mathrm{CDCl}_{3}\right) \delta: 168.3$ (2 CO); $138.8\left(\mathrm{C}_{\text {aro }}\right) ; 133.8\left(2 \mathrm{C}_{\text {aro }}\right) ; 132.3$ (2 $\left.\mathrm{C}_{\text {aro }}\right) ; 128.9$ (2 $\left.\mathrm{C}_{\text {aro }}\right)$; 128.1 (2 $\left.\mathrm{C}_{\text {aro }}\right) ; 126.9\left(\mathrm{C}_{\text {aro }}\right) ; 123.1\left(2 \mathrm{C}_{\text {aro }}\right) ; 62.1\left(\mathrm{CH}_{2}\right) ; 54.5\left(\mathrm{CH}_{2}\right) ; 42.2\left(\mathrm{CH}_{3}\right) ; 35.9\left(\mathrm{CH}_{2}\right)$. LCMS $\mathrm{m} / \mathrm{z}$ calc for $\left[\mathrm{M}+\mathrm{H}^{+}\right]: 295.1$; found: .295.0.

\section{2-[4-(Benzylmethylamino)butyl]-2,3-dihydro-1H-isoindole-1,3-dione (6b)}

Yield 53\%. ${ }^{1} \mathrm{H}$ NMR (300 MHz, $\left.\mathrm{CDCl}_{3}\right), \delta: 7.82\left(\mathrm{~m}, 2 \mathrm{H}, \mathrm{H}_{\text {aro }}\right) ; 7.69\left(\mathrm{~m}, 2 \mathrm{H}, \mathrm{H}_{\text {aro }}\right) ; 7.15-7.32(\mathrm{~m}, 5 \mathrm{H}$, $\mathrm{H}_{\text {aro }}$ ); $3.71\left(\mathrm{t}, J=7.2 \mathrm{~Hz}, 2 \mathrm{H}, \mathrm{CH}_{2}\right) ; 3.48\left(\mathrm{~s}, 2 \mathrm{H}, \mathrm{CH}_{2}\right) ; 2.41\left(\mathrm{t}, J=7.2 \mathrm{~Hz}, 2 \mathrm{H}, \mathrm{CH}_{2}\right) ; 2.18\left(\mathrm{~s}, 3 \mathrm{H}, \mathrm{CH}_{3}\right)$; $1.74\left(\mathrm{~m}, 2 \mathrm{H}, \mathrm{CH}_{2}\right) ; 1.55$ (m, 2H, $\left.\mathrm{CH}_{2}\right) .{ }^{13} \mathrm{C} \mathrm{NMR}\left(75 \mathrm{MHz}, \mathrm{CDCl}_{3}\right) \delta: 168.4$ (2 CO); $138.9\left(\mathrm{C}_{\text {aro }}\right) ; 133.9$ 
$\left(2 \mathrm{C}_{\text {aro }}\right) ; 132.1\left(\mathrm{C}_{\text {aro }}\right) ; 129.0\left(2 \mathrm{C}_{\text {aro }}\right) ; 128.2\left(2 \mathrm{C}_{\text {aro }}\right) ; 126.9\left(2 \mathrm{C}_{\text {aro }}\right) ; 123.1\left(2 \mathrm{C}_{\text {aro }}\right) ; 62.4\left(\mathrm{CH}_{2}\right) ; 56.8\left(\mathrm{CH}_{2}\right)$; $42.1\left(\mathrm{CH}_{3}\right) ; 37.9\left(\mathrm{CH}_{2}\right) ; 26.5\left(\mathrm{CH}_{2}\right) ; 24.6\left(\mathrm{CH}_{2}\right)$. LCMS m/z calc for [M+H'] $\left.{ }^{+}\right]$323.1; found: 323.0.

\section{2-[2-(N-methyl-N-(2-phenylethyl)amino)ethyl]-2,3-dihydro-1H-isoindole-1,3-dione (6c)}

Yield: 64\%. ${ }^{1} \mathrm{H}$ NMR (300 MHz, $\left.\mathrm{CDCl}_{3}\right), \delta: 7.85$ (m, 2H, $\left.\mathrm{H}_{\text {aro }}\right) ; 7.70$ (m, 2H, $\mathrm{H}_{\text {aro }}$ ); 7.05-7.20 (m, 5H, $\left.\mathrm{H}_{\text {aro }}\right) ; 3.80\left(\mathrm{t}, J=6.6 \mathrm{~Hz}, 2 \mathrm{H}, \mathrm{CH}_{2}\right) ; 2.62-2.75\left(\mathrm{~m}, 6 \mathrm{H}, 3 \mathrm{CH}_{2}\right) ; 2.38\left(\mathrm{~s}, 3 \mathrm{H}, \mathrm{CH}_{3}\right) .{ }^{13} \mathrm{C} \mathrm{NMR}(75 \mathrm{MHz}$,

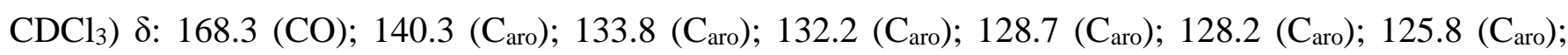
$123.1\left(\mathrm{C}_{\text {aro }}\right) ; 59.4\left(\mathrm{CH}_{2}\right) ; 54.7\left(\mathrm{CH}_{2}\right) ; 42.2\left(\mathrm{CH}_{3}\right) ; 35.8\left(\mathrm{CH}_{2}\right) ; 33.7\left(\mathrm{CH}_{2}\right)$. LCMS m/z calc for $\left[\mathrm{M}+\mathrm{H}^{+}\right]$: 309.1; found: 309.0 .

\section{General procedure for the synthesis of substitutedcompounds 5a-c}

The compound 1.3 (1 eq) was dissolved in $72 \mathrm{~mL}$ of $3 \mathrm{M} \mathrm{HCl}$ in dry 1,4-dioxane. The resulting mixture was stirred at room temperature overnight. Then, the solvent was removed under reduced pressure to give the desired product of sufficient purity for use without purification in the next step.

\section{$N^{1}$-Benzyl- $N^{1}$-methylpropane-1,3-diamine (5a)}

Yield 98\%. Mp: $77^{\circ} \mathrm{C} .{ }^{1} \mathrm{H}$ NMR (300 MHz, $\mathrm{CDCl}_{3}$ ), $\delta: 11.27$ (br s, $\left.1 \mathrm{H}, \mathrm{NH}\right) ; 8.37$ (br s, 3H, NH); 7.66$7.41\left(\mathrm{~m}, 5 \mathrm{H}, \mathrm{H}_{\text {aro }}\right) ; 4.27$ (m, 2H, $\left.\mathrm{CH}_{2}\right), 3.27-2.28\left(\mathrm{~m}, 4 \mathrm{H}, 2 \mathrm{CH}_{2}\right) ; 2.60\left(\mathrm{~s}, 3 \mathrm{H}, \mathrm{CH}_{3}\right) ; 2.13$ (p, J= 7.4 Hz, $\left.2 \mathrm{H}, \mathrm{CH}_{2}\right) .{ }^{13} \mathrm{C}$ NMR $\left(75 \mathrm{MHz}, \mathrm{CDCl}_{3}\right) \delta$ : $123.0\left(\mathrm{C}_{\text {aro }}\right) ; 130.3\left(\mathrm{C}_{\text {aro }}\right) ; 129.9\left(2 \mathrm{C}_{\text {aro }}\right) ; 129.2\left(2 \mathrm{C}_{\text {aro }}\right) ; 58.6$ $\left(\mathrm{CH}_{2}\right) ; 52.1\left(\mathrm{CH}_{2}\right) ; 39.0\left(\mathrm{CH}_{3}\right) ; 36.7\left(\mathrm{CH}_{2}\right) ; 22.0\left(\mathrm{CH}_{2}\right)$. LCMS $\mathrm{m} / z$ calc for $\left[\mathrm{M}+\mathrm{H}^{+}\right]$: 179.1; found: .179.0

\section{$N^{1}$-Benzyl- $N^{1}$-(2-phenylethyl)propane-1,3-diamine (5b)}

Yield: 88\%. ${ }^{1} \mathrm{H}$ NMR (300 MHz, $\mathrm{CDCl}_{3}$ ), $\delta: ~ 7.38-7.22$ (m, 5H, $\mathrm{H}_{\text {aro }}$ ); 6.20 (br s, 2H, NH ); 3.37-3.24 (m, $\left.4 \mathrm{H}, \mathrm{CH}_{2}\right) ; 3.19-3.01\left(\mathrm{~m}, 4 \mathrm{H}, 2 \mathrm{CH}_{2}\right) ; 2.83\left(\mathrm{~s}, 3 \mathrm{H}, \mathrm{CH}_{3}\right) ; 2.15\left(\mathrm{q}, J=7.4 \mathrm{~Hz}, 2 \mathrm{H}, \mathrm{CH}_{2}\right) .{ }^{13} \mathrm{C}$ NMR $(75$ $\left.\mathrm{MHz}, \mathrm{CDCl}_{3}\right)$ \&: $137.0\left(\mathrm{C}_{\text {aro }}\right) ; 128.7\left(2 \mathrm{C}_{\text {aro }}\right) ; 128.6\left(2 \mathrm{C}_{\text {aro }}\right) ; 126.7\left(\mathrm{C}_{\text {aro }}\right) ; 57.6\left(\mathrm{CH}_{2}\right) 39.6\left(\mathrm{CH}_{3}\right) ; 37.3$ $\left(\mathrm{CH}_{2}\right) ; 30.6\left(\mathrm{CH}_{2}\right) ; 22.4\left(\mathrm{CH}_{2}\right)$. LCMS $m / z$ calc for $\left[\mathrm{M}+\mathrm{H}^{+}\right]$: 193.1; found: 193.0.

\section{3-(Isoindolin-2-yl)propan-1-amine (5c)}

Yield: 83\%. ${ }^{1} \mathrm{H}$ NMR (300 MHz, $\mathrm{CDCl}_{3}$ ), $\delta: 8.04$ (m, 4H, $\mathrm{H}_{\text {aro }}$ ); 5.58 (br s, 2H, NH ); 4.12 (t, J = 7.9 Hz, $\left.2 \mathrm{H}, \mathrm{CH}_{2}\right) ; 3.91\left(\mathrm{~s}, 4 \mathrm{H}, \mathrm{CH}_{2}\right), 3.74\left(\mathrm{t}, J=7.6 \mathrm{~Hz}, 2 \mathrm{H}, \mathrm{CH}_{2}\right) ; 2.71\left(\mathrm{t}, J=7.8 \mathrm{~Hz}, 2 \mathrm{H}, \mathrm{CH}_{2}\right) .{ }^{13} \mathrm{C}$ NMR $(75$ $\left.\mathrm{MHz}, \mathrm{CDCl}_{3}\right) \delta: 133.9\left(2 \mathrm{C}_{\text {aro }}\right) ; 128.6\left(2 \mathrm{C}_{\text {aro }}\right) ; 122.6\left(2 \mathrm{C}_{\text {aro }}\right) ; 58.5\left(2 \mathrm{CH}_{2}\right) ; 51.7\left(\mathrm{CH}_{2}\right) ; 36.6\left(\mathrm{CH}_{2}\right) ; 23.7$ $\left(\mathrm{CH}_{2}\right)$. LCMS $m / z$ calc for $\left[\mathrm{M}+\mathrm{H}^{+}\right]$: 177.1; found: 177.0.

\section{General procedure for the synthesis of substituted compounds $5 \mathrm{~d}-\mathrm{f}$}

In $50 \mathrm{~mL}$ of ethanol $96^{\circ}$, was added a mixture of 2-[N,N-disubstitutedaminoalkyl]-2,3-dihydro- $1 \mathrm{H}$ isoindole-1,3-dione $(6.2 \mathrm{mmol})$ and hydrazine hydrate $(62.0 \mathrm{mmol}, 3.1 \mathrm{~mL})$. The resulting mixture was 
heated at reflux for 16 hours. The solution was removed under reduced pressure. The mineral was eliminated by filtration and washed with ethyl acetate. The filtrate was evaporated under reduced pressure to give an oily residue. Purification by column chromatography (DCM: $\mathrm{MeOH}\left(\mathrm{NH}_{3}\right)$, 9:1 (v/v)) was performed.

\section{$N^{1}$-Benzyl- $N^{1}$-methylethane-1,2-diamine (5d)}

Yield 55\%. ${ }^{1} \mathrm{H}$ NMR (300 MHz, $\left.\mathrm{CDCl}_{3}\right), \delta: 7.35-7.30\left(\mathrm{~m}, 5 \mathrm{H}, \mathrm{H}_{\text {aro }}\right) ; 4.90$ (br s, $\left.2 \mathrm{H}, \mathrm{NH}_{2}\right) ; 3.58(\mathrm{~s}, 2 \mathrm{H}$, $\left.\mathrm{CH}_{2}\right) ; 2.91\left(\mathrm{t}, J=6.3 \mathrm{~Hz}, 2 \mathrm{H}, \mathrm{CH}_{2}\right) ; 2.60\left(\mathrm{t}, J=6.2 \mathrm{~Hz}, 2 \mathrm{H}, \mathrm{CH}_{2}\right) ; 2.22\left(\mathrm{~s}, 3 \mathrm{H}, \mathrm{CH}_{3}\right) .{ }^{13} \mathrm{C} \mathrm{NMR}(75 \mathrm{MHz}$, $\left.\mathrm{CDCl}_{3}\right) \delta: 138.0\left(\mathrm{C}_{\text {aro }}\right) ; 129.0\left(2 \mathrm{C}_{\text {aro }}\right) ; 128.0\left(2 \mathrm{C}_{\text {aro }}\right) ; 127.0\left(\mathrm{C}_{\text {aro }}\right) ; 62.1\left(\mathrm{CH}_{2}\right) ; 55.9\left(\mathrm{CH}_{2}\right) ; 40.7\left(\mathrm{CH}_{3}\right)$; $37.4\left(\mathrm{CH}_{2}\right)$. LCMS $m / z$ calc for $\left[\mathrm{M}+\mathrm{H}^{+}\right]$: 165.1; found: 165.0 .

\section{$N^{1}$-Benzyl- $N^{1}$-methylbutane-1,4-diamine (5e)}

Yield 73\%. ${ }^{1} \mathrm{H}$ NMR (300 MHz, $\left.\mathrm{CDCl}_{3}\right), \delta: 7.35-7.25\left(\mathrm{~m}, 5 \mathrm{H}, \mathrm{H}_{\mathrm{aro}}\right) ; 3.50\left(\mathrm{~s}, 2 \mathrm{H}, \mathrm{CH}_{2}\right) ; 2.72(\mathrm{t}, J=6.8$ $\left.\mathrm{Hz}, 2 \mathrm{H}, \mathrm{CH}_{2}\right) ; 2.39$ (t, $\left.J=6.9 \mathrm{~Hz}, 2 \mathrm{H}, \mathrm{CH}_{2}\right) ; 2.22\left(\mathrm{~s}, 5 \mathrm{H}, \mathrm{NH}_{2}, \mathrm{CH}_{3}\right) ; 1.61-1.45\left(\mathrm{~m}, 4 \mathrm{H}, 2 \mathrm{CH}_{2}\right) .{ }^{13} \mathrm{C} \mathrm{NMR}$ $\left(75 \mathrm{MHz}, \mathrm{CDCl}_{3}\right)$ \&: $139.1\left(\mathrm{C}_{\mathrm{aro}}\right) ; 129.10\left(2 \mathrm{C}_{\mathrm{aro}}\right) ; 128.2\left(2 \mathrm{C}_{\mathrm{aro}}\right) ; 126.9\left(\mathrm{C}_{\mathrm{aro}}\right) ; 62.3\left(\mathrm{CH}_{2}\right) ; 57.2\left(\mathrm{CH}_{2}\right)$; $42.1\left(\mathrm{CH}_{3}\right) ; 42.0\left(\mathrm{CH}_{2}\right) ; 31.4\left(\mathrm{CH}_{2}\right) ; 24.7\left(\mathrm{CH}_{2}\right)$. LCMS m/z calc for [M+H'] : 193.1; found: 193.0.

\section{$N^{1}$-(2-phenylethyl)- $N^{\mathbf{1}}$-methylethane-1,2-diamine dihydrochloride (5f)}

Yield: 64\%. ${ }^{1} \mathrm{H}$ NMR (300 MHz, $\left.\mathrm{CDCl}_{3}\right), \delta: 7.30-7.22$ (m, 2H, $\mathrm{H}_{\text {aro }}$ ); 7.20-7.10 (m, 3H, $\left.\mathrm{H}_{\text {aro }}\right) ; 2.80-2.70$ $\left(\mathrm{m}, 4 \mathrm{H}, 2 \mathrm{CH}_{2}\right) ; 2.62\left(\mathrm{~m}, 2 \mathrm{H}, \mathrm{CH}_{2}\right) ; 2.47\left(\mathrm{t}, J=6.0 \mathrm{~Hz}, 2 \mathrm{H}, \mathrm{CH}_{2}\right) ; 2.26\left(\mathrm{~s}, 3 \mathrm{H}, \mathrm{CH}_{3}\right) .{ }^{13} \mathrm{C} \mathrm{NMR}(75 \mathrm{MHz}$, $\left.\mathrm{CDCl}_{3}\right)$ \&: $140.5\left(\mathrm{C}_{\text {aro }}\right) ; 128.7\left(\mathrm{C}_{\text {aro }}\right) ; 128.3\left(\mathrm{C}_{\text {aro }}\right) ; 125.9\left(\mathrm{C}_{\text {aro }}\right) ; 59.7\left(\mathrm{CH}_{2}\right) ; 59.6\left(\mathrm{CH}_{2}\right) ; 42.1\left(\mathrm{CH}_{3}\right) ; 39.2$ $\left(\mathrm{CH}_{2}\right) ; 33.8\left(\mathrm{CH}_{2}\right)$. LCMS $\mathrm{m} / \mathrm{z}$ calc for $\left[\mathrm{M}+\mathrm{H}^{+}\right]: 179.1$; found: 179.1 .

\section{General procedure E1}

A solution of $N, N$-disubstitutedalkyldiamine 5a-f or commercially available amine (1 eq), and triethylamine (3 eq) in $10 \mathrm{~mL}$ of DCM was cooled at $0^{\circ} \mathrm{C}$. A solution of substituted benzoylchloride $(1$ eq) in $5 \mathrm{~mL}$ of DCM was added slowly. The resulting mixture was stirred at room temperature overnight. The solution was evaporated under reduced pressure. An aqueous solution of $3 \%$ sodium hydroxide (20 $\mathrm{mL}$ ) was added and the mixture was stirred for 1 hour. The solution was extracted with DCM. The organic layer was dried over magnesium sulphate and concentrated to give an oily product. The residue was purified by thick layer chromatography ( $\left.\mathrm{DCM}: \mathrm{MeOH}\left(\mathrm{NH}_{3}\right), 9: 1(\mathrm{v} / \mathrm{v})\right)$ or column chromatography (DCM:MeOH( $\left.\mathrm{NH}_{3}\right)$, 9:1 (v/v)).

\section{General procedure E2}

Reaction was carried out under nitrogen atmosphere. In $10 \mathrm{~mL}$ of DCM, benzoic acid (1 eq), HOBt (1.2 eq) and HBtu (1.2 eq) were added and stirred at room temperature for 10 minutes. A solution of $N, N$ - 
disubstitutedalkyldiamine 5a-f or commercially available amine (1 eq) and DIEA (15 eq) in DCM was added to the reacting mixture. After stirring at room temperature for 24 hours, the solvent was removed under reduced pressure and DCM was added to the residue. The solution was washed with a solution of $\mathrm{NaHCO}_{3}(5 \%)$ then saturated $\mathrm{NaCl}$ solution. The organic layer was dried over magnesium sulfate and evaporated under reduced pressure. The crude product was purified by thick layer chromatography (DCM:MeOH(NH3), 9:1 (v/v)) or column chromatography (DCM:MeOH( $\left.\mathrm{NH}_{3}\right)$, 9:1 (v/v)).

\section{N-[3-(N-benzyl-N-methylamino)propyl]benzamide (7a)}

Procedure E2. Purification by thick layer chromatography was performed. Yield: $75 \%$. ${ }^{1} \mathrm{H}$ NMR (300 $\mathrm{MHz}, \mathrm{CDCl}_{3}$ ), $\delta: 8.05$ (br s, $\left.1 \mathrm{H}, \mathrm{NH}\right) ; 7.70$ (m, 2H, $\left.\mathrm{H}_{2}, \mathrm{H}_{6}\right) ; 7.49-7.30$ (m, 3H, H3, H4, $\mathrm{H}_{5}$ ); 7.29-7.22 (m, $\left.5 \mathrm{H}, \mathrm{H}_{\text {aro }}\right) ; 3.61-3.52\left(\mathrm{~m}, 4 \mathrm{H}, 2 \mathrm{CH}_{2}\right) ; 2.65\left(\mathrm{t}, J=6.7 \mathrm{~Hz}, 2 \mathrm{H}, \mathrm{CH}_{2}\right) ; 2.29\left(\mathrm{~s}, 3 \mathrm{H}, \mathrm{CH}_{3}\right) ; 1.84(\mathrm{p}, J=6.8 \mathrm{~Hz}$, 2H, $\left.\mathrm{CH}_{2}\right) .{ }^{13} \mathrm{C}$ NMR (75 MHz, $\left.\mathrm{CDCl}_{3}\right) \delta: 167.3(\mathrm{CO}) ; 137.8\left(\mathrm{C}_{\text {aro }}\right) ; 134.7\left(\mathrm{C}_{\text {aro }}\right) ; 131.1$ (2 $\left.\mathrm{C}_{\text {aro }}\right) ; 129.4(2$ $\left.\mathrm{C}_{\text {aro }}\right) ; 128.4\left(\mathrm{C}_{\text {aro }}\right) ; 128.4$ (2 $\left.\mathrm{C}_{\text {aro }}\right) ; 127.4\left(\mathrm{C}_{\text {aro }}\right) ; 126.9\left(2 \mathrm{C}_{\text {aro }}\right) ; 63.1\left(\mathrm{CH}_{2}\right) ; 56.9\left(\mathrm{CH}_{2}\right) ; 41.6\left(\mathrm{CH}_{3}\right) ; 40.1$ $\left(\mathrm{CH}_{2}\right) ; 25.3\left(\mathrm{CH}_{2}\right)$. LCMS $\mathrm{m} / z$ calc for $\left[\mathrm{M}+\mathrm{H}^{+}\right]: 283.2$; found: 283.1. HPLC $\left(\mathrm{C}_{4}, 35 \mathrm{~min}\right): t_{R} 17.5 \mathrm{~min}$, $\mathrm{P}_{\text {HPLC }}$ 97\%; HPLC ( $\left.\mathrm{C}_{18}, 35 \mathrm{~min}\right): t_{R} 15.2 \mathrm{~min}, \mathrm{P}_{\text {HPLC }} 99 \%$.

\section{$N$-[3-(benzylmethylamino)propyl]-4-propylbenzamide (7b)}

Procedure E1. Purification by column chromatography (DCM: $\mathrm{MeOH}\left(\mathrm{NH}_{3}\right)$, 9:1 (v/v)) was performed. Yield: 61\%. ${ }^{1} \mathrm{H}$ NMR (300 MHz, $\mathrm{CDCl}_{3}$ ), $\delta: 7.90$ (br s, $\left.1 \mathrm{H}, \mathrm{NH}\right) ; 7.60$ (d, J=8.2 Hz, 2H, H2, H6); 7.29$7.20\left(\mathrm{~m}, 5 \mathrm{H}, \mathrm{H}_{\text {aro }}\right) ; 7.13\left(\mathrm{~d}, J=8.1 \mathrm{~Hz}, 2 \mathrm{H}, \mathrm{H}_{3}, \mathrm{H}_{5}\right) ; 3.55\left(\mathrm{t}, J=6.0 \mathrm{~Hz}, 2 \mathrm{H}, \mathrm{CH}_{2}\right) ; 3.50\left(\mathrm{~s}, 2 \mathrm{H}, \mathrm{CH}_{2}\right) ; 2.60$ $\left(\mathrm{m}, 4 \mathrm{H}, 2 \mathrm{CH}_{2}\right) ; 2.23\left(\mathrm{~s}, 3 \mathrm{H}, \mathrm{CH}_{3}\right) ; 1.80\left(\mathrm{p}, J=6.0 \mathrm{~Hz}, 2 \mathrm{H}, \mathrm{CH}_{2}\right) ; 1.62\left(\mathrm{~s}, J=7.5 \mathrm{~Hz}, 2 \mathrm{H}, \mathrm{CH}_{2}\right) ; 0.95(\mathrm{t}, J$ $\left.=7.3 \mathrm{~Hz}, 2 \mathrm{H}, \mathrm{CH}_{3}\right) .{ }^{13} \mathrm{C} \mathrm{NMR}\left(75 \mathrm{MHz}, \mathrm{CDCl}_{3}\right) \delta: 167.2(\mathrm{CO}) ; 146.1\left(\mathrm{C}_{\text {aro }}\right) ; 138.4\left(\mathrm{C}_{\text {aro }}\right) ; 132.2\left(\mathrm{C}_{\text {aro }}\right)$; $129.3\left(\mathrm{C}_{\text {aro }}\right) ; 128.5\left(\mathrm{C}_{\text {aro }}\right) ; 128.4\left(\mathrm{C}_{\text {aro }}\right) ; 127.2\left(\mathrm{C}_{\text {aro }}\right) ; 126.9\left(\mathrm{C}_{\text {aro }}\right) ; 63.3\left(\mathrm{CH}_{2}\right) ; 57.1\left(\mathrm{CH}_{2}\right) ; 42.1\left(\mathrm{CH}_{3}\right)$; $40.2\left(\mathrm{CH}_{2}\right) ; 37.9\left(\mathrm{CH}_{2}\right) ; 25.5\left(\mathrm{CH}_{2}\right) ; 24.3\left(\mathrm{CH}_{2}\right) ; 14.2\left(\mathrm{CH}_{3}\right)$. LCMS $\mathrm{m} / z$ calc for $\left[\mathrm{M}+\mathrm{H}^{+}\right]$: 325.2; found: 325.0. HRMS: calcd for $\left(\mathrm{C}_{21} \mathrm{H}_{28} \mathrm{ON}_{2}\right) \mathrm{H}^{+}$: 325.22744; found: 325.22617 . HPLC $\left(\mathrm{C}_{4}, 35 \mathrm{~min}\right): t_{R} 16.5 \mathrm{~min}$, $\mathrm{P}_{\mathrm{HPLC}}$ 96\%; HPLC ( $\left.\mathrm{C}_{18}, 35 \mathrm{~min}\right): t_{R} 22.5 \mathrm{~min}, \mathrm{P}_{\mathrm{HPLC}} 97 \%$.

\section{$N$-[3-(benzylmethylamino)propyl]-4-butylbenzamide (7c)}

Procedure E1. Purification by column chromatography (DCM: $\mathrm{MeOH}\left(\mathrm{NH}_{3}\right)$, 9:1 (v/v)) was performed. Yield: $30 \% .{ }^{1} \mathrm{H}$ NMR (300 MHz, $\mathrm{CDCl}_{3}$ ), $\delta: 7.97$ (br s, $\left.1 \mathrm{H}, \mathrm{NH}\right) ; 7.60$ (d, J=8.2 Hz, 2H, H2, H6); 7.29$7.23\left(\mathrm{~m}, 5 \mathrm{H}, \mathrm{H}_{\text {aro }}\right) ; 7.13\left(\mathrm{~d}, J=8.2 \mathrm{~Hz}, 2 \mathrm{H}, \mathrm{H}_{3}, \mathrm{H}_{5}\right) ; 3.56\left(\mathrm{~m}, 4 \mathrm{H}, 2 \mathrm{CH}_{2}\right) ; 2.64\left(\mathrm{~m}, 4 \mathrm{H}, 2 \mathrm{CH}_{2}\right) ; 2.28(\mathrm{~s}, 3 \mathrm{H}$, $\left.\mathrm{CH}_{3}\right) ; 1.83\left(\mathrm{p}, J=6.1 \mathrm{~Hz}, 2 \mathrm{H}, \mathrm{CH}_{2}\right) ; 1.62\left(\mathrm{~m}, 2 \mathrm{H}, \mathrm{CH}_{2}\right) ; 1.35\left(\mathrm{~m}, 2 \mathrm{H}, \mathrm{CH}_{2}\right) ; 0.97$ (t, J=7.1 Hz, 2H, $\left.\mathrm{CH}_{3}\right)$.

${ }^{13} \mathrm{C} \mathrm{NMR}\left(75 \mathrm{MHz}, \mathrm{CDCl}_{3}\right)$ \&: $167.7(\mathrm{CO}) ; 146.7\left(\mathrm{C}_{\text {aro }}\right) ; 138.0\left(\mathrm{C}_{\text {aro }}\right) ; 132.5\left(\mathrm{C}_{\text {aro }}\right) ; 129.8\left(2 \mathrm{C}_{\text {aro }}\right) ; 128.8$ (4 $\left.\mathrm{C}_{\text {aro }}\right) ; 127.9\left(\mathrm{C}_{\text {aro }}\right) ; 127.3\left(2 \mathrm{C}_{\text {aro }}\right) ; 63.5\left(\mathrm{CH}_{2}\right) ; 57.1\left(\mathrm{CH}_{2}\right) ; 41.9\left(\mathrm{CH}_{3}\right) ; 40.3\left(\mathrm{CH}_{2}\right) ; 35.9\left(\mathrm{CH}_{2}\right) ; 33.7$ $\left(\mathrm{CH}_{2}\right) ; 25.7\left(\mathrm{CH}_{2}\right) ; 22.6\left(\mathrm{CH}_{2}\right) ; 14.3\left(\mathrm{CH}_{3}\right)$. LCMS $\mathrm{m} / z$ calc for $\left[\mathrm{M}+\mathrm{H}^{+}\right]$: 339.2; found: 339.0. HPLC $\left(\mathrm{C}_{4}\right.$, $35 \mathrm{~min}): t_{R} 16.0 \mathrm{~min}, \mathrm{P}_{\mathrm{HPLC}} 96 \%$; HPLC $\left(\mathrm{C}_{18}, 35 \mathrm{~min}\right): t_{R} 21.9 \mathrm{~min}, \mathrm{P}_{\mathrm{HPLC}} 97 \%$. 


\section{$N$-[3-(benzylmethylamino)propyl]-4-tert-butylbenzamide (7d)}

Procedure E1. Purification by column chromatography (DCM:MeOH(NH$)$, 9:1 (v/v)) was performed. Yield: 27\%. ${ }^{1} \mathrm{H}$ NMR (300 MHz, $\mathrm{CDCl}_{3}$ ), $\delta: 8.03$ (br s, 1H, NH); 7.63 (d, J=8.5 Hz, 2H, H2, H6); 7.37 $\left(\mathrm{d}, J=8.5 \mathrm{~Hz}, 2 \mathrm{H}, \mathrm{H}_{3}, \mathrm{H}_{5}\right) ; 7.29-7.24\left(\mathrm{~m}, 5 \mathrm{H}, \mathrm{H}_{\text {aro }}\right) ; 3.57\left(\mathrm{~m}, 4 \mathrm{H}, 2 \mathrm{CH}_{2}\right) ; 2.63\left(\mathrm{t}, J=6.0 \mathrm{~Hz}, 2 \mathrm{H}, \mathrm{CH}_{2}\right)$; $2.28\left(\mathrm{~s}, 3 \mathrm{H}, \mathrm{NCH}_{3}\right) ; 1.84\left(\mathrm{p}, J=5.9 \mathrm{~Hz}, 2 \mathrm{H}, \mathrm{CH}_{2}\right) ; 1.32\left(\mathrm{~s}, 9 \mathrm{H}, 3 \mathrm{CH}_{3}\right) .{ }^{13} \mathrm{C} \mathrm{NMR}\left(75 \mathrm{MHz}, \mathrm{CDCl}_{3}\right) \delta$ : $167.1(\mathrm{CO}) ; 154.4\left(\mathrm{C}_{\mathrm{aro}}\right) ; 137.8\left(\mathrm{C}_{\mathrm{aro}}\right) ; 131.8\left(\mathrm{C}_{\mathrm{aro}}\right) ; 129.5\left(2 \mathrm{C}_{\mathrm{aro}}\right) ; 128.4\left(2 \mathrm{C}_{\text {aro }}\right) ; 127.4\left(\mathrm{C}_{\text {aro }}\right) ; 126.8(2$ $\left.\mathrm{C}_{\text {aro }}\right) ; 125.3\left(2 \mathrm{C}_{\text {aro }}\right) ; 63.1\left(\mathrm{CH}_{2}\right) ; 56.9\left(\mathrm{CH}_{2}\right) ; 41.5\left(\mathrm{CH}_{3}\right) ; 40.1\left(\mathrm{CH}_{2}\right) ; 34.8(\mathrm{C}) ; 31.2\left(\mathrm{CH}_{3}\right) ; 25.3\left(\mathrm{CH}_{2}\right)$. LCMS $m / z$ calc for $\left[\mathrm{M}+\mathrm{H}^{+}\right]$: 339.2; found: 339.0. HPLC $\left(\mathrm{C}_{4}, 35 \mathrm{~min}\right): t_{R} 17.2 \mathrm{~min}, \mathrm{P}_{\mathrm{HPLC}}$ 97\%; HPLC (C $18,35 \mathrm{~min}): t_{R} 23.5 \mathrm{~min}, \mathrm{P}_{\mathrm{HPLC}} 98 \%$.

\section{$N$-[3-(benzylmethylamino)propyl]-4-trifluoromethylbenzamide (7e)}

Procedure E1. Purification by column chromatography (DCM: $\mathrm{MeOH}\left(\mathrm{NH}_{3}\right)$, 9:1 (v/v)) was performed. Yield: $57 \%$. ${ }^{1} \mathrm{H}$ NMR (300 MHz, $\left.\mathrm{CDCl}_{3}\right), \delta: 8.50$ (br s, $\left.1 \mathrm{H}, \mathrm{NH}\right) ; 7.78$ (d, J=8.2 Hz, 2H, H, $\left.\mathrm{H}_{6}\right) ; 7.59$ $\left(\mathrm{d}, J=8.2 \mathrm{~Hz}, 2 \mathrm{H}, \mathrm{H}_{3}, \mathrm{H}_{5}\right) ; 7.28-7.21\left(\mathrm{~m}, 5 \mathrm{H}, \mathrm{H}_{\text {aro }}\right) ; 3.63-3.55\left(\mathrm{~m}, 4 \mathrm{H}, 2 \mathrm{CH}_{2}\right) ; 2.68(\mathrm{t}, J=5.8 \mathrm{~Hz}, 2 \mathrm{H}$, $\left.\mathrm{CH}_{2}\right) ; 2.30\left(\mathrm{~s}, 3 \mathrm{H}, \mathrm{CH}_{3}\right) ; 1.85\left(\mathrm{p}, J=5.7 \mathrm{~Hz}, 2 \mathrm{H}, \mathrm{CH}_{2}\right) .{ }^{13} \mathrm{C} \mathrm{NMR}\left(75 \mathrm{MHz}, \mathrm{CDCl}_{3}\right) \delta: 165.8(\mathrm{CO}) ; 138.0$ $\left(\mathrm{C}_{\text {aro }}\right) ; 129.5$ (2 $\left.\mathrm{C}_{\text {aro }}\right) ; 128.5$ (2 $\left.\mathrm{C}_{\text {aro }}\right) ; 127.7\left(\mathrm{C}_{\text {aro }}\right) ; 127.4$ (2 $\left.\mathrm{C}_{\text {aro }}\right) ; 125.5$ (2 $\left.\mathrm{C}_{\text {aro }}\right) ; 125.4\left(2 \mathrm{C}_{\text {aro }}\right) ; 62.9\left(\mathrm{CH}_{2}\right)$; $57.1\left(\mathrm{CH}_{2}\right) ; 41.3\left(\mathrm{CH}_{3}\right) ; 40.5\left(\mathrm{CH}_{2}\right) ; 24.8\left(\mathrm{CH}_{2}\right)$. LCMS $\mathrm{m} / z$ calc for $\left[\mathrm{M}+\mathrm{H}^{+}\right]$: 351.1; found: 351.0 . HRMS: calcd for $\left(\mathrm{C}_{19} \mathrm{H}_{21} \mathrm{ON}_{2} \mathrm{~F}_{3}\right) \mathrm{H}^{+}$: 351.16787; found: 351.16663. HPLC (C 45 min): $t_{R} 18.5 \mathrm{~min}$, $\mathrm{P}_{\text {HPLC }}$ 96\%; HPLC ( $\left.\mathrm{C}_{18}, 35 \mathrm{~min}\right): t_{R} 25.2 \mathrm{~min}, \mathrm{P}_{\text {HPLC }} 97 \%$.

\section{$N$-[3-(benzylmethylamino)propyl]-2-chlorobenzamide (7f)}

Procedure E1. Purification by column chromatography (DCM: $\mathrm{MeOH}\left(\mathrm{NH}_{3}\right)$, 9:1 (v/v)) was performed. Yield: 46\%. ${ }^{1} \mathrm{H}$ NMR $\left(300 \mathrm{MHz}, \mathrm{CDCl}_{3}\right), \delta: 7.52\left(\mathrm{dd}, J=7.0 \mathrm{~Hz}, J=1.9 \mathrm{~Hz}, 1 \mathrm{H}, \mathrm{H}_{6}\right)$; 7.39-7.25 (m, 4H, $\left.\mathrm{NH}, \mathrm{H}_{3}, \mathrm{H}_{4}, \mathrm{H}_{5}\right) ; 7.17-7.09\left(\mathrm{~m}, 5 \mathrm{H}, \mathrm{H}_{\mathrm{aro}}\right) ; 3.54\left(\mathrm{q}, J=6.2 \mathrm{~Hz}, 2 \mathrm{H}, \mathrm{CH}_{2}\right) ; 3.49\left(\mathrm{~s}, 2 \mathrm{H}, \mathrm{CH}_{2}\right) ; 2.58(\mathrm{t}, J=6.3$ $\left.\mathrm{Hz}, 2 \mathrm{H}, \mathrm{CH}_{2}\right) ; 2.21\left(\mathrm{~s}, 3 \mathrm{H}, \mathrm{NCH}_{3}\right) ; 1.83\left(\mathrm{p}, J=6.2 \mathrm{~Hz}, 2 \mathrm{H}, \mathrm{CH}_{2}\right) .{ }^{13} \mathrm{C} \mathrm{NMR}\left(75 \mathrm{MHz}, \mathrm{CDCl}_{3}\right) \delta: 166.7$ $(\mathrm{CO}) ; 137.9\left(\mathrm{C}_{\text {aro }}\right) ; 136.0\left(\mathrm{C}_{\text {aro }}\right) ; 130.8\left(\mathrm{C}_{\text {aro }}\right) ; 130.7\left(\mathrm{C}_{\text {aro }}\right) ; 130.1\left(\mathrm{C}_{\text {aro }}\right) ; 129.5\left(\mathrm{C}_{\text {aro }}\right) ; 128.9\left(2 \mathrm{C}_{\text {aro }}\right) ; 128.3$ $\left(2 \mathrm{C}_{\text {aro }}\right) ; 127.2\left(\mathrm{C}_{\mathrm{aro}}\right) ; 126.9\left(\mathrm{C}_{\mathrm{aro}}\right) ; 62.6\left(\mathrm{CH}_{2}\right) ; 56.0\left(\mathrm{CH}_{2}\right) ; 41.8\left(\mathrm{CH}_{3}\right) ; 39.7\left(\mathrm{CH}_{2}\right) ; 25.3\left(\mathrm{CH}_{2}\right)$. LCMS $\mathrm{m} / \mathrm{z}$ calc for $\left[\mathrm{M}+\mathrm{H}^{+}\right]: 317.1,319.1$; found: 317.0, 319.0. HPLC $\left(\mathrm{C}_{4}, 35 \mathrm{~min}\right): t_{R} 12.6 \mathrm{~min}, \mathrm{P}_{\mathrm{HPLC}}$ 95\%; HPLC ( $\left.\mathrm{C}_{18}, 35 \mathrm{~min}\right): t_{R} 17.1 \mathrm{~min}, \mathrm{P}_{\mathrm{HPLC}} 96 \%$.

\section{$N$-[3-(benzylmethylamino)propyl]-3-chlorobenzamide (7g)}

Procedure E1. Purification by column chromatography (DCM: $\mathrm{MeOH}\left(\mathrm{NH}_{3}\right)$, 9:1 (v/v)) was performed. Yield: $8 \% .{ }^{1} \mathrm{H}$ NMR (300 MHz, $\mathrm{CDCl}_{3}$ ), $\delta: 8.22$ (br s, $\left.1 \mathrm{H}, \mathrm{NH}\right) ; 7.78$ (dd, $J=1.5 \mathrm{~Hz}, J=2.0 \mathrm{~Hz}, 1 \mathrm{H}, \mathrm{H}_{2}$ ); $7.68\left(\mathrm{~d}, J=8.0 \mathrm{~Hz}, 1 \mathrm{H}, \mathrm{H}_{6}\right) ; 7.52\left(\mathrm{~d}, J=7.8 \mathrm{~Hz}, 1 \mathrm{H}, \mathrm{H}_{4}\right) ; 7.52\left(\mathrm{t}, J=7.3 \mathrm{~Hz}, 1 \mathrm{H}, \mathrm{H}_{5}\right) ; 7.32-7.22(\mathrm{~m}, 5 \mathrm{H}$, $\mathrm{H}_{\text {aro }}$ ); 3.58-3.51 (m, 4H, 2CH$) ; 2.63\left(\mathrm{t}, J=7.5 \mathrm{~Hz}, 2 \mathrm{H}, \mathrm{CH}_{2}\right) ; 2.30\left(\mathrm{~s}, 3 \mathrm{H}, \mathrm{CH}_{3}\right) ; 1.84$ (p, J=6.4 Hz, 2H, 
$\left.\mathrm{CH}_{2}\right) .{ }^{13} \mathrm{C}$ NMR $\left(75 \mathrm{MHz}, \mathrm{CDCl}_{3}\right) \delta: 165.8(\mathrm{CO}) ; 136.5\left(\mathrm{C}_{\text {aro }}\right) ; 134.6\left(\mathrm{C}_{\text {aro }}\right) ; 131.2\left(\mathrm{C}_{\text {aro }}\right) ; 129.7\left(\mathrm{C}_{\text {aro }}\right)$; 129.4 (2 $\left.\mathrm{C}_{\text {aro }}\right) ; 128.5$ (2 $\left.\mathrm{C}_{\text {aro }}\right) ; 127.7$ (2 $\left.\mathrm{C}_{\text {aro }}\right) ; 127.5\left(\mathrm{C}_{\text {aro }}\right) ; 125.0\left(\mathrm{C}_{\text {aro }}\right) ; 63.1\left(\mathrm{CH}_{2}\right) ; 56.7\left(\mathrm{CH}_{2}\right) ; 41.6$ $\left(\mathrm{CH}_{3}\right) ; 40.4\left(\mathrm{CH}_{2}\right) ; 24.8\left(\mathrm{CH}_{2}\right)$. LCMS $\mathrm{m} / z$ calc for $\left[\mathrm{M}+\mathrm{H}^{+}\right]: 317.1$, 319.1; found: 317.0, 319.0. HPLC (C 4 , $35 \mathrm{~min}): t_{R} 14.8 \mathrm{~min}, \mathrm{P}_{\mathrm{HPLC}}$ 97\%; HPLC (C $\left.18,35 \mathrm{~min}\right): t_{R} 20.2 \mathrm{~min}, \mathrm{P}_{\mathrm{HPLC}} 97 \%$.

\section{$N$-[3-(2-(N-methylbenzyl)amino)ethyl]-4-chlorobenzamide (7h)}

Procedure E1. Purification by column chromatography (DCM: $\mathrm{MeOH}\left(\mathrm{NH}_{3}\right)$, 9:1 (v/v)) was performed. Yield: 20\%. ${ }^{1} \mathrm{H}$ NMR (300 MHz, $\left.\mathrm{CDCl}_{3}\right), \delta: 7.67$ (d, $\left.J=8.6 \mathrm{~Hz}, 2 \mathrm{H}, \mathrm{H}_{2}, \mathrm{H}_{6}\right) ; 7.41\left(\mathrm{~d}, J=8.6 \mathrm{~Hz}, 2 \mathrm{H}, \mathrm{H}_{3}\right.$, $\left.\mathrm{H}_{5}\right)$; 7.23-7,33 (m, 5H, $\left.\mathrm{H}_{\text {aro }}\right) ; 6.78$ (br s, $\left.1 \mathrm{H}, \mathrm{NH}\right) ; 3.56\left(\mathrm{~s}, 2 \mathrm{H}, \mathrm{CH}_{2}\right) ; 3.51$ (q, J = 5.2 Hz, 2H, $\left.\mathrm{CH}_{2}\right) ; 2.62$ $\left(\mathrm{t}, J=5.9 \mathrm{~Hz}, 2 \mathrm{H}, \mathrm{CH}_{2}\right) ; 2.31\left(\mathrm{~s}, 3 \mathrm{H}, \mathrm{NCH}_{3}\right) .{ }^{13} \mathrm{C} \mathrm{NMR}\left(75 \mathrm{MHz}, \mathrm{CDCl}_{3}\right) \delta: 166.4(\mathrm{CO}) ; 138.6\left(\mathrm{C}_{\text {aro }}\right)$; 137.5 ( $\left.\mathrm{C}_{\text {aro }}\right) ; 133.1$ ( $\left.\mathrm{C}_{\text {aro }}\right) ; 129.4$ (2 $\left.\mathrm{C}_{\text {aro }}\right) ; 129.1$ (2 $\left.\mathrm{C}_{\text {aro }}\right) ; 128.9$ (2 $\left.\mathrm{C}_{\text {aro }}\right) ; 128.7$ (2 $\left.\mathrm{C}_{\text {aro }}\right) ; 127.4$ ( $\left.\mathrm{C}_{\text {aro }}\right) ; 62.3$ $\left(\mathrm{CH}_{2}\right) ; 54.9\left(\mathrm{CH}_{2}\right) ; 42.1\left(\mathrm{CH}_{3}\right) ; 37.1\left(\mathrm{CH}_{2}\right)$. LCMS m/z calc for $\left[\mathrm{M}+\mathrm{H}^{+}\right]$: 303.1, 305.1; found: 303.0, 305.0. HRMS: calcd for $\left(\mathrm{C}_{17} \mathrm{H}_{19} \mathrm{ON}_{2} \mathrm{Cl}\right) \mathrm{H}^{+}$: 303.12531; found: 303.12587. HPLC ( $\left.\mathrm{C}_{4}, 35 \mathrm{~min}\right): t_{R} 14.2$ $\min , \mathrm{P}_{\text {HPLC }} 97 \%$; HPLC (C $\left.18,35 \mathrm{~min}\right): t_{R} 19.3 \mathrm{~min}, \mathrm{P}_{\text {HPLC }} 97 \%$.

\section{$N$-[3-(benzylmethylamino)propyl]-4-chlorobenzamide (7i)}

Procedure E1. Purification by column chromatography (DCM: $\mathrm{MeOH}\left(\mathrm{NH}_{3}\right)$, 9:1 (v/v)) was performed. Yield: 55\%. IR $\left(\mathrm{cm}^{-1}\right): 1625(\mathrm{C}=\mathrm{O}), 3012(\mathrm{NH}) .{ }^{1} \mathrm{H}$ NMR (300 MHz, $\left.\mathrm{CDCl}_{3}\right), \delta: 8.25$ (br s, 1H, NH); $7.60\left(\mathrm{~d}, J=9 \mathrm{~Hz}, 2 \mathrm{H}, \mathrm{H}_{2}, \mathrm{H}_{6}\right) ; 7.33-7,21\left(\mathrm{~m}, 7 \mathrm{H}, \mathrm{H}_{3}, \mathrm{H}_{5}, \mathrm{H}_{\text {aro }}\right) ; 3.62-3.51\left(\mathrm{~m}, 4 \mathrm{H}, 2 \mathrm{CH}_{2}\right) ; 2.65$ (t, $J=5.4$ $\left.\mathrm{Hz}, 2 \mathrm{H}, \mathrm{CH}_{2}\right) ; 2.27$ (s, 3H, $\left.\mathrm{NCH}_{3}\right) ; 1.83\left(\mathrm{p}, J=5.5 \mathrm{~Hz}, 2 \mathrm{H}, \mathrm{CH}_{2}\right) .{ }^{13} \mathrm{C} \mathrm{NMR}\left(75 \mathrm{MHz}, \mathrm{CDCl}_{3}\right) \delta: 166.0$ (CO); 137.8 ( $\left.\mathrm{C}_{\text {aro }}\right) ; 137.3$ ( $\left.\mathrm{C}_{\text {aro }}\right) ; 133.1$ ( $\left.\mathrm{C}_{\text {aro }}\right) ; 129.4$ (2 $\left.\mathrm{C}_{\text {aro }}\right) ; 128.6$ (2 $\left.\mathrm{C}_{\text {aro }}\right) ; 128.5$ (2 $\left.\mathrm{C}_{\text {aro }}\right) ; 128.4$ (2 $\left.\mathrm{C}_{\text {aro }}\right)$; $127.5\left(\mathrm{C}_{\text {aro }}\right) ; 63.2\left(\mathrm{CH}_{2}\right) ; 57.2\left(\mathrm{CH}_{2}\right) ; 41.5\left(\mathrm{CH}_{3}\right) ; 40.5\left(\mathrm{CH}_{2}\right) ; 25.0\left(\mathrm{CH}_{2}\right)$. LCMS $\mathrm{m} / z$ calc for $\left[\mathrm{M}+\mathrm{H}^{+}\right]$: 317.1, 319.1; found: 316.9, 318.9. HRMS: calcd for $\left(\mathrm{C}_{18} \mathrm{H}_{21} \mathrm{ON}_{2} \mathrm{Cl}\right) \mathrm{H}^{+}$: 317.14152; found: 317.14083 . HPLC $\left(\mathrm{C}_{4}, 35 \mathrm{~min}\right): t_{R} 7.7 \mathrm{~min}, \mathrm{P}_{\mathrm{HPLC}} 98 \%$; HPLC ( $\left.\mathrm{C}_{18}, 35 \mathrm{~min}\right): t_{R} 18.0 \mathrm{~min}, \mathrm{P}_{\mathrm{HPLC}} 98 \%$.

\section{$N$-[4-(benzylmethylamino)butyl]-4-chlorobenzamide (7j)}

Procedure E1. Purification by column chromatography (DCM: $\mathrm{MeOH}\left(\mathrm{NH}_{3}\right)$, 9:1 (v/v)) was performed. Yield: 25\%. ${ }^{1} \mathrm{H}$ NMR (300 MHz, $\left.\mathrm{CDCl}_{3}\right), \delta: 7.60$ (d, $\left.J=9.2 \mathrm{~Hz}, 2 \mathrm{H}, \mathrm{H}_{2}, \mathrm{H}_{6}\right) ; 7.41$ (br s, 1H, NH); 7.33$7,26\left(\mathrm{~m}, 7 \mathrm{H}, \mathrm{H}_{3}, \mathrm{H}_{5}, \mathrm{H}_{\text {aro }}\right) ; 3.53\left(\mathrm{~s}, 2 \mathrm{H}, \mathrm{CH}_{2}\right) ; 3.45$ (q, J = 6.2 Hz, 2H, $\left.\mathrm{CH}_{2}\right) ; 2.45$ (t, J=6.4 Hz, 2H, $\mathrm{CH}_{2}$ ); $2.17\left(\mathrm{~s}, 3 \mathrm{H}, \mathrm{NCH}_{3}\right) ; 1.73-1.62\left(\mathrm{~m}, 4 \mathrm{H}, 2 \mathrm{CH}_{2}\right) .{ }^{13} \mathrm{C} \mathrm{NMR}\left(75 \mathrm{MHz}, \mathrm{CDCl}_{3}\right) \delta: 166.6(\mathrm{CO}) ; 137.7\left(\mathrm{C}_{\text {aro }}\right)$; 137.3 ( $\left.\mathrm{C}_{\text {aro }}\right) ; 133.3$ ( $\left.\mathrm{C}_{\text {aro }}\right) ; 129.3$ (2 $\left.\mathrm{C}_{\text {aro }}\right) ; 128.6$ (2 $\left.\mathrm{C}_{\text {aro }}\right) ; 128.5$ (2 $\left.\mathrm{C}_{\text {aro }}\right) ; 128.4$ (2 $\left.\mathrm{C}_{\text {aro }}\right) ; 127.4$ ( $\left.\mathrm{C}_{\text {aro }}\right) ; 61.8$ $\left(\mathrm{CH}_{2}\right) ; 56.7\left(\mathrm{CH}_{2}\right) ; 42.1\left(\mathrm{CH}_{3}\right) ; 39.9\left(\mathrm{CH}_{2}\right) ; 27.1\left(\mathrm{CH}_{2}\right) ; 24.8\left(\mathrm{CH}_{2}\right)$. LCMS m/z calc for $\left[\mathrm{M}+\mathrm{H}^{+}\right]: 331.1$, 333.1; found: 331.0, 333.0. HPLC ( $\left.\mathrm{C}_{4}, 35 \mathrm{~min}\right): t_{R} 14.8 \mathrm{~min}, \mathrm{P}_{\mathrm{HPLC}} 96 \%$; HPLC (C $\left.18,35 \mathrm{~min}\right): t_{R} 20.2$ $\min , \mathrm{P}_{\mathrm{HPLC}} 97 \%$. 
Procedure E1. Purification by column chromatography (DCM: $\mathrm{MeOH}\left(\mathrm{NH}_{3}\right)$, 9:1 (v/v)) was performed. Yield: $52 \% .{ }^{1} \mathrm{H}$ NMR $\left(300 \mathrm{MHz}, \mathrm{CDCl}_{3}\right), \delta: 7.56\left(\mathrm{dd}, J=7.8 \mathrm{~Hz}, J=1.3 \mathrm{~Hz}, 1 \mathrm{H}, \mathrm{H}_{6}\right) ; 7.47$ (br s, $1 \mathrm{H}$, $\mathrm{NH}) ; 7.37\left(\mathrm{dd}, J=7.4 \mathrm{~Hz}, J=2.0 \mathrm{~Hz}, 1 \mathrm{H}, \mathrm{H}_{3}\right) ; 7.31\left(\mathrm{td}, J=7.3 \mathrm{~Hz}, J=1.2 \mathrm{~Hz}, 1 \mathrm{H}, \mathrm{H}_{\text {aro }}\right) ; 7.24(\mathrm{td}, J=7.4$ $\left.\mathrm{Hz}, J=1.9 \mathrm{~Hz}, 1 \mathrm{H}, \mathrm{H}_{\text {aro }}\right) ; 7.16-7.07\left(\mathrm{~m}, 5 \mathrm{H}, \mathrm{H}_{\text {aro }}\right) ; 3.52\left(\mathrm{q}, J=6.2 \mathrm{~Hz}, 2 \mathrm{H}, \mathrm{CH}_{2}\right) ; 3.48\left(\mathrm{~s}, 2 \mathrm{H}, \mathrm{CH}_{2}\right) ; 2.57$ $\left(\mathrm{t}, J=6.1 \mathrm{~Hz}, 2 \mathrm{H}, \mathrm{CH}_{2}\right) ; 2.19\left(\mathrm{~s}, 3 \mathrm{H}, \mathrm{NCH}_{3}\right) ; 1.80$ (p, $\left.J=6.2 \mathrm{~Hz}, 2 \mathrm{H}, \mathrm{CH}_{2}\right) .{ }^{13} \mathrm{C} \mathrm{NMR}\left(75 \mathrm{MHz}, \mathrm{CDCl}_{3}\right)$

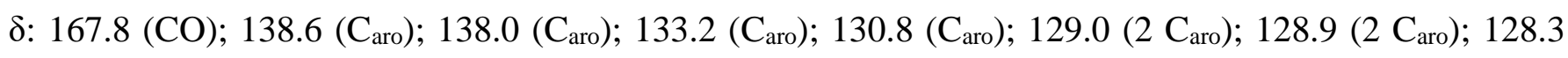
$\left(\mathrm{C}_{\text {aro }}\right) ; 127.4\left(\mathrm{C}_{\text {aro }}\right) ; 127.1\left(\mathrm{C}_{\text {aro }}\right) ; 119.5\left(\mathrm{C}_{\text {aro }}\right) ; 62.6\left(\mathrm{CH}_{2}\right) ; 56.1\left(\mathrm{CH}_{2}\right) ; 41.8\left(\mathrm{CH}_{3}\right) ; 39.6\left(\mathrm{CH}_{2}\right) ; 25.3$ $\left(\mathrm{CH}_{2}\right)$. LCMS $\mathrm{m} / \mathrm{z}$ calc for $\left[\mathrm{M}+\mathrm{H}^{+}\right]: 361.1 ; 363.1$; found: 360.9; 362.9. HPLC $\left(\mathrm{C}_{4}, 35 \mathrm{~min}\right): t_{R} 13.0 \mathrm{~min}$, $\mathrm{P}_{\text {HPLC }}$ 96\%; HPLC ( $\left.\mathrm{C}_{18}, 35 \mathrm{~min}\right): t_{R} 17.8 \mathrm{~min}, \mathrm{P}_{\text {HPLC }} 96 \%$.

\section{$N$-[3-(benzylmethylamino)propyl]-3-bromobenzamide (7l)}

Procedure E1. Purification by column chromatography (DCM: $\mathrm{MeOH}\left(\mathrm{NH}_{3}\right)$, 9:1 (v/v)) was performed. Yield: 53\%. ${ }^{1} \mathrm{H}$ NMR (300 MHz, $\left.\mathrm{CDCl}_{3}\right), \delta: 8.27$ (br s, $\left.1 \mathrm{H}, \mathrm{NH}\right) ; 7.82$ (t, $\left.J=1.8 \mathrm{~Hz}, 2 \mathrm{H}, \mathrm{H}_{2}\right) ; 7.55$ (m,

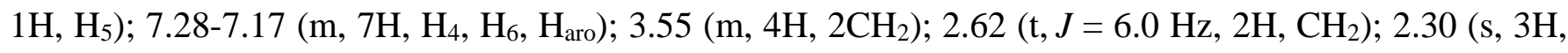
$\left.\mathrm{NCH}_{3}\right) ; 1.83\left(\mathrm{p}, J=5.9 \mathrm{~Hz}, 2 \mathrm{H}, \mathrm{CH}_{2}\right) .{ }^{13} \mathrm{C} \mathrm{NMR}\left(75 \mathrm{MHz}, \mathrm{CDCl}_{3}\right) \delta: 165.7(\mathrm{CO}) ; 137.6\left(\mathrm{C}_{\text {aro }}\right) ; 136.7$ $\left(\mathrm{C}_{\text {aro }}\right) ; 134.0\left(\mathrm{C}_{\text {aro }}\right) ; 130.3\left(\mathrm{C}_{\text {aro }}\right) ; 129.9\left(\mathrm{C}_{\text {aro }}\right) ; 129.4$ (2 $\left.\mathrm{C}_{\text {aro }}\right) ; 128.5\left(2 \mathrm{C}_{\text {aro }}\right) ; 127.6\left(\mathrm{C}_{\text {aro }}\right) ; 125.4\left(\mathrm{C}_{\text {aro }}\right)$; $122.6\left(\mathrm{C}_{\text {aro }}\right) ; 63.1\left(\mathrm{CH}_{2}\right) ; 56.8\left(\mathrm{CH}_{2}\right) ; 41.8\left(\mathrm{CH}_{3}\right) ; 40.4\left(\mathrm{CH}_{2}\right) ; 24.9\left(\mathrm{CH}_{2}\right)$. LCMS $\mathrm{m} / z$ calc for $\left[\mathrm{M}+\mathrm{H}^{+}\right]$: 361.1; 363.1; found: 360.9; 362.9. HRMS: calcd for $\left(\mathrm{C}_{18} \mathrm{H}_{21} \mathrm{ON}_{2} \mathrm{Br}\right) \mathrm{H}^{+}$: 361.09100; found: 361.08984 . $\operatorname{HPLC}\left(\mathrm{C}_{4}, 35 \mathrm{~min}\right): t_{R} 14.8 \mathrm{~min}, \mathrm{P}_{\mathrm{HPLC}} 98 \%$; HPLC (C $\left.18,35 \mathrm{~min}\right): t_{R} 20.2 \mathrm{~min}, \mathrm{P}_{\mathrm{HPLC}} 98 \%$.

\section{$N$-[3-(benzylmethylamino)propyl]-4-bromobenzamide (7m)}

Procedure E2. Purification by thick layer chromatography (DCM:MeOH(NH$), ~ 9: 1(v / v)$ ) was performed. Yield: $67 \% .{ }^{1} \mathrm{H}$ NMR (300 MHz, $\left.\mathrm{CDCl}_{3}\right), \delta: 8.29$ (br s, $\left.1 \mathrm{H}, \mathrm{NH}\right) ; 7.54$ (d, $\left.J=9.1 \mathrm{~Hz}, 2 \mathrm{H}, \mathrm{H}_{2}, \mathrm{H}_{6}\right) ; 7.46$ $\left(\mathrm{d}, J=9.2 \mathrm{~Hz}, 2 \mathrm{H}, \mathrm{H}_{3}, \mathrm{H}_{5}\right) ; 7.33-7.20\left(\mathrm{~m}, 5 \mathrm{H}, \mathrm{H}_{\mathrm{aro}}\right) ; 3.65-3.47\left(\mathrm{~m}, 4 \mathrm{H}, 2 \mathrm{CH}_{2}\right) ; 2.66(\mathrm{t}, J=5.9 \mathrm{~Hz}, 2 \mathrm{H}$, $\left.\mathrm{CH}_{2}\right) ; 2.29$ (s, 3H, $\left.\mathrm{CH}_{3}\right) ; 1.84\left(\mathrm{p}, J=5.8 \mathrm{~Hz}, 2 \mathrm{H}, \mathrm{CH}_{2}\right) .{ }^{13} \mathrm{C} \mathrm{NMR}\left(75 \mathrm{MHz}, \mathrm{CDCl}_{3}\right) \delta: 166.2(\mathrm{CO}) ; 137.5$ $\left(\mathrm{C}_{\text {aro }}\right) ; 133.5\left(\mathrm{C}_{\mathrm{aro}}\right) ; 131.6\left(2 \mathrm{C}_{\mathrm{aro}}\right) ; 129.5\left(2 \mathrm{C}_{\mathrm{aro}}\right) ; 128.6\left(2 \mathrm{C}_{\mathrm{aro}}\right) ; 128.5\left(2 \mathrm{C}_{\mathrm{aro}}\right) ; 127.7\left(\mathrm{C}_{\mathrm{aro}}\right) ; 125.7\left(\mathrm{C}_{\mathrm{aro}}\right)$; $63.0\left(\mathrm{CH}_{2}\right) ; 57.0\left(\mathrm{CH}_{2}\right) ; 41.4\left(\mathrm{CH}_{3}\right) ; 40.3\left(\mathrm{CH}_{2}\right) ; 24.9\left(\mathrm{CH}_{2}\right)$. LCMS $\mathrm{m} / \mathrm{z}$ calc for $\left[\mathrm{M}+\mathrm{H}^{+}\right]: 361.1 ; 363.1$; found: 360.9; 362.9. HRMS: calcd for $\left(\mathrm{C}_{18} \mathrm{H}_{21} \mathrm{ON}_{2} \mathrm{Br}\right) \mathrm{H}^{+}$: 361.09100; found: 361.08948. HPLC (C 35 $\min ): t_{R} 8.8 \mathrm{~min}, \mathrm{P}_{\mathrm{HPLC}}>99 \%$; HPLC $\left(\mathrm{C}_{18}, 35 \mathrm{~min}\right): t_{R} 18.4 \mathrm{~min}, \mathrm{P}_{\mathrm{HPLC}}>99 \%$.

\section{$N$-[3-(benzylmethylamino)propyl]-4-fluorobenzamide (7n)}

Procedure E2. Purification by thick layer chromatography (DCM:MeOH(NH3), 9:1 (v/v)) was performed. Yield: 58\%. ${ }^{1} \mathrm{H}$ NMR (300 MHz, $\mathrm{CDCl}_{3}$ ), $\delta: 8.20$ (br s, $\left.1 \mathrm{H}, \mathrm{NH}\right) ; 7.66\left(\mathrm{~m}, 2 \mathrm{H}, \mathrm{H}_{2}\right.$ and $\left.\mathrm{H}_{6}\right) ; 7.28-7.24(\mathrm{~m}$, $\left.5 \mathrm{H}, \mathrm{H}_{\mathrm{aro}}\right) ; 7.00\left(\mathrm{t},{ }^{3} J_{3-\mathrm{F}}=9 \mathrm{~Hz}, 2 \mathrm{H}, \mathrm{H}_{3}\right.$ and $\left.\mathrm{H}_{5}\right) ; 3.60-3.52\left(\mathrm{~m}, 4 \mathrm{H}, \mathrm{H}_{\mathrm{a}}\right.$ et $\left.\mathrm{H}_{\mathrm{e}}\right) ; 2.65\left(\mathrm{t},{ }^{3} J=6 \mathrm{~Hz}, 2 \mathrm{H}, \mathrm{H}_{\mathrm{c}}\right)$; $2.28\left(\mathrm{~s}, 3 \mathrm{H}, \mathrm{H}_{\mathrm{d}}\right) ; 1.83\left(\mathrm{p},{ }^{3} \mathrm{~J}=6 \mathrm{~Hz}, 2 \mathrm{H}, \mathrm{H}_{\mathrm{b}}\right) .{ }^{13} \mathrm{C} \mathrm{NMR}\left(75 \mathrm{MHz}, \mathrm{CDCl}_{3}\right) \delta: 166.1(\mathrm{CO}) ; 164.5\left(\mathrm{~d},{ }^{1} J_{4-\mathrm{F}}=\right.$ $\left.250 \mathrm{~Hz}, \mathrm{C}_{4}\right) ; 137.6\left(\mathrm{C}_{\mathrm{aro}}\right) ; 130.8\left(\mathrm{~d},{ }^{4} J_{1-\mathrm{F}}=3 \mathrm{~Hz}, \mathrm{C}_{1}\right) ; 129.5\left(2 \mathrm{C}_{\mathrm{aro}}\right) ; 129.2\left(\mathrm{~d},{ }^{3} J_{2-\mathrm{F}}=9 \mathrm{~Hz}, \mathrm{C}_{2}\right.$ and $\left.\mathrm{C}_{6}\right)$; 
$128.5\left(2 \mathrm{C}_{\text {aro }}\right) ; 127.6\left(\mathrm{C}_{\text {aro }}\right) ; 115.3\left(\mathrm{~d},{ }^{2} J_{3-\mathrm{F}}=20 \mathrm{~Hz}, \mathrm{C}_{3}\right.$ and $\left.\mathrm{C}_{5}\right) ; 63.1\left(\mathrm{CH}_{2}\right) ; 57.1\left(\mathrm{CH}_{2}\right) ; 41.4\left(\mathrm{CH}_{3}\right) ; 40.3$ $\left(\mathrm{CH}_{2}\right) ; 25.0\left(\mathrm{CH}_{2}\right)$. LCMS m/z calc for $\left[\mathrm{M}+\mathrm{H}^{+}\right]$: 301.2; found: 301.1. HPLC $\left(\mathrm{C}_{4}, 35 \mathrm{~min}\right): t_{R} 8.4 \mathrm{~min}$, $\mathrm{P}_{\text {HPLC }}>99 \%$; HPLC $\left(\mathrm{C}_{18}, 35 \mathrm{~min}\right): t_{R} 16.3 \mathrm{~min}, \mathrm{P}_{\mathrm{HPLC}}>99 \%$.

\section{$N$-[3-(benzylmethylamino)propyl]-2,3-dichlorobenzamide (7o)}

Procedure E1. Purification by column chromatography (DCM: $\mathrm{MeOH}\left(\mathrm{NH}_{3}\right)$, 9:1 (v/v)) was performed. Yield: 66\%. ${ }^{1} \mathrm{H}$ NMR $\left(300 \mathrm{MHz}, \mathrm{CDCl}_{3}\right), \delta: 7.58$ (br s, $\left.1 \mathrm{H}, \mathrm{NH}\right) ; 7.51(\mathrm{dd}, J=7.9 \mathrm{~Hz}, J=1.6 \mathrm{~Hz}, 1 \mathrm{H}$, $\left.\mathrm{H}_{6}\right) ; 7.32\left(\mathrm{dd}, J=7.7 \mathrm{~Hz}, J=1.6 \mathrm{~Hz}, 1 \mathrm{H}, \mathrm{H}_{4}\right) ; 7.25\left(\mathrm{~m}, 1 \mathrm{H}, \mathrm{H}_{5}\right) ; 7.17-7.07\left(\mathrm{~m}, 5 \mathrm{H}, \mathrm{H}_{\text {aro }}\right) ; 3.55(\mathrm{q}, J=6.7$ $\left.\mathrm{Hz}, 2 \mathrm{H}, \mathrm{CH}_{2}\right) ; 3.48\left(\mathrm{~s}, 2 \mathrm{H}, \mathrm{CH}_{2}\right) ; 2.58\left(\mathrm{t}, J=5.9 \mathrm{~Hz}, 2 \mathrm{H}, \mathrm{CH}_{2}\right) ; 2.21\left(\mathrm{~s}, 3 \mathrm{H}, \mathrm{NCH}_{3}\right) ; 1.82(\mathrm{p}, J=6.0 \mathrm{~Hz}$, $\left.2 \mathrm{H}, \mathrm{CH}_{2}\right) .{ }^{13} \mathrm{C}$ NMR $\left(75 \mathrm{MHz}, \mathrm{CDCl}_{3}\right) \delta: 166.2(\mathrm{CO}) ; 138.6\left(\mathrm{C}_{\text {aro }}\right) ; 137.8\left(\mathrm{C}_{\text {aro }}\right) ; 133.7\left(\mathrm{C}_{\text {aro }}\right) ; 131.3\left(\mathrm{C}_{\text {aro }}\right)$; $128.9\left(\mathrm{C}_{\text {aro }}\right) ; 128.3\left(2 \mathrm{C}_{\text {aro }}\right) ; 127.6\left(2 \mathrm{C}_{\text {aro }}\right) ; 127.5\left(\mathrm{C}_{\text {aro }}\right) ; 127.3\left(\mathrm{C}_{\text {aro }}\right) ; 127.0\left(\mathrm{C}_{\text {aro }}\right) ; 62.7\left(\mathrm{CH}_{2}\right) ; 56.0\left(\mathrm{CH}_{2}\right)$; $41.8\left(\mathrm{CH}_{3}\right) ; 39.7\left(\mathrm{CH}_{2}\right) ; 25.1\left(\mathrm{CH}_{2}\right)$. LCMS $\mathrm{m} / z$ calc for $\left[\mathrm{M}+\mathrm{H}^{+}\right]$: 351.1, 353.1, 355.1; found: 351.0, 353.0, 355.0. HPLC (C4, $35 \mathrm{~min}): t_{R} 14.7 \mathrm{~min}$, PHPLC 98\%; HPLC ( $\left.\mathrm{C}_{18}, 35 \mathrm{~min}\right): t_{R} 20.0 \mathrm{~min}, \mathrm{P}_{\mathrm{HPLC}} 98 \%$.

\section{$N$-[2-(benzylmethylamino)ethyl]-2,3-dichlorobenzamide (7p)}

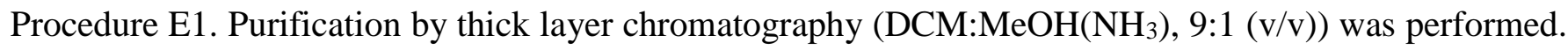
Yield: $18 \% .{ }^{1} \mathrm{H}$ NMR (300 MHz, $\left.\mathrm{CDCl}_{3}\right), \delta: 7.60$ (d, $\left.J=8.3 \mathrm{~Hz}, 1 \mathrm{H}, \mathrm{H}_{\mathrm{aro}}\right) ; 7.44$ (d, J=2.0 Hz, 1H, $\mathrm{H}_{\text {aro }}$ ); $7.32\left(\mathrm{dd}, J=8.4 \mathrm{~Hz} J=2.0 \mathrm{~Hz}, 1 \mathrm{H}, \mathrm{H}_{\text {aro }}\right) ; 7.30-7.25$ (m, 1H, $\mathrm{H}_{\text {aro }}$ ); 6.90 (br s, 1H, NH); 3.59-3.52 (m, 4H, $\left.2 \mathrm{CH}_{2}\right) ; 2.63\left(\mathrm{~d}, J=5.6 \mathrm{~Hz}, 2 \mathrm{H}, \mathrm{CH}_{2}\right) ; 2.26\left(\mathrm{~s}, 3 \mathrm{H}, \mathrm{NCH}_{3}\right) .{ }^{13} \mathrm{C} \mathrm{NMR}\left(75 \mathrm{MHz}, \mathrm{CDCl}_{3}\right) \delta: 165.3(\mathrm{CO})$; $138.4\left(\mathrm{C}_{\text {aro }}\right) ; 136.6\left(\mathrm{C}_{\text {aro }}\right) ; 133.5\left(\mathrm{C}_{\text {aro }}\right) ; 131.6\left(\mathrm{C}_{\text {aro }}\right) ; 131.4\left(\mathrm{C}_{\text {aro }}\right) ; 130.0\left(\mathrm{C}_{\text {aro }}\right) ; 129.0\left(2 \mathrm{C}_{\text {aro }}\right) ; 128.4(2$ $\left.\mathrm{C}_{\text {aro }}\right) ; 127.4\left(\mathrm{C}_{\text {aro }}\right) ; 127.3\left(\mathrm{C}_{\text {aro }}\right) ; 62.4\left(\mathrm{CH}_{2}\right) ; 55.0\left(\mathrm{CH}_{2}\right) ; 41.6\left(\mathrm{CH}_{3}\right) ; 37.3\left(\mathrm{CH}_{2}\right)$. LCMS $\mathrm{m} / z$ calc for $\left[\mathrm{M}+\mathrm{H}^{+}\right]: 337.1 ; 341.1$; found: 337.0; 341.0. HPLC ( $\left.\mathrm{C}_{4}, 35 \mathrm{~min}\right): t_{R} 15.0 \mathrm{~min}, \mathrm{P}_{\mathrm{HPLC}}$ 97\%; HPLC (C 18,35 $\min ): t_{R} 20.5 \min , \mathrm{P}_{\mathrm{HPLC}} 97 \%$.

\section{$N$-[3-(benzylmethylamino)propyl]-3,4-dichlorobenzamide (7q)}

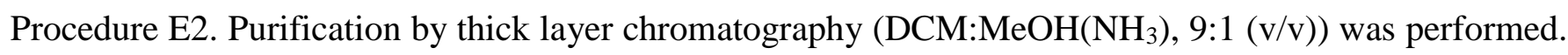
Yield: $31 \% .{ }^{1} \mathrm{H}$ NMR (300 MHz, $\left.\mathrm{CDCl}_{3}\right), \delta: 8.44$ (br s, $\left.1 \mathrm{H}, \mathrm{NH}\right) ; 7.82$ (d, J=2.0 Hz, 1H, H2); 7.47 (dd, $J$ $\left.=8.2 \mathrm{~Hz}, J=2.0 \mathrm{~Hz}, 1 \mathrm{H}, \mathrm{H}_{6}\right) ; 7.38\left(\mathrm{~d}, J=8.3 \mathrm{~Hz}, 1 \mathrm{H}, \mathrm{H}_{5}\right) ; 7.31-7.22\left(\mathrm{~m}, 5 \mathrm{H}, \mathrm{H}_{\text {aro }}\right) ; 3.60\left(\mathrm{~s}, 2 \mathrm{H}, \mathrm{CH}_{2}\right)$; $3.56\left(\mathrm{q}, J=6.1 \mathrm{~Hz}, 2 \mathrm{H}, \mathrm{CH}_{2}\right) ; 2.68\left(\mathrm{t}, J=6.1 \mathrm{~Hz}, 2 \mathrm{H}, \mathrm{CH}_{2}\right) ; 2.33\left(\mathrm{~s}, 3 \mathrm{H}, \mathrm{CH}_{3}\right) ; 1.86(\mathrm{p}, J=6.2 \mathrm{~Hz}, 2 \mathrm{H}$, $\left.\mathrm{CH}_{2}\right) .{ }^{13} \mathrm{C}$ NMR $\left(75 \mathrm{MHz}, \mathrm{CDCl}_{3}\right) \delta: 164.9(\mathrm{CO}) ; 135.4\left(\mathrm{C}_{\mathrm{aro}}\right) ; 134.5\left(\mathrm{C}_{\mathrm{aro}}\right) ; 132.9\left(\mathrm{C}_{\mathrm{aro}}\right) ; 130.4\left(2 \mathrm{C}_{\text {aro }}\right)$; 129.5 (2 $\left.\mathrm{C}_{\text {aro }}\right) ; 129.3\left(\mathrm{C}_{\text {aro }}\right) ; 128.6\left(2 \mathrm{C}_{\text {aro }}\right) ; 127.8\left(\mathrm{C}_{\text {aro }}\right) ; 126.1\left(\mathrm{C}_{\text {aro }}\right) ; 62.8\left(\mathrm{CH}_{2}\right) ; 56.7\left(\mathrm{CH}_{2}\right) ; 41.4\left(\mathrm{CH}_{3}\right)$; $40.3\left(\mathrm{CH}_{2}\right) ; 24.7\left(\mathrm{CH}_{2}\right)$. LCMS $\mathrm{m} / \mathrm{z}$ calc for $\left[\mathrm{M}+\mathrm{H}^{+}\right]$: 351.1, 353.1, 355.1; found: 350.9, 352.9, 354.9 . HPLC $\left(\mathrm{C}_{4}, 35 \mathrm{~min}\right): t_{R} 15.6 \mathrm{~min}, \mathrm{P}_{\mathrm{HPLC}}>99 \%$; HPLC $\left(\mathrm{C}_{18}, 35 \mathrm{~min}\right): t_{R} 19.8 \mathrm{~min}, \mathrm{P}_{\mathrm{HPLC}}>99 \%$.

\section{$N$-[3-(benzylmethylamino)propyl]-3,5-dichlorobenzamide (7r)}




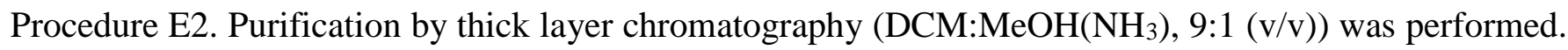
Yield: 34\%. ${ }^{1} \mathrm{H}$ NMR (300 MHz, $\left.\mathrm{CDCl}_{3}\right), \delta: 8.42$ (br s, 1H, NH) ; 7.55 (m, 2H, H2, H6); 7.44 (m, 1H, H4); 7.28-7.20 (m, 5H, $\mathrm{H}_{\text {aro }}$ ); 3.57-3.51 (m, 4H, $\left.2 \mathrm{CH}_{2}\right) ; 2.63\left(\mathrm{t}, J=6.1 \mathrm{~Hz}, 2 \mathrm{H}, \mathrm{CH}_{2}\right) ; 2.32\left(\mathrm{~s}, 3 \mathrm{H}, \mathrm{CH}_{3}\right) ; 1.82$ $\left(\mathrm{p}, J=6.0 \mathrm{~Hz}, 2 \mathrm{H}, \mathrm{CH}_{2}\right) .{ }^{13} \mathrm{C} \mathrm{NMR}\left(75 \mathrm{MHz}, \mathrm{CDCl}_{3}\right) \delta: 164.6(\mathrm{CO}) ; 137.7\left(\mathrm{C}_{\text {aro }}\right) ; 137.5\left(\mathrm{C}_{\text {aro }}\right) ; 135.3$ $\left(\mathrm{C}_{\text {aro }}\right) ; 130.9$ (2 $\left.\mathrm{C}_{\text {aro }}\right) ; 129.3$ (2 $\left.\mathrm{C}_{\text {aro }}\right) ; 128.5$ (2 $\left.\mathrm{C}_{\text {aro }}\right) ; 127.6\left(\mathrm{C}_{\text {aro }}\right) ; 125.7\left(2 \mathrm{C}_{\text {aro }}\right) ; 63.0\left(\mathrm{CH}_{2}\right) ; 56.7\left(\mathrm{CH}_{2}\right)$; $41.8\left(\mathrm{CH}_{3}\right) ; 40.7\left(\mathrm{CH}_{2}\right) ; 24.8\left(\mathrm{CH}_{2}\right)$. LCMS m/z calc for $\left[\mathrm{M}+\mathrm{H}^{+}\right]$: 351.1, 353.1, 355.1; found: 350.9, 352.9, 354.9. HPLC ( $\left.\mathrm{C}_{4}, 35 \mathrm{~min}\right): t_{R} 21.9 \mathrm{~min}, \mathrm{P}_{\mathrm{HPLC}}>99 \%$; $\mathrm{HPLC}\left(\mathrm{C}_{18}, 35 \mathrm{~min}\right): t_{R} 20.3 \mathrm{~min}, \mathrm{P}_{\mathrm{HPLC}}$ $>99 \%$.

\section{$N$-[3-(benzylmethylamino)propyl]-4-bromo-2-fluorobenzamide (7s)}

Procedure E1. Purification by column chromatography (DCM: $\mathrm{MeOH}\left(\mathrm{NH}_{3}\right)$, 9:1 (v/v)) was performed. Yield: 22\%. ${ }^{1} \mathrm{H}$ NMR (300 MHz, MeOD), $\delta: 7.60$ (d, $\left.J=8.2 \mathrm{~Hz}, 1 \mathrm{H}, \mathrm{H}_{6}\right) ; 7.50$ (m, 1H, $\mathrm{H}_{\text {aro }}$ ); 7.44 (m, $1 \mathrm{H}, \mathrm{H}_{\text {aro }}$ ); 7.22-7.34 (m, 5H, $\left.\mathrm{H}_{\text {aro }}\right) ; 3.59\left(\mathrm{~s}, 2 \mathrm{H}, \mathrm{CH}_{2}\right) ; 3.43\left(\mathrm{t}, J=6.7 \mathrm{~Hz}, 2 \mathrm{H}, \mathrm{CH}_{2}\right) ; 2.56$ (t, J= 7.1 Hz, $\left.2 \mathrm{H}, \mathrm{CH}_{2}\right) ; 2.28\left(\mathrm{~s}, 3 \mathrm{H}, \mathrm{CH}_{3}\right) ; 1.85\left(\mathrm{p}, J=7.0 \mathrm{~Hz}, 2 \mathrm{H}, \mathrm{CH}_{2}\right) .{ }^{13} \mathrm{C} \mathrm{NMR}\left(75 \mathrm{MHz}, \mathrm{CDCl}_{3}\right) \delta: 162.5(\mathrm{CO})$; $132.9\left(\mathrm{C}_{\text {aro }}\right) ; 129.5\left(\mathrm{C}_{\text {aro }}\right) ; 128.7\left(\mathrm{C}_{\text {aro }}\right) ; 128.4\left(2 \mathrm{C}_{\text {aro }}\right) ; 128.1\left(2 \mathrm{C}_{\text {aro }}\right) ; 125.1\left(\mathrm{C}_{\text {aro }}\right) ; 119.8\left(\mathrm{C}_{\text {aro }}\right) ; 119.4$ $\left(\mathrm{C}_{\text {aro }}\right) ; 62.4\left(\mathrm{CH}_{2}\right) ; 55.3\left(\mathrm{CH}_{2}\right) ; 41.4\left(\mathrm{CH}_{3}\right) ; 29.7\left(\mathrm{CH}_{2}\right) ; 25.4\left(\mathrm{CH}_{2}\right)$. LCMS m/z calc for $\left[\mathrm{M}+\mathrm{H}^{+}\right]: 379.1$; 381.1 found: $379.0 ; 381.0 \mathrm{HPLC}\left(\mathrm{C}_{4}, 35 \mathrm{~min}\right): t_{R} 15.1 \mathrm{~min}, \mathrm{P}_{\mathrm{HPLC}}>99 \%$; HPLC $\left(\mathrm{C}_{18}, 35 \mathrm{~min}\right): t_{R} 20.6$ $\min , \mathrm{P}_{\mathrm{HPLC}}>99 \%$.

\section{$N$-[3-(benzylmethylamino)propyl]-3-methoxybenzamide (7t)}

Procedure E1. Purification by column chromatography (DCM: $\mathrm{MeOH}\left(\mathrm{NH}_{3}\right)$, 9:1 (v/v)) was performed. Yield: 35\%. ${ }^{1} \mathrm{H}$ NMR (300 MHz, $\left.\mathrm{CDCl}_{3}\right), \delta: 8.10$ (br s, 1H, NH); 7.35 (m, 1H, H2); 7.28-7.14 (m, 7H, $\mathrm{H}_{5}$, $\left.\mathrm{H}_{6}, \mathrm{H}_{\text {aro }}\right) ; 7.11\left(\mathrm{~m}, 1 \mathrm{H}, \mathrm{H}_{4}\right) ; 3.78\left(\mathrm{~s}, 3 \mathrm{H}, \mathrm{OCH}_{3}\right) ; 3.55\left(\mathrm{~m}, 4 \mathrm{H}, 2 \mathrm{CH}_{2}\right) ; 2.63\left(\mathrm{t}, J=6.2 \mathrm{~Hz}, 2 \mathrm{H}, \mathrm{CH}_{2}\right) ; 2.28$ $\left(\mathrm{s}, 3 \mathrm{H}, \mathrm{NCH}_{3}\right) ; 1.83\left(\mathrm{p}, J=6.4 \mathrm{~Hz}, 2 \mathrm{H}, \mathrm{CH}_{2}\right) .{ }^{13} \mathrm{C} \mathrm{NMR}\left(75 \mathrm{MHz}, \mathrm{CDCl}_{3}\right) \delta: 165.3(\mathrm{CO}) ; 159.7\left(\mathrm{C}_{\text {aro }}\right)$; $137.6\left(\mathrm{C}_{\text {aro }}\right) ; 136.2$ ( $\left.\mathrm{C}_{\text {aro }}\right) ; 129.4$ (3 $\left.\mathrm{C}_{\text {aro }}\right) ; 128.4\left(2 \mathrm{C}_{\text {aro }}\right) ; 127.4\left(\mathrm{C}_{\text {aro }}\right) ; 118.8\left(\mathrm{C}_{\text {aro }}\right) ; 117.6\left(\mathrm{C}_{\text {aro }}\right) ; 112.1$ $\left(\mathrm{C}_{\text {aro }}\right) ; 63.0\left(\mathrm{CH}_{2}\right) ; 56.8\left(\mathrm{CH}_{2}\right) ; 55.3\left(\mathrm{OCH}_{3}\right) ; 41.5\left(\mathrm{NCH}_{3}\right) ; 40.2\left(\mathrm{CH}_{2}\right) ; 25.2\left(\mathrm{CH}_{2}\right)$. LCMS m/z calc for $\left[\mathrm{M}+\mathrm{H}^{+}\right]$: 313.2; found: 313.0. HRMS: calcd for $\left(\mathrm{C}_{19} \mathrm{H}_{24} \mathrm{O}_{2} \mathrm{~N}_{2}\right) \mathrm{H}^{+}$: 313.19105; found: 313.18948. HPLC $\left(\mathrm{C}_{4}, 35 \mathrm{~min}\right): t_{R} 13.8 \mathrm{~min}, \mathrm{P}_{\mathrm{HPLC}} 98 \%$; HPLC ( $\left.\mathrm{C}_{18}, 35 \mathrm{~min}\right): t_{R} 18.8 \mathrm{~min}, \mathrm{P}_{\mathrm{HPLC}} 98 \%$.

\section{$N$-[3-(benzylmethylamino)propyl]-4-methoxybenzamide (7u)}

Procedure E2. Purification by thick layer chromatography (DCM:MeOH(NH3), 9:1 (v/v)) was performed. Yield: 73\%. ${ }^{1} \mathrm{H}$ NMR (300 MHz, $\mathrm{CDCl}_{3}$ ), $\delta: 7.97$ (br s, $\left.1 \mathrm{H}, \mathrm{NH}\right) ; 7.67$ (m, 2H, H, $\left.\mathrm{H}_{6}\right) ; 7.32-7.24$ (m, $\left.5 \mathrm{H}, \mathrm{H}_{\text {aro }}\right) ; 6.84\left(\mathrm{~m}, 2 \mathrm{H}, \mathrm{H}_{3}, \mathrm{H}_{5}\right) ; 3.84\left(\mathrm{~s}, 3 \mathrm{H}, \mathrm{OCH}_{3}\right) ; 3.60-3.52\left(\mathrm{~m}, 4 \mathrm{H}, 2 \mathrm{CH}_{2}\right) ; 2.65(\mathrm{t}, J=6.0 \mathrm{~Hz}, 2 \mathrm{H}$, $\left.\mathrm{CH}_{2}\right) ; 2.29$ (s, 3H, $\left.\mathrm{CH}_{3}\right) ; 1.85\left(\mathrm{p}, J=6.1 \mathrm{~Hz}, 2 \mathrm{H}, \mathrm{CH}_{2}\right) .{ }^{13} \mathrm{C} \mathrm{NMR}\left(75 \mathrm{MHz}, \mathrm{CDCl}_{3}\right) \delta: 166.9(\mathrm{CO}) ; 162.0$ $\left(\mathrm{C}_{\text {aro }}\right) ; 137.2\left(\mathrm{C}_{\mathrm{aro}}\right) ; 129.6$ (2 $\left.\mathrm{C}_{\mathrm{aro}}\right) ; 128.8$ (2 $\left.\mathrm{C}_{\mathrm{aro}}\right) ; 128.5$ (2 $\left.\mathrm{C}_{\mathrm{aro}}\right) ; 127.7\left(\mathrm{C}_{\mathrm{aro}}\right) ; 125.0\left(\mathrm{C}_{\text {aro }}\right) ; 113.6\left(2 \mathrm{C}_{\text {aro }}\right)$; $62.9\left(\mathrm{CH}_{2}\right) ; 56.7\left(\mathrm{CH}_{2}\right) ; 55.4\left(\mathrm{OCH}_{3}\right) ; 41.4\left(\mathrm{CH}_{3}\right) ; 39.9\left(\mathrm{CH}_{2}\right) ; 25.3\left(\mathrm{CH}_{2}\right)$. LCMS m/z calc for $\left[\mathrm{M}+\mathrm{H}^{+}\right]$: 
313.2; found: 313.0. HRMS: calcd for $\left(\mathrm{C}_{19} \mathrm{H}_{24} \mathrm{O}_{2} \mathrm{~N}_{2}\right) \mathrm{H}^{+}$: 313.19105; found: 313.18976. HPLC (C4, 35 $\min ): t_{R} 18.1 \mathrm{~min}, \mathrm{P}_{\mathrm{HPLC}}>99 \%$; HPLC $\left(\mathrm{C}_{18}, 35 \mathrm{~min}\right): t_{R} 16.2 \mathrm{~min}, \mathrm{P}_{\mathrm{HPLC}} 98 \%$.

\section{$N$-[3-(benzylmethylamino)propyl]-3-dimethylaminobenzamide (7v)}

Procedure E1. Purification by column chromatography (DCM: $\mathrm{MeOH}\left(\mathrm{NH}_{3}\right)$, 9:1 (v/v)) was performed. Yield: $11 \% .{ }^{1} \mathrm{H}$ NMR (300 MHz, $\mathrm{CDCl}_{3}$ ), $\delta: 7.90$ (br s, $\left.1 \mathrm{H}, \mathrm{NH}\right) ; 7.28-7.24$ (m, 5H, Haro); 7.22-7.19 (m, $\left.2 \mathrm{H}, \mathrm{H}_{2}, \mathrm{H}_{5}\right) ; 6.92\left(\mathrm{~d}, J=7.5 \mathrm{~Hz}, 1 \mathrm{H}, \mathrm{H}_{6}\right) ; 6.82\left(\mathrm{dd}, J=8.1 \mathrm{~Hz}, J=2.2 \mathrm{~Hz}, 1 \mathrm{H}, \mathrm{H}_{4}\right) ; 3.62-3.51(\mathrm{~m}, 4 \mathrm{H}, 2$ $\left.\mathrm{CH}_{2}\right) ; 2.95\left(\mathrm{~s}, 6 \mathrm{H}, 2 \mathrm{CH}_{3}\right) ; 2.64\left(\mathrm{t}, J=6.0 \mathrm{~Hz}, 2 \mathrm{H}, \mathrm{CH}_{2}\right) ; 2.31\left(\mathrm{~s}, 3 \mathrm{H}, \mathrm{CH}_{3}\right) ; 1.85\left(\mathrm{p}, J=5.8 \mathrm{~Hz}, 2 \mathrm{H}, \mathrm{CH}_{2}\right)$.

${ }^{13} \mathrm{C} \mathrm{NMR}\left(75 \mathrm{MHz}, \mathrm{CDCl}_{3}\right) \delta$ : $162.4(\mathrm{CO}) ; 138.5\left(\mathrm{C}_{\text {aro }}\right) ; 133.1$ (2 $\left.\mathrm{C}_{\text {aro }}\right) ; 129.0\left(2 \mathrm{C}_{\text {aro }}\right) ; 128.2$ (2 $\left.\mathrm{C}_{\text {aro }}\right)$; $128.0\left(2 \mathrm{C}_{\text {aro }}\right) ; 127.1\left(\mathrm{C}_{\text {aro }}\right) ; 119.7\left(\mathrm{C}_{\text {aro }}\right) ; 119.4\left(\mathrm{C}_{\text {aro }}\right) ; 63.0\left(\mathrm{CH}_{2}\right) ; 55.9\left(\mathrm{CH}_{2}\right) ; 50.9\left(\mathrm{CH}_{2}\right) ; 41.9\left(3 \mathrm{CH}_{3}\right)$; $39.9\left(\mathrm{CH}_{2}\right) ; 25.6\left(\mathrm{CH}_{2}\right)$. LCMS $m / z$ calc for $\left[\mathrm{M}+\mathrm{H}^{+}\right]: 326.2$; found: 326.0. HPLC $\left(\mathrm{C}_{4}, 35 \mathrm{~min}\right): t_{R} 14.5$ $\min , \mathrm{P}_{\mathrm{HPLC}}>99 \%$; HPLC $\left(\mathrm{C}_{18}, 35 \mathrm{~min}\right): t_{R} 19.8 \mathrm{~min}, \mathrm{P}_{\mathrm{HPLC}}>99 \%$.

\section{$N$-[2-(benzylmethylamino)ethyl]-4-cyanobenzamide (7w)}

Procedure E1. Purification by column chromatography (DCM: $\mathrm{MeOH}\left(\mathrm{NH}_{3}\right)$, 9:1 (v/v)) was performed. Yield: $33 \% .{ }^{1} \mathrm{H}$ NMR (300 MHz, $\left.\mathrm{CDCl}_{3}\right), \delta: 8.00\left(\mathrm{~d}, 2 \mathrm{H}, J=7.3 \mathrm{~Hz}, 2 \mathrm{H}, \mathrm{H}_{\mathrm{aro}}\right) ; 7.57(\mathrm{~d}, 2 \mathrm{H}, J=7.4 \mathrm{~Hz}$, $2 \mathrm{H}, \mathrm{H}_{\text {aro }}$ ); 7.30-7.24 (m, $5 \mathrm{H}, \mathrm{H}_{\text {aro }}$ ); 6.71 (br s, $\left.1 \mathrm{H}, \mathrm{NH}\right) ; 3.53$ (s, 2H, $\left.\mathrm{CH}_{2}\right) ; 3.00$ (t, 2H, J = 5.5 Hz, $\mathrm{CH}_{2}$ ); $2.65\left(\mathrm{t}, 2 \mathrm{H}, J=5.7 \mathrm{~Hz}, \mathrm{CH}_{2}\right) ; 2.18\left(\mathrm{~s}, 3 \mathrm{H}, \mathrm{CH}_{3}\right) .{ }^{13} \mathrm{C} \mathrm{NMR}\left(75 \mathrm{MHz}, \mathrm{CDCl}_{3}\right) \delta: 171.4(\mathrm{CO}) ; 137.5\left(\mathrm{C}_{\mathrm{aro}}\right)$; 131.7 (2 $\left.\mathrm{C}_{\text {aro }}\right) ; 129.8$ (2 $\left.\mathrm{C}_{\text {aro }}\right) ; 129.0$ (2 $\left.\mathrm{C}_{\text {aro }}\right) ; 128.5$ (2 $\left.\mathrm{C}_{\text {aro }}\right) ; 127.5$ ( $\left.\mathrm{C}_{\text {aro }}\right) ; 118.7$ ( $\left.\mathrm{C}_{\text {aro }}\right) ; 114.0\left(\mathrm{C}_{\text {aro }}\right) ; 62.2$ $\left(\mathrm{CH}_{2}\right) ; 54.7\left(\mathrm{CH}_{2}\right) ; 41.6\left(\mathrm{CH}_{3}\right) ; 37.0\left(\mathrm{CH}_{2}\right)$. LCMS $\mathrm{m} / z$ calc for $\left[\mathrm{M}+\mathrm{H}^{+}\right]$: 294.1; found: 294.0. HRMS: calcd for $\left(\mathrm{C}_{18} \mathrm{H}_{19} \mathrm{ON}_{3}\right) \mathrm{H}^{+}$: 294.16009; found: 294.15906. HPLC (C $\left.435 \mathrm{~min}\right): t_{R} 12.7 \mathrm{~min}, \mathrm{P}_{\mathrm{HPLC}}$ 97\%; HPLC ( $\left.\mathrm{C}_{18}, 35 \mathrm{~min}\right): t_{R} 17.3 \mathrm{~min}, \mathrm{P}_{\mathrm{HPLC}} 97 \%$.

\section{$N$-[3-(benzylmethylamino)propyl]-4-cyanobenzamide (7x)}

Procedure E1. Purification by column chromatography (DCM: $\mathrm{MeOH}\left(\mathrm{NH}_{3}\right)$, 9:1 (v/v)) was performed. Yield: 7\%. ${ }^{1} \mathrm{H}$ NMR (300 MHz, $\left.\mathrm{CDCl}_{3}\right), \delta: 8.61$ (br s, $\left.1 \mathrm{H}, \mathrm{NH}\right) ; 7.71\left(\mathrm{~d}, J=8.2 \mathrm{~Hz}, 2 \mathrm{H}, \mathrm{H}_{3}, \mathrm{H}_{5}\right) ; 7.61(\mathrm{~d}$, $\left.J=8.3 \mathrm{~Hz}, 2 \mathrm{H}, \mathrm{H}_{2}, \mathrm{H}_{6}\right) ; 7.30-7.20\left(\mathrm{~m}, 5 \mathrm{H}, \mathrm{H}_{\mathrm{aro}}\right) ; 3.62\left(\mathrm{q}, J=6.4 \mathrm{~Hz}, 2 \mathrm{H}, \mathrm{CH}_{2}\right) ; 3.55\left(\mathrm{~s}, 2 \mathrm{H}, \mathrm{CH}_{2}\right) ; 2.69(\mathrm{t}$, $\left.J=5.8 \mathrm{~Hz}, 2 \mathrm{H}, \mathrm{CH}_{2}\right) ; 2.27\left(\mathrm{~s}, 3 \mathrm{H}, \mathrm{CH}_{3}\right) ; 1.84\left(\mathrm{p}, J=6.0 \mathrm{~Hz}, 2 \mathrm{H}, \mathrm{CH}_{2}\right) .{ }^{13} \mathrm{C} \mathrm{NMR}\left(75 \mathrm{MHz}, \mathrm{CDCl}_{3}\right) \delta$ : $165.3(\mathrm{CO}) ; 138.4\left(\mathrm{C}_{\text {aro }}\right) ; 136.8\left(\mathrm{C}_{\text {aro }}\right) ; 132.2$ (2 $\left.\mathrm{C}_{\text {aro }}\right)$; $129.6\left(2 \mathrm{C}_{\text {aro }}\right) ; 128.6$ (2 $\left.\mathrm{C}_{\text {aro }}\right) ; 127.7$ (2 $\left.\mathrm{C}_{\text {aro }}\right) ; 118.2$ $\left(\mathrm{C}_{\text {aro }}\right) ; 114.6\left(\mathrm{C}_{\text {aro }}\right) ; 63.3\left(\mathrm{CH}_{2}\right) ; 57.6\left(\mathrm{CH}_{2}\right) ; 41.5\left(\mathrm{CH}_{3}\right) ; 40.9\left(\mathrm{CH}_{2}\right) ; 25.1\left(\mathrm{CH}_{2}\right)$. LCMS $m / z$ calc for $\left[\mathrm{M}+\mathrm{H}^{+}\right]$: 308.1; found: 308.0. HPLC $\left(\mathrm{C}_{4}, 35 \mathrm{~min}\right): t_{R} 13.2 \mathrm{~min}, \mathrm{P}_{\mathrm{HPLC}} 98 \%$; HPLC $\left(\mathrm{C}_{18}, 35 \mathrm{~min}\right): t_{R} 18.0$ $\min , \mathrm{P}_{\text {HPLC }}>99 \%$.

\section{$N$-[2-(benzylmethylamino)ethyl]-4-nitrobenzamide (7y)}

Procedure E1. Purification by column chromatography (DCM: $\mathrm{MeOH}\left(\mathrm{NH}_{3}\right)$, 9:1 (v/v)) was performed. Yield: 52\%. ${ }^{1} \mathrm{H}$ NMR (300 MHz, $\left.\mathrm{CDCl}_{3}\right), \delta: 8.30\left(\mathrm{~d}, J=8.8 \mathrm{~Hz}, 2 \mathrm{H}, \mathrm{H}_{\mathrm{aro}}\right) ; 7.85\left(\mathrm{~d}, J=8.7 \mathrm{~Hz}, 2 \mathrm{H}, \mathrm{H}_{\text {aro }}\right.$ ); 
7.34-7.28 (m, 5H, $\left.\mathrm{H}_{\text {aro }}\right) ; 6.85(\mathrm{br} \mathrm{s}, 1 \mathrm{H}, \mathrm{NH}) ; 3.58\left(\mathrm{~s}, 2 \mathrm{H}, \mathrm{CH}_{2}\right) ; 3.53\left(\mathrm{q} J=4.9 \mathrm{~Hz}, 2 \mathrm{H}, \mathrm{CH}_{2}\right) ; 2.64(\mathrm{t}, J=$

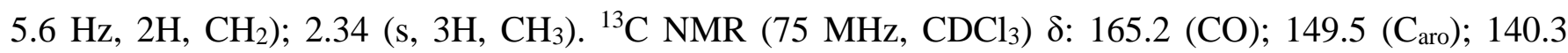
$\left(\mathrm{C}_{\text {aro }}\right) ; 138.6\left(\mathrm{C}_{\text {aro }}\right) ; 129.1$ (2 $\left.\mathrm{C}_{\text {aro }}\right) ; 128.8$ (2 $\left.\mathrm{C}_{\text {aro }}\right) ; 128.5\left(2 \mathrm{C}_{\text {aro }}\right) ; 127.5\left(\mathrm{C}_{\text {aro }}\right) ; 123.8\left(2 \mathrm{C}_{\text {aro }}\right) ; 62.3\left(\mathrm{CH}_{2}\right)$; 54.6 $\left(\mathrm{CH}_{2}\right)$; $42.2\left(\mathrm{CH}_{3}\right)$; $37.3\left(\mathrm{CH}_{2}\right)$. LCMS $\left(\mathrm{ESI}^{+}\right)$: calc for $\left[\mathrm{M}+\mathrm{H}^{+}\right]$: 314.1; found: 314.1. HRMS: calcd for $\left(\mathrm{C}_{17} \mathrm{H}_{19} \mathrm{O}_{3} \mathrm{~N}_{3}\right) \mathrm{H}^{+}$: 314.14992; found: 314.14905. HPLC $\left(\mathrm{C}_{4}, 35 \mathrm{~min}\right): t_{R} 15.1 \mathrm{~min}, \mathrm{P}_{\mathrm{HPLC}}>99 \%$; HPLC $\left(\mathrm{C}_{18}, 35 \mathrm{~min}\right): t_{R} 20.6 \mathrm{~min}, \mathrm{P}_{\mathrm{HPLC}}>99 \%$.

\section{$N$-[3-(benzylmethylamino)propyl]-4-nitrobenzamide (7z)}

Procedure E1. Purification by column chromatography (DCM: $\mathrm{MeOH}\left(\mathrm{NH}_{3}\right)$, 9:1 (v/v)) was performed. Yield: 50\%. ${ }^{1} \mathrm{H}$ NMR (300 MHz, $\left.\mathrm{CDCl}_{3}\right), \delta: 8.68$ (br s, $\left.1 \mathrm{H}, \mathrm{NH}\right) ; 8.17$ (d, J = 8.8 Hz, 2H, H3, H5); 7.79 $\left(\mathrm{d}, J=8.8 \mathrm{~Hz}, 2 \mathrm{H}, \mathrm{H}_{2}, \mathrm{H}_{6}\right) ; 7.32-7.22\left(\mathrm{~m}, 5 \mathrm{H}, \mathrm{H}_{\text {aro }}\right) ; 3.65-3.56\left(\mathrm{~m}, 4 \mathrm{H}, 2 \mathrm{CH}_{2}\right) ; 2.72(\mathrm{t}, J=5.6 \mathrm{~Hz}, 2 \mathrm{H}$, $\mathrm{CH}_{2}$ ); 2.32 (s, 3H, NCH 3$) ; 1.88\left(\mathrm{p}, J=5.7 \mathrm{~Hz}, 2 \mathrm{H}, \mathrm{CH}_{2}\right) .{ }^{13} \mathrm{C} \mathrm{NMR}\left(75 \mathrm{MHz}, \mathrm{CDCl}_{3}\right) \delta: 166.7(\mathrm{CO})$; 149.3 ( $\left.\mathrm{C}_{\text {aro }}\right) ; 140.1$ ( $\left.\mathrm{C}_{\text {aro }}\right) ; 137.1$ ( $\left.\mathrm{C}_{\text {aro }}\right) ; 129.6$ (2 $\left.\mathrm{C}_{\text {aro }}\right) ; 128.6$ (2 $\left.\mathrm{C}_{\text {aro }}\right) ; 128.1$ (2 $\left.\mathrm{C}_{\text {aro }}\right) ; 127.8\left(\mathrm{C}_{\text {aro }}\right) ; 123.6(2$ $\left.\mathrm{C}_{\text {aro }}\right) ; 63.5\left(\mathrm{CH}_{2}\right) ; 57.6\left(\mathrm{CH}_{2}\right) ; 41.7\left(\mathrm{CH}_{3}\right) ; 41.1\left(\mathrm{CH}_{2}\right) ; 25.0\left(\mathrm{CH}_{2}\right)$. LCMS m/z calc for $\left[\mathrm{M}+\mathrm{H}^{+}\right]: 328.1$; found: 328.0. HRMS: calcd for $\left(\mathrm{C}_{18} \mathrm{H}_{21} \mathrm{O}_{3} \mathrm{~N}_{3}\right) \mathrm{H}^{+}$: 328.16557; found: 328.16388. HPLC (C $\left.435 \mathrm{~min}\right): t_{R}$ $13.6 \mathrm{~min}, \mathrm{P}_{\mathrm{HPLC}} 96 \%$; HPLC $\left(\mathrm{C}_{18}, 35 \mathrm{~min}\right): t_{R} 18.6 \mathrm{~min}, \mathrm{P}_{\mathrm{HPLC}} 96 \%$.

\section{$N$-[3-(N-methyl-2-phenylethylamino)propyl]-4-chlorobenzamide (8a)}

Procedure E1. Purification by column chromatography (DCM: $\mathrm{MeOH}\left(\mathrm{NH}_{3}\right)$, 9:1 (v/v)) was performed. Yield: 69\%. ${ }^{1} \mathrm{H}$ NMR (300 MHz, $\left.\mathrm{CDCl}_{3}\right), \delta: 8.25$ (br s, $\left.1 \mathrm{H}, \mathrm{NH}\right) ; 7.58\left(\mathrm{~d}, J=8.3 \mathrm{~Hz}, 2 \mathrm{H}, \mathrm{H}_{2}, \mathrm{H}_{6}\right) ; 7.34$ $\left(\mathrm{d}, J=8.4 \mathrm{~Hz}, 2 \mathrm{H}, \mathrm{H}_{3}, \mathrm{H}_{5}\right) ; 7.26-7.12\left(\mathrm{~m}, 5 \mathrm{H}, \mathrm{H}_{\text {aro }}\right) ; 3.53$ (q, $\left.J=6.2 \mathrm{~Hz}, 2 \mathrm{H}, \mathrm{CH}_{2}\right) ; 2.82\left(\mathrm{~m}, 2 \mathrm{H}, \mathrm{CH}_{2}\right)$; $2.75\left(\mathrm{~m}, 2 \mathrm{H}, \mathrm{CH}_{2}\right) ; 2.66\left(\mathrm{t}, J=6.0 \mathrm{~Hz}, 2 \mathrm{H}, \mathrm{CH}_{2}\right) ; 2.35\left(\mathrm{~s}, 3 \mathrm{H}, \mathrm{NCH}_{3}\right) ; 1.80\left(\mathrm{p}, J=5.9 \mathrm{~Hz}, 2 \mathrm{H}, \mathrm{CH}_{2}\right) .{ }^{13} \mathrm{C}$ NMR (75 MHz, $\left.\mathrm{CDCl}_{3}\right)$ \&: $165.9(\mathrm{CO}) ; 139.5\left(\mathrm{C}_{\text {aro }}\right) ; 137.2\left(\mathrm{C}_{\text {aro }}\right) ; 133.1\left(\mathrm{C}_{\text {aro }}\right) ; 128.6\left(4 \mathrm{C}_{\text {aro }}\right) ; 128.5(2$ $\left.\mathrm{C}_{\mathrm{aro}}\right) ; 128.3\left(2 \mathrm{C}_{\text {aro }}\right) ; 126.3\left(\mathrm{C}_{\text {aro }}\right) ; 59.6\left(\mathrm{CH}_{2}\right) ; 57.1\left(\mathrm{CH}_{2}\right) ; 41.7\left(\mathrm{CH}_{3}\right) ; 40.4\left(\mathrm{CH}_{2}\right) ; 33.3\left(\mathrm{CH}_{2}\right) ; 24.3$ $\left(\mathrm{CH}_{2}\right)$. LCMS $\mathrm{m} / \mathrm{z}$ calc for $\left[\mathrm{M}+\mathrm{H}^{+}\right]$: 331.1, 333.1; found: 331.0, 333.0. HRMS: calcd for $\left(\mathrm{C}_{19} \mathrm{H}_{23} \mathrm{ON}_{2} \mathrm{Cl}\right) \mathrm{H}^{+}$: 331.15717; found: 331.15601. HPLC $\left(\mathrm{C}_{4}, 35 \mathrm{~min}\right): t_{R} 15.5 \mathrm{~min}, \mathrm{P}_{\mathrm{HPLC}}>99 \%$; HPLC $\left(\mathrm{C}_{18}, 35 \mathrm{~min}\right): t_{R} 21.2 \mathrm{~min}, \mathrm{P}_{\mathrm{HPLC}}>99 \%$.

\section{$N$-[3-(isoindolin-2-yl)methylamino)propyl]-4-chlorobenzamide (8b)}

Procedure E1. Purification by column chromatography (DCM:MeOH( $\left.\mathrm{NH}_{3}\right)$, 9:1 (v/v)) was performed. Yield: $36 \%$. ${ }^{1} \mathrm{H}$ NMR (300 MHz, $\mathrm{CDCl}_{3}$ ), $\delta: 9.00$ (br s, $1 \mathrm{H}, \mathrm{NH}$ ); 7.48 (d, J=8.6 Hz, 2H, H2, H6); 7.31$7.21\left(\mathrm{~m}, 4 \mathrm{H}, \mathrm{H}_{\mathrm{aro}}\right) ; 7.03\left(\mathrm{~d}, J=8.5 \mathrm{~Hz}, 2 \mathrm{H}, \mathrm{H}_{3}, \mathrm{H}_{5}\right) ; 4.02\left(\mathrm{~s}, 4 \mathrm{H}, 2 \mathrm{CH}_{2}\right) ; 3.63$ (q, J = 5.0 Hz, 2H, $\mathrm{CH}_{2}$ ); $3.05\left(\mathrm{t}, J=5.8 \mathrm{~Hz}, 2 \mathrm{H}, \mathrm{CH}_{2}\right) ; 1.89\left(\mathrm{p}, J=5.8 \mathrm{~Hz}, 2 \mathrm{H}, \mathrm{CH}_{2}\right) .{ }^{13} \mathrm{C} \mathrm{NMR}\left(75 \mathrm{MHz}, \mathrm{CDCl}_{3}\right) \delta: 165.6(\mathrm{CO})$; 139.2 (2 $\left.\mathrm{C}_{\text {aro }}\right) ; 137.1\left(\mathrm{C}_{\mathrm{aro}}\right) ; 132.6\left(\mathrm{C}_{\mathrm{aro}}\right) ; 128.4\left(2 \mathrm{C}_{\mathrm{aro}}\right) ; 128.2\left(2 \mathrm{C}_{\mathrm{aro}}\right) ; 127.2\left(2 \mathrm{C}_{\mathrm{aro}}\right) ; 122.4\left(2 \mathrm{C}_{\text {aro }}\right) ; 58.6$ $\left(2 \mathrm{CH}_{2}\right) ; 55.3\left(\mathrm{CH}_{2}\right) ; 40.8\left(\mathrm{CH}_{2}\right) ; 25.9\left(\mathrm{CH}_{2}\right)$. LCMS $\mathrm{m} / z$ calc for $\left[\mathrm{M}+\mathrm{H}^{+}\right]$: 315.1, 317.1; found: 315.0, 317.0. HPLC $\left(\mathrm{C}_{4}, 35 \mathrm{~min}\right): t_{R} 14.6 \mathrm{~min}, \mathrm{P}_{\mathrm{HPLC}} 97 \%$; HPLC $\left(\mathrm{C}_{18}, 35 \mathrm{~min}\right): t_{R} 20.0 \mathrm{~min}, \mathrm{P}_{\mathrm{HPLC}} 98 \%$. 


\section{$N$-[2-pyrrolidinylethyl]-4-chlorobenzamide (8c)}

Procedure E1. Purification by column chromatography (DCM:MeOH( $\left.\mathrm{NH}_{3}\right)$, 9:1 (v/v)) was performed. Yield: 22\%. ${ }^{1} \mathrm{H}$ NMR (300 MHz, $\left.\mathrm{CDCl}_{3}\right), \delta: 7.82\left(\mathrm{~d}, J=8.5 \mathrm{~Hz}, 2 \mathrm{H}, \mathrm{H}_{2}, \mathrm{H}_{6}\right) ; 7.51$ (br s, 1H, NH); 7.48 $\left(\mathrm{d}, J=8.5 \mathrm{~Hz}, 2 \mathrm{H}, \mathrm{H}_{3}, \mathrm{H}_{5}\right) ; 3.63\left(\mathrm{q}, J=6.1 \mathrm{~Hz}, 2 \mathrm{H}, \mathrm{CH}_{2}\right) ; 2.91\left(\mathrm{t}, J=6.0 \mathrm{~Hz}, 2 \mathrm{H}, \mathrm{CH}_{2}\right) ; 2.78(\mathrm{~m}, 4 \mathrm{H}$, $\left.2 \mathrm{CH}_{2}\right) ; 1.90\left(\mathrm{~m}, 4 \mathrm{H}, 2 \mathrm{CH}_{2}\right) .{ }^{13} \mathrm{C} \mathrm{NMR}\left(75 \mathrm{MHz}, \mathrm{CDCl}_{3}\right) \delta: 165.6(\mathrm{CO}) ; 137.6\left(\mathrm{C}_{\text {aro }}\right) ; 132.6\left(\mathrm{C}_{\text {aro }}\right) ; 128.7$ $\left(4 \mathrm{C}_{\text {aro }}\right) ; 54.9\left(\mathrm{CH}_{2}\right) ; 54.0\left(2 \mathrm{CH}_{2}\right) ; 37.9\left(\mathrm{CH}_{2}\right) ; 23.4\left(2 \mathrm{CH}_{2}\right)$. LCMS $\mathrm{m} / z$ calc for $\left[\mathrm{M}^{+} \mathrm{H}^{+}\right]: 253.1,255.1$; found: 253.0, 255.0. HPLC $\left(\mathrm{C}_{4}, 35 \mathrm{~min}\right): t_{R} 12.1 \mathrm{~min}, \mathrm{P}_{\mathrm{HPLC}}>99 \%$; HPLC $\left(\mathrm{C}_{18}, 35 \mathrm{~min}\right): t_{R} 16.5 \mathrm{~min}$, $\mathrm{P}_{\text {HPLC }}>99 \%$.

\section{$N$-[3-pyrrolidinylpropyl]-4-chlorobenzamide (8d)}

Procedure E1. Purification by column chromatography (DCM: $\mathrm{MeOH}\left(\mathrm{NH}_{3}\right)$, 9:1 (v/v)) was performed. Yield: 7\%. ${ }^{1} \mathrm{H}$ NMR (300 MHz, $\mathrm{CDCl}_{3}$ ), $\delta: 8.48$ (br s, $\left.1 \mathrm{H}, \mathrm{NH}\right) ; 7.96$ (d, J=8.8 Hz, 2H, H2, H6); 7.39 (d, $\left.J=8.8 \mathrm{~Hz}, 2 \mathrm{H}, \mathrm{H}_{3}, \mathrm{H}_{5}\right) ; 3.77\left(\mathrm{~m}, 2 \mathrm{H}, \mathrm{CH}_{2}\right) ; 3.63\left(\mathrm{~m}, 2 \mathrm{H}, \mathrm{CH}_{2}\right) ; 3.18\left(\mathrm{q}, J=6.1 \mathrm{~Hz}, 2 \mathrm{H}, \mathrm{CH}_{2}\right) ; 2.84(\mathrm{~m}$, $\left.2 \mathrm{H}, \mathrm{CH}_{2}\right) ; 2.37-1.88\left(\mathrm{~m}, 6 \mathrm{H}, 3 \mathrm{CH}_{2}\right) .{ }^{13} \mathrm{C} \mathrm{NMR}\left(75 \mathrm{MHz}, \mathrm{CDCl}_{3}\right) \delta: 166.7(\mathrm{CO}) ; 137.8\left(\mathrm{C}_{\text {aro }}\right) ; 131.9$ $\left(\mathrm{C}_{\text {aro }}\right) ; 129.3\left(2 \mathrm{C}_{\text {aro }}\right) ; 129.1\left(2 \mathrm{C}_{\text {aro }}\right) ; 54.1\left(2 \mathrm{CH}_{2}\right) ; 53.0\left(\mathrm{CH}_{2}\right) ; 36.7\left(\mathrm{CH}_{2}\right) ; 25.6\left(\mathrm{CH}_{2}\right) ; 23.6\left(2 \mathrm{CH}_{2}\right)$. LCMS $\mathrm{m} / \mathrm{z}$ calc for $\left[\mathrm{M}+\mathrm{H}^{+}\right]:$267.1, 269.1; found: 267.0, 269.0. HPLC (C $\left.4,35 \mathrm{~min}\right): t_{R} 12.7 \mathrm{~min}, \mathrm{P}_{\mathrm{HPLC}}$ 98\%; HPLC ( $\left.\mathrm{C}_{18}, 35 \mathrm{~min}\right): t_{R} 17.3 \mathrm{~min}, \mathrm{P}_{\mathrm{HPLC}} 98 \%$.

\section{$N$-[2-morpholinethyl]-4-chlorobenzamide (8e)}

Procedure E1. Purification by column chromatography (DCM: $\mathrm{MeOH}\left(\mathrm{NH}_{3}\right)$, 9:1 (v/v)) was performed. Yield: 35\%. ${ }^{1} \mathrm{H}$ NMR (300 MHz, $\left.\mathrm{CDCl}_{3}\right), \delta: 7.66\left(\mathrm{~d}, J=8.6 \mathrm{~Hz}, 2 \mathrm{H}, \mathrm{H}_{2}, \mathrm{H}_{6}\right) ; 7.32\left(\mathrm{~d}, J=8.6 \mathrm{~Hz}, 2 \mathrm{H}, \mathrm{H}_{3}\right.$, $\left.\mathrm{H}_{5}\right) ; 6.99$ (br s, $\left.1 \mathrm{H}, \mathrm{NH}\right) ; 3.65\left(\mathrm{~m}, 4 \mathrm{H}, 2 \mathrm{CH}_{2}\right) ; 3.45$ (q, J=6.0 Hz, 2H, $\left.\mathrm{CH}_{2}\right) ; 2.53\left(\mathrm{t}, J=6.2 \mathrm{~Hz}, 2 \mathrm{H}, \mathrm{CH}_{2}\right)$; $2.42\left(\mathrm{~m}, 4 \mathrm{H}, 2 \mathrm{CH}_{2}\right) .{ }^{13} \mathrm{C}$ NMR $\left(75 \mathrm{MHz}, \mathrm{CDCl}_{3}\right) \delta: 166.4(\mathrm{CO}) ; 137.5\left(\mathrm{C}_{\text {aro }}\right) ; 132.9\left(\mathrm{C}_{\text {aro }}\right) ; 128.7\left(2 \mathrm{C}_{\text {aro }}\right)$; $128.4\left(2 \mathrm{C}_{\text {aro }}\right) ; 66.9\left(2 \mathrm{CH}_{2}\right) ; 56.9\left(\mathrm{CH}_{2}\right) ; 53.3\left(2 \mathrm{CH}_{2}\right) ; 36.2\left(\mathrm{CH}_{2}\right)$. LCMS $m / z$ calc for $\left[\mathrm{M}+\mathrm{H}^{+}\right]: 269.1$, 271.1; found: 269.0, 271.0. HPLC ( $\left.\mathrm{C}_{4}, 35 \mathrm{~min}\right): t_{R} 12.2 \mathrm{~min}, \mathrm{P}_{\mathrm{HPLC}} 98 \%$; HPLC ( $\left.\mathrm{C}_{18}, 35 \mathrm{~min}\right): t_{R} 16.6$ $\min , \mathrm{P}_{\text {HPLC }} 98 \%$.

\section{$N$-[3-morpholinpropyl]-4-chlorobenzamide (8f)}

Procedure E1. Purification by column chromatography (DCM:MeOH(NH$)$, 9:1 (v/v)) was performed. Yield: 42\%. ${ }^{1} \mathrm{H}$ NMR (300 MHz, $\mathrm{CDCl}_{3}$ ), $\delta: 8.09$ (br s, $\left.1 \mathrm{H}, \mathrm{NH}\right) ; 7.73$ (d, J=8.6 Hz, 2H, H2, H6); 7.48 $\left(\mathrm{d}, J=8.6 \mathrm{~Hz}, 2 \mathrm{H}, \mathrm{H}_{3}, \mathrm{H}_{5}\right) ; 3.67\left(\mathrm{~m}, 4 \mathrm{H}, 2 \mathrm{CH}_{2}\right) ; 3.52\left(\mathrm{q}, J=6.1 \mathrm{~Hz}, 2 \mathrm{H}, \mathrm{CH}_{2}\right) ; 2.58-2.43\left(\mathrm{~m}, 6 \mathrm{H}, 3 \mathrm{CH}_{2}\right)$; $1.76\left(\mathrm{p}, J=6.1 \mathrm{~Hz}, 2 \mathrm{H}, \mathrm{CH}_{2}\right) .{ }^{13} \mathrm{C} \mathrm{NMR}\left(75 \mathrm{MHz}, \mathrm{CDCl}_{3}\right) \delta: 166.8(\mathrm{CO}) ; 137.8\left(\mathrm{C}_{\text {aro }}\right) ; 133.5\left(\mathrm{C}_{\text {aro }}\right) ; 129.1$ $\left(2 \mathrm{C}_{\text {aro }}\right) ; 128.8\left(2 \mathrm{C}_{\text {aro }}\right) ; 67.2\left(2 \mathrm{CH}_{2}\right) ; 58.7\left(\mathrm{CH}_{2}\right) ; 54.4\left(2 \mathrm{CH}_{2}\right) ; 40.8\left(\mathrm{CH}_{2}\right) ; 24.5\left(\mathrm{CH}_{2}\right)$. LCMS $m / z$ calc for $\left[\mathrm{M}+\mathrm{H}^{+}\right]: 283.1$, 285.1; found: 283.0, 285.0. HPLC ( $\left.\mathrm{C}_{4}, 35 \mathrm{~min}\right): t_{R} 11.5 \mathrm{~min}, \mathrm{P}_{\mathrm{HPLC}}$ 98\%; HPLC ( $\mathrm{C}_{18}$, $35 \mathrm{~min}): t_{R} 15.7 \mathrm{~min}, \mathrm{P}_{\mathrm{HPLC}} 99 \%$. 


\section{$N$-[2-piperazinylethyl]-4-chlorobenzamide (8g)}

Procedure E1. Purification by column chromatography (DCM:MeOH( $\left.\mathrm{NH}_{3}\right)$, 9:1 (v/v)) was performed. Yield: 42\%. ${ }^{1} \mathrm{H}$ NMR (300 MHz, $\left.\mathrm{CDCl}_{3}\right), \delta: 7.72\left(\mathrm{~d}, J=7.9 \mathrm{~Hz}, 2 \mathrm{H}, \mathrm{H}_{2}, \mathrm{H}_{6}\right) ; 7.37$ (d, J = 7.9 Hz, 2H, H3, $\mathrm{H}_{5}$ ); 6.94 (br s, 1H, NH); 3.54 (q, $\left.J=5.5 \mathrm{~Hz}, 2 \mathrm{H}, \mathrm{CH}_{2}\right) ; 2.67-2.48\left(\mathrm{~m}, 10 \mathrm{H}, 5 \mathrm{CH}_{2}\right) ; 2.32$ (s, 3H, $\mathrm{NCH}_{3}$ ). ${ }^{13} \mathrm{C}$ NMR (75 MHz, $\left.\mathrm{CDCl}_{3}\right) \delta$ : $166.3(\mathrm{CO}) ; 137.6\left(\mathrm{C}_{\text {aro }}\right) ; 132.9\left(\mathrm{C}_{\text {aro }}\right) ; 128.7\left(2 \mathrm{C}_{\text {aro }}\right) ; 128.4\left(2 \mathrm{C}_{\text {aro }}\right) ; 56.2$ $\left(\mathrm{CH}_{2}\right) ; 54.8\left(2 \mathrm{CH}_{2}\right) ; 52.5\left(2 \mathrm{CH}_{2}\right) ; 45.8\left(\mathrm{CH}_{3}\right) ; 36.4\left(\mathrm{CH}_{2}\right)$. LCMS $\mathrm{m} / z$ calc for $\left[\mathrm{M}+\mathrm{H}^{+}\right]$: $282.1,284.1$; found: 282.0, 284.0. HPLC ( $\left.\mathrm{C}_{4}, 35 \mathrm{~min}\right): t_{R} 13.0 \mathrm{~min}, \mathrm{P}_{\mathrm{HPLC}} 96 \%$; HPLC $\left(\mathrm{C}_{18}, 35 \mathrm{~min}\right): t_{R} 17.8 \mathrm{~min}, \mathrm{P}_{\mathrm{HPLC}}$ $96 \%$.

\section{$N$-[3-piperazinylpropyl]-4-chlorobenzamide (8h)}

Procedure E1. Purification by column chromatography (DCM: $\mathrm{MeOH}\left(\mathrm{NH}_{3}\right)$, 9:1 (v/v)) was performed. Yield: 43\%. ${ }^{1} \mathrm{H}$ NMR (300 MHz, $\mathrm{CDCl}_{3}$ ), $\delta: 8.28$ (br s, 1H, NH); 7.78 (d, J = 8.5 Hz, 2H, H2, $\mathrm{H}_{6}$ ); 7.39 $\left(\mathrm{d}, J=8.5 \mathrm{~Hz}, 2 \mathrm{H}, \mathrm{H}_{3}, \mathrm{H}_{5}\right) ; 3.56\left(\mathrm{q}, J=5.5 \mathrm{~Hz}, 2 \mathrm{H}, \mathrm{CH}_{2}\right) ; 2.62\left(\mathrm{t}, J=5.7 \mathrm{~Hz}, 2 \mathrm{H}, \mathrm{CH}_{2}\right) ; 2.58-2.42(\mathrm{~m}$, $\left.8 \mathrm{H}, 4 \mathrm{CH}_{2}\right) ; 2.32\left(\mathrm{~s}, 3 \mathrm{H}, \mathrm{NCH}_{3}\right) ; 1.81\left(\mathrm{p}, J=5.8 \mathrm{~Hz}, 2 \mathrm{H}, \mathrm{CH}_{2}\right) .{ }^{13} \mathrm{C} \mathrm{NMR}\left(75 \mathrm{MHz}, \mathrm{CDCl}_{3}\right) \delta: 166.3$ $(\mathrm{CO}) ; 137.4\left(\mathrm{C}_{\text {aro }}\right) ; 133.1\left(\mathrm{C}_{\text {aro }}\right) ; 128.6\left(4 \mathrm{C}_{\text {aro }}\right) ; 57.9\left(\mathrm{CH}_{2}\right) ; 54.7\left(2 \mathrm{CH}_{2}\right) ; 52.9\left(2 \mathrm{CH}_{2}\right) ; 45.9\left(\mathrm{CH}_{3}\right) ; 40.5$ $\left(\mathrm{CH}_{2}\right) ; 24.1\left(\mathrm{CH}_{2}\right)$. LCMS $m / z$ calc for $\left[\mathrm{M}+\mathrm{H}^{+}\right]: 296.1$, 298.1; found: 296.0, 298.0. HPLC (C $\left.435 \mathrm{~min}\right): t_{R}$ $11.6 \mathrm{~min}, \mathrm{P}_{\mathrm{HPLC}} 95 \%$; HPLC $\left(\mathrm{C}_{18}, 35 \mathrm{~min}\right): t_{R} 15.9 \mathrm{~min}, \mathrm{P}_{\mathrm{HPLC}} 95 \%$.

\section{$N$-[3-(benzylmethylamino)propyl]-4-chlorobenzensulfonamide (9)}

Procedure E1. Purification by column chromatography (petroleum ether:DCM:MeOH(NH3), 5:4:1 (v/v)) was performed. Yield: 60\%. IR ( $\left.\mathrm{cm}^{-1}\right): 1323$ and $1156\left(\mathrm{SO}_{2}\right) .{ }^{1} \mathrm{H} \mathrm{NMR}\left(300 \mathrm{MHz}, \mathrm{CDCl}_{3}\right), \delta: 7.76(\mathrm{~d}, J=$ $\left.9.1 \mathrm{~Hz}, 2 \mathrm{H}, \mathrm{H}_{2}, \mathrm{H}_{6}\right) ; 7.47\left(\mathrm{~d}, J=9.2 \mathrm{~Hz}, 2 \mathrm{H}, \mathrm{H}_{3}, \mathrm{H}_{5}\right) ; 7.36-7.22\left(\mathrm{~m}, 5 \mathrm{H}, \mathrm{H}_{\mathrm{aro}}\right) ; 3.46\left(\mathrm{~s}, 2 \mathrm{H}, \mathrm{CH}_{2}\right) ; 3.05(\mathrm{t}, J$ $\left.=7.2 \mathrm{~Hz}, 2 \mathrm{H}, \mathrm{CH}_{2}\right) ; 2.45\left(\mathrm{t}, J=7.1 \mathrm{~Hz}, 2 \mathrm{H}, \mathrm{CH}_{2}\right) ; 2.18\left(\mathrm{~s}, 3 \mathrm{H}, \mathrm{CH}_{3}\right) ; 1.67\left(\mathrm{p}, J=7.0 \mathrm{~Hz}, 2 \mathrm{H}, \mathrm{CH}_{2}\right) .{ }^{13} \mathrm{C}$ NMR (75 MHz, $\left.\mathrm{CDCl}_{3}\right) \delta$ : $138.8\left(\mathrm{C}_{\text {aro }}\right) ; 138.7\left(\mathrm{C}_{\text {aro }}\right) ; 137.9\left(\mathrm{C}_{\text {aro }}\right) ; 129.3\left(2 \mathrm{C}_{\text {aro }}\right) ; 129.0\left(2 \mathrm{C}_{\text {aro }}\right) ; 128.6(2$ $\left.\mathrm{C}_{\text {aro }}\right) ; 128.5\left(2 \mathrm{C}_{\text {aro }}\right) ; 127.4\left(\mathrm{C}_{\text {aro }}\right) ; 62.8\left(\mathrm{CH}_{2}\right) ; 56.8\left(\mathrm{CH}_{2}\right) ; 44.0\left(\mathrm{CH}_{3}\right) ; 41.9\left(\mathrm{CH}_{2}\right) ; 24.7\left(\mathrm{CH}_{2}\right)$. LCMS $\mathrm{m} / \mathrm{z}$ calc for $\left[\mathrm{M}+\mathrm{H}^{+}\right]$: 353.1, 355.1; found: 353.0, 355.0. HRMS: calcd for $\left(\mathrm{C}_{17} \mathrm{H}_{21} \mathrm{O}_{2} \mathrm{~N}_{2} \mathrm{ClS}\right) \mathrm{H}^{+}$: 353.10850 ; found: 353.10782 . HPLC $\left(\mathrm{C}_{4}, 35 \mathrm{~min}\right): t_{R} 13.8 \mathrm{~min}, \mathrm{P}_{\mathrm{HPLC}}>99 \%$; $\mathrm{HPLC}\left(\mathrm{C}_{18}, 35 \mathrm{~min}\right): t_{R} 18.6 \mathrm{~min}, \mathrm{P}_{\mathrm{HPLC}}$ $>99 \%$.

\section{$N$-(4-chlorobenzyl)-3-(benzylmethylamino)propanamine (10)}

A solution of 4-chlorobenzaldehyde $(0.55 \mathrm{mmol}, 77 \mathrm{mg})$ and $N^{1}$-benzyl- $N^{1}$-methylpropane-1,3-diamine 5a $(0.55 \mathrm{mmol}, 100 \mathrm{mg})$ in $\mathrm{MeOH}(10 \mathrm{~mL})$ was stirred at room temperature for 16 hours. Then, sodium borohydride $(0.82 \mathrm{mmol}, 32 \mathrm{mg})$ was added and the reaction media was stirred for 3 hours. The mixture was quenched with water $(5 \mathrm{~mL})$ and evaporated under reduce pressure. The crude product was purified by thick layer chromatography (DCM:MeOH(NH$), 9: 1(\mathrm{v} / \mathrm{v}))$. Yield: $35 \%$. IR $\left(\mathrm{cm}^{-1}\right): 2950(\mathrm{NH}) .{ }^{1} \mathrm{H}$ 
NMR (300 MHz, $\mathrm{CDCl}_{3}$ ), $\delta: 7.80$ (br s, 1H, NH); 7.48 (d, J=8.4 Hz, 2H, $\left.\mathrm{H}_{2}, \mathrm{H}_{6}\right) ; 7.33$ (d, J=8.5 Hz, $\left.2 \mathrm{H}, \mathrm{H}_{3}, \mathrm{H}_{5}\right) ; 7.30-7.26\left(\mathrm{~m}, 3 \mathrm{H}, \mathrm{H}_{\text {aro }}\right) ; 7.13\left(\mathrm{~m}, 2 \mathrm{H}, \mathrm{H}_{\mathrm{aro}}\right) ; 4.00\left(\mathrm{~s}, 2 \mathrm{H}, \mathrm{CH}_{2}\right) ; 3.53\left(\mathrm{~s}, 2 \mathrm{H}, \mathrm{CH}_{2}\right) ; 2.94(\mathrm{t}, J=$ $\left.6.5 \mathrm{~Hz}, 2 \mathrm{H}, \mathrm{CH}_{2}\right) ; 2.60\left(\mathrm{t}, J=6.3 \mathrm{~Hz}, 2 \mathrm{H}, \mathrm{CH}_{2}\right) ; 2.27\left(\mathrm{~s}, 3 \mathrm{H}, \mathrm{CH}_{3}\right) ; 2.02\left(\mathrm{p}, J=6.2 \mathrm{~Hz}, 2 \mathrm{H}, \mathrm{CH}_{2}\right) .{ }^{13} \mathrm{C}$

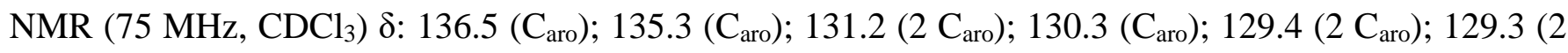
$\left.\mathrm{C}_{\text {aro }}\right) ; 128.6\left(2 \mathrm{C}_{\text {aro }}\right) ; 127.8\left(\mathrm{C}_{\text {aro }}\right) ; 62.2\left(\mathrm{CH}_{2}\right) ; 55.4\left(\mathrm{CH}_{2}\right) ; 50.9\left(\mathrm{CH}_{2}\right) ; 47.3\left(\mathrm{CH}_{2}\right) ; 41.5\left(\mathrm{CH}_{3}\right) ; 22.6$ $\left(\mathrm{CH}_{2}\right)$. LCMS $m / z$ calc for $\left[\mathrm{M}+\mathrm{H}^{+}\right]$: 303.1, 305.1; found: 303.0, 305.0. HRMS: calcd for $\left(\mathrm{C}_{18} \mathrm{H}_{23} \mathrm{~N}_{2} \mathrm{Cl}\right) \mathrm{H}^{+}$: 303.16225; found: 303.16180. HPLC ( $\left.\mathrm{C}_{4}, 35 \mathrm{~min}\right): t_{R} 12.4 \mathrm{~min}, \mathrm{P}_{\mathrm{HPLC}} 95 \%$; HPLC $\left(\mathrm{C}_{18}, 35 \mathrm{~min}\right): t_{R} 21.1$ $\min , \mathrm{P}_{\mathrm{HPLC}} 95 \%$.

\section{4-Chloro- $N$-(4-chlorophenyl)butyramide (11)}

To a solution of 4-chloroaniline $(7.8 \mathrm{mmol}, 1.0 \mathrm{~g})$ in $15 \mathrm{~mL}$ of $\mathrm{DCM}$ at $0^{\circ} \mathrm{C}$ was added slowly a solution of 4-chlorobutyryl chloride $(7.8 \mathrm{mmol}, 878 \mu \mathrm{L})$ in $5 \mathrm{~mL}$ of DCM. The resulting mixture was stirred at room temperature for 12 hours. Then the reaction was quenched with $25 \mathrm{~mL}$ of water and the product extract with $3 \times 25 \mathrm{~mL}$ of DCM. The combined organic layers were dried over magnesium sulphate and concentrated to give the desired product $\mathbf{2 . 2}$ with sufficient purity to be used without purification in the next step. Yield: $87 \% . \mathrm{Mp}=98^{\circ} \mathrm{C} .{ }^{1} \mathrm{H} \mathrm{NMR}\left(300 \mathrm{MHz}, \mathrm{CDCl}_{3}\right), \delta: 7.75$ (br s, 1H, NH); $7.46(\mathrm{~d}, J=9.1$ $\left.\mathrm{Hz}, 2 \mathrm{H}, \mathrm{H}_{2}, \mathrm{H}_{6}\right) ; 7.26\left(\mathrm{~d}, J=9.0 \mathrm{~Hz}, 2 \mathrm{H}, \mathrm{H}_{3}, \mathrm{H}_{5}\right) ; 3.65\left(\mathrm{t}, J=6.2 \mathrm{~Hz}, 2 \mathrm{H}, \mathrm{CH}_{2}\right) ; 2.55(\mathrm{t}, J=7.3 \mathrm{~Hz}, 2 \mathrm{H}$, $\left.\mathrm{CH}_{2}\right) ; 2.18\left(\mathrm{p}, J=6.3 \mathrm{~Hz}, 2 \mathrm{H}, \mathrm{CH}_{2}\right) .{ }^{13} \mathrm{C} \mathrm{NMR}\left(75 \mathrm{MHz}, \mathrm{CDCl}_{3}\right) \delta: 170.0(\mathrm{CO}) ; 136.2\left(\mathrm{C}_{\text {aro }}\right) ; 129.4$ $\left(\mathrm{C}_{\text {aro }}\right) ; 129.0$ (2 $\left.\mathrm{C}_{\text {aro }}\right) ; 121.1\left(2 \mathrm{C}_{\text {aro }}\right) ; 44.4\left(\mathrm{CH}_{2}\right) ; 34.1\left(\mathrm{CH}_{2}\right) ; 27.8\left(\mathrm{CH}_{2}\right)$. LCMS m/z calc for $\left[\mathrm{M}+\mathrm{H}^{+}\right]$: 232.0, 234.0, 236.0; found: 232.0, 234.0, 236.0.

\section{1-(4-Chlorophenyl)pyrrolidin-2-one (12)}

To a solution of $N$-methyl- $N$-benzylamine $(106 \mu \mathrm{L}, 0.82 \mathrm{mmol})$ in $10 \mathrm{~mL}$ of DMF was added a $340 \mathrm{mg}$ $(2.46 \mathrm{mmol})$ amount of potassium carbonate. The resulting mixture was stirred at $70^{\circ} \mathrm{C}$. After 30 minutes, the 4-chloro- $N$-(4-chlorophenyl)butyramide 11 (210 $\mathrm{mg}, 0.91 \mathrm{mmol})$ was added and the reacting mixture was stirred at $70^{\circ} \mathrm{C}$ overnight. The solvent was removed under reduced pressure and $15 \mathrm{~mL}$ of water added to the residue. The crude product was extracted with $3 \times 15 \mathrm{~mL}$ of DCM. The combined organic layers were washed with water and dried over magnesium sulphate. Purification by column chromatography (DCM:MeOH(NH$)$, 99:1 (v/v)) was performed. Yield: $67 \%$. Mp $=98^{\circ} \mathrm{C} .{ }^{1} \mathrm{H}$ NMR $(300$ $\left.\mathrm{MHz}, \mathrm{CDCl}_{3}\right), \delta: 7.63-7.55\left(\mathrm{~m}, 2 \mathrm{H}, \mathrm{H}_{2}\right.$ and $\left.\mathrm{H}_{6}\right) ; 7.36-7.29\left(\mathrm{~m}, 2 \mathrm{H}, \mathrm{H}_{3}, \mathrm{H}_{5}\right) ; 3.84\left(\mathrm{t}, J=7.3 \mathrm{~Hz}, 2 \mathrm{H}, \mathrm{CH}_{2}\right)$; $2.62\left(\mathrm{t}, J=8.5 \mathrm{~Hz}, 2 \mathrm{H}, \mathrm{CH}_{2}\right) ; 2.16\left(\mathrm{p}, J=7.3 \mathrm{~Hz}, 2 \mathrm{H}, \mathrm{CH}_{2}\right) .{ }^{13} \mathrm{C} \mathrm{NMR}\left(75 \mathrm{MHz}, \mathrm{CDCl}_{3}\right) \delta: 174.2(\mathrm{CO})$; $138.0\left(\mathrm{C}_{\text {aro }}\right) ; 129.4\left(\mathrm{C}_{\text {aro }}\right) ; 128.8\left(2 \mathrm{C}_{\text {aro }}\right) ; 120.9\left(2 \mathrm{C}_{\text {aro }}\right) ; 48.6\left(\mathrm{CH}_{2}\right) ; 32.6\left(\mathrm{CH}_{2}\right) ; 17.8\left(\mathrm{CH}_{2}\right)$.

\section{4-(benzylmethylamino)- $N$-(4-chlorophenyl)butanamide (13)}

A solution of compound 11 (1.29 mmol) in $N$-benzylmethylamine $(7.75 \mathrm{mmol}, 1 \mathrm{~mL})$ was stirred at room temperature for 12 hours. A $5 \mathrm{~mL}$ amount of hexane was added and the white solid, identified as 
disubstitutedamine hydrochloride, was filtered. The filtrate was concentrated and purified by thick layer chromatography (cyclohexane: ethyl acetate: $\mathrm{MeOH}\left(\mathrm{NH}_{3}\right), 4.5: 4.5: 1(\mathrm{v} / \mathrm{v})$ ) to afford compound 13. Yield: 70\%. IR ( $\left.\mathrm{cm}^{-1}\right): 1686(\mathrm{C}=0) .{ }^{1} \mathrm{H} \mathrm{NMR}\left(300 \mathrm{MHz}, \mathrm{CDCl}_{3}\right), 9.63$ (br s, 1H, NH); 7.45 (d, J=9.1 Hz, 2H, $\mathrm{H}_{2}, \mathrm{H}_{6}$ ); 7.34-7.27 (m, 5H, $\mathrm{H}_{\text {aro }}$ ); 7.21 (d, $\left.J=9.0 \mathrm{~Hz}, 2 \mathrm{H}, \mathrm{H}_{3}, \mathrm{H}_{5}\right) ; 3.69$ (s, 2H, $\mathrm{CH}_{2}$ ); 2.62 (t, $J=6.2 \mathrm{~Hz}$, $\left.2 \mathrm{H}, \mathrm{CH}_{2}\right) ; 2.51\left(\mathrm{t}, J=7.0 \mathrm{~Hz}, 2 \mathrm{H}, \mathrm{CH}_{2}\right) ; 2.35\left(\mathrm{~s}, 3 \mathrm{H}, \mathrm{CH}_{3}\right) ; 1.96\left(\mathrm{p}, J=6.1 \mathrm{~Hz}, 2 \mathrm{H}, \mathrm{CH}_{2}\right) .{ }^{13} \mathrm{C}$ NMR $(75$ $\left.\mathrm{MHz}, \mathrm{CDCl}_{3}\right) \delta: 171.4(\mathrm{CO}) ; 137.2\left(\mathrm{C}_{\mathrm{aro}}\right) ; 135.9\left(\mathrm{C}_{\mathrm{aro}}\right) ; 129.7$ (2 $\left.\mathrm{C}_{\mathrm{aro}}\right) ; 128.8$ (2 $\left.\mathrm{C}_{\text {aro }}\right) ; 128.7$ (2 $\left.\mathrm{C}_{\text {aro }}\right) ; 128.5$ $\left(2 \mathrm{C}_{\text {aro }}\right) ; 128.0\left(\mathrm{C}_{\text {aro }}\right) ; 120.8\left(\mathrm{C}_{\text {aro }}\right) ; 62.2\left(\mathrm{CH}_{2}\right) ; 56.5\left(\mathrm{CH}_{2}\right) ; 41.4\left(\mathrm{CH}_{3}\right) ; 36.2\left(\mathrm{CH}_{2}\right) ; 22.2\left(\mathrm{CH}_{2}\right)$. LCMS $m / z$ calc for $\left[\mathrm{M}+\mathrm{H}^{+}\right]: 317.1,319.1$; found: 317.2, 319.2. HRMS: calcd for $\left(\mathrm{C}_{18} \mathrm{H}_{21} \mathrm{ON}_{2} \mathrm{Cl}\right) \mathrm{H}^{+}$: 317.14152 ; found: 317.14026 . HPLC (C $4,35 \mathrm{~min}): t_{R} 8.6 \mathrm{~min}, \mathrm{P}_{\mathrm{HPLC}}>99 \%$; $\mathrm{HPLC}\left(\mathrm{C}_{18}, 35 \mathrm{~min}\right): t_{R} 20.3 \mathrm{~min}, \mathrm{P}_{\mathrm{HPLC}}$ $>99 \%$.

\subsection{In vitro testing}

\subsubsection{Assay for binding to sigma receptors}

The binding assays were performed by CEREP (Poitiers, France), according to Ganapathy [43]. Rapidely, the S1R binding assay was carried out by incubating Jurkat cell membranes (10-20 mg protein per tube) with $\left[{ }^{3} \mathrm{H}\right](+)$-pentazocine $(15 \mathrm{nM})$ and a range of concentrations of test compounds, at $37^{\circ} \mathrm{C}$ for 2 hours, in $5 \mathrm{mM}$ Tris/ $\mathrm{HCl}$ buffer $(\mathrm{pH}=7.4)$. The $\mathrm{S} 2 \mathrm{R}$ binding assay was performed by incubating Jurkat cell membranes (10-20 mg protein per tube) with $\left[{ }^{3} \mathrm{H}\right]$-DTG $(25 \mathrm{nM})$ in the presence of $(+)$-pentazocine $(1$ $\mu \mathrm{M}$ ) to saturate $\mathrm{S} 1 \mathrm{R}$, and a range of concentrations of test compounds, at room temperature for 1 hour in $5 \mathrm{mM}$ TrisHCl buffer ( $\mathrm{pH}=7.4$ ). Bound radioactivity was measured using liquid scintillation counting. Nonspecific binding was determined, in both assays, under similar conditions, but in the presence of 10 $\mu \mathrm{M}$ unlabelled haloperidol. Inhibition constants $\left(K_{i}\right)$ were calculated from the $\mathrm{IC}_{50}$ values according to the method of Cheng and Prusoff [53].

\subsubsection{Cell culture and cytotoxicity assay}

The human neuroblastoma cell line (SY5Y) was cultured in DMEM (Dulbecco's Modified Eagle Medium) (Gibco) supplemented with $2 \mathrm{mM} \mathrm{L-glutamine,} 100 \mu \mathrm{g} / \mathrm{ml}$ streptomycin, $100 \mathrm{IU} / \mathrm{mL}$ penicillin, $1 \mathrm{mM}$ non-essential amino acids and $10 \%$ (v/v) heat-inactivated foetal bovine serum (Sigma Aldrich), and grown at $37^{\circ} \mathrm{C}$ in a humidified incubator with $5 \% \mathrm{CO}_{2}$.

Cells were starved for 24 hours to obtain synchronous cultures, and were then incubated in culture medium that contained various concentrations of test compounds $(100,50,10,5,1,0.5,0.1,0.05 \mu \mathrm{M})$, each dissolved in less than $0.1 \%$ DMSO. After 72 hours of incubation, cell growth was estimated by the colorimetric MTT (thiazolyl blue tetrazolium bromide) assay.

\subsubsection{Physicochemical properties}


Standardised ADME experiments were performed by CEREP (Paris, France). Bioavailabily-related profile was measured according to Lipinski et al. for aqueous solubility in PBS (pH 7.4, [48]); Sangster et al. [45] for partition coefficient ( $\log \mathrm{D}, \mathrm{n}$-octanol-PBS, $\mathrm{pH}$ 7.4) and Kuhnz and Gieschen [49] for metabolic stability (human liver microsomes). The LC/MS system for microsomal stability and metabolites identification consisted of an Orbitrap Exactive instrument (Thermo) equipped with an electrospray ionization source used in positive mode $\left(\mathrm{M}+\mathrm{H}^{+}\right)$. The apparatus was managed with Xcalibur software.

5.2.4 Selectivity profile (agonist and antagonist activities) over a panel of 40 recombinant human receptors

Rapidely, the tests were performed by Euroscreen (www.ogeda.com) with recombinant human G coupled receptor expressing cell lines using aequorin functional assays for serotonin 5-HT2A, 2B, 2C, 3 and 5A, adrenergic alpha1a and 1b, angiotensin AT1, cholesistokinin CCFK1, endothelin ETA, histamine H1, muscarinic M1 and 3, neurokinin NK1 and 2, vasopressin V1a and vasoactive intestinal peptide VPAC1 receptor analysis [50]. cAMP $\mathrm{HTRF}^{\mathrm{TM}}$ assays were used to analyse serotonin 5-HT1A, 4E, 6 and 7, adenosine A1, 2A and 3, adrenergic beta1 and 2, cannabinoid CB1, dopamine D1, histamine $\mathrm{H} 2$ and neuropeptide Y NPY receptors [51]. GTP $\gamma \mathrm{S}^{35}$ assays were used to analyse serotonin 5-HT1B, adrenergic alpha2a and b, dopamine D2L, muscarinic M2 and 4, opïod delta, kappa and mu, and somatostatine STT4 receptor [52].

Agonist and antagonist activities of the test compound are expressed as the percentage of the activity of the reference agonist at its $\mathrm{EC}_{100}$ concentration or the percentage of inhibition of the reference agonist activity at its $\mathrm{EC}_{80}$ concentration, respectively.

For the aequorin assays, different cell lines coexpressing the receptors were grown in specific culture media and incubated for 4 hours with coelenterazine h. For agonist testing, cell suspensions were mixed with test or reference agonist in a 96-well plate. For antagonist testing, reference agonist at its $\mathrm{EC}_{80}$ (final concentration) was injected to the mix containing cells and tested compound. The resulting emission of light was recorded using Hamamatsu Functional Drug Screening System 6000 [50].

For the cAMP HTRF ${ }^{\mathrm{TM}}$ assays, different cell lines coexpressing the receptors were grown in specific culture media and resuspended in assay buffer. For agonist testing on Gs coupled receptor, the tested compound was added at increasing concentrations. For antagonist testing, the tested compound and the reference agonist at its $\mathrm{EC}_{80}$ (final concentration) were added. For agonist and antagonist testing on Gi coupled receptor, forskolin was added to the reagents listed above. After incubation, cells were lysed and cAMP concentrations were estimated with the HTRF kit, according to the manufacturer specifications [51]. 
For the GTP $\gamma \mathrm{S}$ scintillation proximity assay, optimized specific conditions were determinated for each receptor. Membrane extracts were prepared from different cell lines coexpressing the receptors, mixed with GDP and incubated on ice. For agonist testing, the tested compound or the reference agonist, GDP mix and GTP $\gamma\left[{ }^{35} \mathrm{~S}\right]$ were added. For antagonist testing, the tested compound or the reference antagonist, the reference agonist at historical EC80, GDP mix and GTP $\gamma\left[{ }^{35} \mathrm{~S}\right]$ were added. GTP concentrations were estimated with PerkinElmer TopCount reader [52].

\subsection{Molecular docking}

The compound was built using the Chembiodraw 3D module and minimized. Docking simulation was then performed into S1R (RCSB Protein Data Bank 5HK2) with the automated GOLD program. The active site was defined around 4-IBP.

\section{Acknowledgments}

The authors acknowledged Nicolas Renault for docking experiments. The $300 \mathrm{MHz}$ NMR facilities were funded by the Région Nord-Pas de Calais (France), the Ministère de la Jeunesse, de l'Education Nationale et de la Recherche (MJENR) and the Fonds Européens de Développement Régional (FEDER).

This work was supported by Lille 2 University, FRI "J'innove", PRES Univ Lille Nord de France and Nord de France SATT Grants. MDM is the recipient of a fellowship from Lille 2 University.

\section{Conflict of Interest:}

The authors declare no competing financial interests. All authors have approved the final article.

\section{Authors contribution}

Marion Donnier-Marechal: Contributed to the compounds synthesis

Pascal Carato: Contributed to the design of the study and wrote the manuscript

Paul-Emmanuel Larchanché : Contributed to the compounds synthesis

Amélie Barczyk: Contributed to the cytotoxicity assays

Bénédicte Oxombre : Contributed to the analyses of biological data and wrote the manuscript

Patrick Vermersch: Contributed to the design of the study

Patricia Melnyk : Contributed to the design of the study and wrote the manuscript

\section{Reference}

NMR and mass spectra of compounds $\mathbf{7 a - z}, \mathbf{8 a - h}, \mathbf{9 , 1 0}$ and $\mathbf{1 3}$ are available as supplementary data. 


\section{Reference}

1. D. C. Mash, C. P. Zabetian, Sigma receptors are associated with cortical limbic areas in the primate brain, Synapse 12 (1992) 195-205.

2. A. D. Weissman, T. P. Su, J. C. Hedreen, E. D. London, Sigma receptors in post-mortem human brains, J. Pharmacol. Exp. Ther. 247 (1988) 29-33.

3. T. A. Mavlyutov, M. L. Epstein, K. A. Andersen, L. Ziskind-Conhaim, A. E. Ruoho, The sigma-1 receptor is enriched in postsynaptic sites of C-terminals in mouse motoneurons. An anatomical and behavioral study, Neuroscience 167 (2010) 247-255.

4. W.R. Martin, C.E. Eades, J.A. Thompson, R.E. Huppler, P.E. Gilbert, The effects of morphine- and nalorphine- like drugs in the nondependent and morphine-dependent chronic spinal dog, J. Pharmacol. Exp. Ther. 197 (1976) 517-532.

5. T. Maurice, Improving Alzheimer's disease-related cognitive deficits with sigma1 receptor agonists, Drug News Perspect. 15 (2002) 617-625.

6. X. Guitart, G. Codony, X. Monroy, Sigma receptors: biology and therapeutic potential, Psychopharmacology 174 (2004) 301-319.

7. S. D. Banister, M. Kassiou, The therapeutic potential of sigma $(\sigma)$ receptors for the treatment of central nervous system diseases: evaluation of the evidence, Curr. Pharm. Des. 18 (2012) 884-901.

8. J.M. Walker, W.D. Bowen, F.O. Walker, R.R. Matsumoto, B.R. de Costa, K.C. Rice, Sigma receptors: biology and function, Pharmacol. Rev. 42 (1990) 355-402.

9. P. Seth, F. H. Leibach, V. Ganapathy, Biochem. Cloning and structural analysis of the cDNA and the gene encoding the murine type 1 sigma receptor, Biophys. Res. Commun. 241 (1997) 535-540.

10. P. Seth, Y.-J. Fei, H. W. Li, W. Huang, F. H. Leibach, V. J. Ganapathy, Cloning and functional characterization of a sigma receptor from rat brain, Neurochem. 70 (1998) 922-931.

11. R. Kekuda, P. D. Prasad, Y.-J. Fei, F. H. Leibach, V. Ganapathy, Cloning and functional expression of the human type 1 sigma receptor (hSigmaR1), Biochem. Biophys. Res. Commun. 229 (1996) 553558.

12. S.-Y. Tsai, T. Hayashi, T. Mori, T.P. Su, Sigma-1 receptor chaperones and diseases, Cent. Nerv. Syst. Agents Med. Chem. 9 (2009) 184-189.

13. T. Hayashi, T.P. Su, Sigma-1 receptor chaperones at the ER-mitochondrion interface regulate $\mathrm{Ca}(2+)$ signaling and cell survival, Cell 131 (2007) 596-610.

14. F. P. Monnet, Sigma-1 receptor as regulator of neuronal intracellular $\mathrm{Ca} 2+$ : clinical and therapeutic relevance, Biol. Cell 97 (2005) 873-883.

15. E. Aydar, C. P. Palmer, V. A. Klyachko, M. B. Jackson, The sigma receptor as a ligand-regulated auxiliary potassium channel subunit, Neuron 34 (2002) 399-410. 
16. A. Renaudo, S. L'Hoste, H. Guizouarn, F. Borgese, O. Soriani, Cancer cell cycle modulated by a functional coupling between sigma-1 receptors and Cl- channels, J. Biol. Chem. 282 (2007) 22592267.

17. T. Kobayashi, K. Matsuno, K. Nakata, S. Mita, Enhancement of acetylcholine release by SA4503, a novel sigma 1 receptor agonist, in the rat brain, J. Pharmacol. Exp. Ther. 279 (1996) 106-113.

18. K. Matsuno, K. Matsunaga, T. Senda, S. J. Mita, Increase in extracellular acetylcholine level by sigma ligands in rat frontal cortex, Pharmacol. Exp. Ther. 265 (1993) 851-859.

19. G. M. Gonzalez-Alvear, L. L. Werling, Sigma receptor regulation of norepinephrine release from rat hippocampal slices, Brain Res. 673 (1995) 61-69.

20. G. Lucas, V. V. Rymar, A. F. Sadikot, G. Debonnel, Further evidence for an antidepressant potential of the selective sigma1 agonist SA 4503: electrophysiological, morphological and behavioural studies, Int. J. Neuropsychopharmacol. 11 (2008) 485-495.

21. G. Debonnel, C. De Montigny, Modulation of NMDA and dopaminergic neurotransmissions by sigma ligands: possible implications for the treatment of psychiatric disorders, Life Sci. 1996, 58, 721-734.

22. G. M. Gonzalez-Alvear, L. L. Werling, Regulation of $[3 \mathrm{H}]$ dopamine release from rat striatal slices by sigma receptor ligands, J. Pharmacol. Exp. Ther. 271 (1994) 212-219.

23. J. E. Bermack, G. Debonnel, Modulation of serotonergic neurotransmission by short- and long-term treatments with sigma ligands, Br. J. Pharmacol. 134 (2001) 691-699.

24. J. A. Butera, Current and Emerging Targets To Treat Neuropathic Pain, J. Med. Chem. 50 (2007) 2543-2546.

25. J. D. Kennedy, Neuropathic pain: molecular complexity underlies continuing unmet medical need, J. Med. Chem. 50 (2007) 2547-2556.

26. J. E. Bermack, G. Debonnel, The role of sigma receptors in depression, J. Pharmacol. Sci. 97 (2005) 317-336.

27. Y. Itzhak, C. O. Kassim, Clorgyline displays high affinity for sigma binding sites in C57BL/6 mouse brain, Eur. J. Pharmacol. 176 (1990) 107-108.

28. N. Narita, K. Hashimoto, S. Tomitaka, Y. Minabe, Interactions of selective serotonin reuptake inhibitors with subtypes of sigma receptors in rat brain, Eur. J. Pharmacol. 307 (1996) 117-119.

29. T. Maurice, B.P. Lockhart, Neuroprotective and anti-amnesic potentials of sigma $(\sigma)$ receptor ligands. Progress Neuro-Psychopharmacol. Biol. Psy. 21 (1997) 69-102.

30. N. Uchida, H. Ujike, Y. Tanaka, A. Sakai, M. Yamamoto, Y. Fujisawa, A. Kanzaki, S. Kuroda, A variant of the sigma receptor type-1 gene is a protective factor for Alzheimer disease, Am. J. Geriatr. Psychiatry. 13 (2005) 1062-1066.

31. T. Mori, T. Hayashi, T.-P. Su, Compromising $\sigma-1$ Receptors at the Endoplasmic Reticulum Render Cytotoxicity to Physiologically Relevant Concentrations of Dopamine in a Nuclear Factor- $\mathrm{KB} / \mathrm{Bcl}-2$ - 
Dependent Mechanism: Potential Relevance to Parkinson's Disease, J. Pharmacol. Exp. Ther. 341 (2012) 663-671.

32. M. Rui, D. Rossi, A. Marra, M. Paolillo, S. Schinelli, D. Curti, A. Tesei, M. Cortesi, A. Zamagni, E. Laurini, S. Pricl, D. Schepmann, B. Wünsch, E. Urban, V. Pace, S. Collina, Synthesis and biological evaluation of new aryl-alkyl(alkenyl)-4-benzylpiperidines, novel Sigma Receptor (SR) modulators, as potential anticancer-agents, Eur. J. Med. Chem. 124 (2016) 649-665.

33. D. Zampieri, L. Vio, M. Fermeglia, S. Pricl, B. Wünsch, D. Schepmann, M. Romano, M. G. Mamolo, E. Laurini, Computer-assisted design, synthesis, binding and cytotoxicity assessments of new 1-(4(aryl(methyl)amino)butyl)-heterocyclic sigma 1 ligands, Eur. J. Med. Chem. 121 (2016) 712-726.

34. D. Zamanillo, E. Portillo-Salido, J.M. Vela, L. Romero, Sigma 1 Receptor Chaperone: Pharmacology and Therapeutic Perspectives, in: Therapeutic Targets, John Wiley \& Sons, Inc., 2012, pp. 225-278.

35. V. Villard, J. Espallergues, E. Keller, A. Vamvakides, T. Maurice, Anti-amnesic and neuroprotective potentials of the mixed muscarinic receptor/sigma 1 ligand ANAVEX2-73, a novel aminotetrahydrofuran derivative. J. Psychopharmacol. 25 (2013) 1101-1117.

36. V. Lahmy, J. Meunier, S. Malmström, G. Naert, L. Givalois, S.H. Kim, V. Villard, A. Vamvakides, T. Maurice, Blockade of Tau hyperphosphorylation and $A \beta_{1-42}$ generation by the aminotetrahydrofuran derivative ANAVEX2-73, a mixed muscarinic and $\sigma_{1}$ receptor agonist, in a nontransgenic mouse model of Alzheimer's disease, Neuropsychopharmacol. 38 (2013) 17061723.

37. M. Toussaint, B. Delair, C. Foulon, N. Lempereur, C. Vaccher, T. Maurice, P. Melnyk, Tic hydantoin sigma-1 agonist: Pharmacological characterization on cocaine-induced stimulant and appetitive effects, Eur. Neuropsychopharmacol. 19 (2009) 504-515.

38. V.R. Venna, D. Deplancke, P. Melnyk, R. Bordet, Neuroprotective and antidepressant-like effects of LC 03/35, a novel sigma-1 receptor ligand, Fund. Clin. Pharmacol. 22 (2008) 1.

39. B. Oxombre Vanteghem, C. Lee-Chang, J. Salleron, M. Giroux, M. Donnier-Marechal, 11P. Carato, D. Lefranc, H. Zephir, L. Prin, P. Melnyk, P. Vermersch. High-affinity sigma-1 protein agonist reduces clinical and pathological signs of experimental auto-immune encephalomyelitis. Br. J. Pharmacol. 172 (2015) 1769-1782.

40. M. Donnier-Maréchal, P.E. Larchanche, D. Le Broc, C. Furman, P. Carato, P. Melnyk. Carboline and phenothiazine-derivated heterocycles as potent sigma-1 protein ligands. Eur. J. Med. Chem. 89 (2015) 198-206.

41. M. Donnier-Maréchal, P. Carato, D. Le Broc, C. Furman, P. Melnyk, Synthesis and pharmacological evaluation of benzannulated derivatives as potent and selective Sigma-1 receptor ligands. Eur. J. Med. Chem. 92 (2015) 575-582. 
42. P. Melnyk, P. Vermersch, P. Carato, B. Vanteghem-Oxombre, H. Zephir, M. Donnier-Maréchal, Compounds, pharmaceutical composition and their use in treating neurodegenerative diseases. PCT/EP2015/063370.

43. V. Megalizzi, V. Mathieu, T. Mijatovic, P. Gailly, O. Debeir, N. De Neve, M. Van DAmme, G. Bontempi, B. Haibe-Kains, C. Decaestecker, Y. Kondo, R. Kiss, F. Lefranc, 4-IBP, a sigma1 receptor agonist, decreases the migration of human cancer cells, including glioblastoma cells, in vitro and sensitizes them in vitro and in vivo to cytotoxic insults of proapoptotic and proautophagig drugs. Neoplasia 9 (2007) 358-369.

44. H.R. Schmidt, S. Zheng, E. Gurpinar, A. Koehl, A. Manglik, A.C. Kruse, Crystal structure of the human $\sigma 1$ receptor. Nature 532 (2016) 527-30.

45. M.E. Ganapathy, P.D. Prasad, W. Huang, P. Seth, F.H. Leibach, V. Ganapathy, Molecular and ligandbinding characterization of the sigma-receptor in the Jurkat human T lymphocyte cell line. J. Pharmacol. Exp. Ther. 289 (1999) 251-260.

46. J. Sangster, Octanol-water Partition Coefficients: Fundamentals and Physical Chemistry, Vol 2 of Wiley series in solution chemistry. John Wiley \& Sons : Chichester (1997).

47. LLE (Lipophilic Ligand efficiency) was calculated with the following equation $L L E=p K i-e \log P$

48. C.A. Lipinski, F. Lombardo, B.W. Dominy, P.J. Feeney, Experimental and computational approaches to estimate solubility and permeability in drug discovery and development settings. Adv. Drug Deliv Rev. 46 (2001) 3-26.

49. W. Kuhnz, H. Gieschen, Predicting the oral bioavailability of 19-nortestosterone progestins in vivo from their metabolic stability in human liver microsomal preparations in vitro. Drug Metab. Dispos 26 (1998) 1120-7.

50. E. Le Poul, S. Hisada, Y. Mizuguchi, V.J. Dupriez, E. Burgeon, M. Detheux, Adaptation of Aequorin Functional Assay to High Throughput Screening. J. Biomol. Screen. 7 (2002) 57-65.

51. F. Degorce, A. Card, S. Soh, E. Trinquet, G.P. Knapik, B. Xie, HTRF: A Technology Tailored for Drug Discovery - A Review of Theoretical Aspects and Recent Applications. Curr. Chem. Genom. 3 (2009) 22-32.

52. M. Ferrer, G.D. Kolodin, P. Zuck, R. Peltier, K. Berry, S.M. Mandala, H. Rosen, H. Ota, S. Ozaki, J. Inglese, B. Strulovici, A fully automated [35S]GTPgammaS scintillation proximity assay for the high-throughput screening of Gi-linked G protein-coupled receptors. Assay Drug Dev. Technol. 1 (2003) 261-73.

53. Y. Cheng, W.H. Prusoff, Relationship between the inhibition constant (K1) and the concentration of inhibitor which causes 50 per cent inhibition (I50) of an enzymatic reaction. Biochem. Pharmacol. 22 (1973) 3099-108. 
